Departamento de Biología Molecular

Facultad de Ciencias

Universidad Autónoma de Madrid

\title{
Meis transcription factors in axial development
}

Doctoral thesis

Alejandra Cristina López Delgado

Licenciada en Biología

Madrid, January 2019

Director: Miguel Torres Sánchez

Centro Nacional de Investigaciones Cardiovasculares (CNIC) 

I hereby certify that Alejandra Cristina López Delgado has carried out the experimental work leading to her $\mathrm{PhD}$ thesis entitled "Meis transcription factors in axial development" under my supervision at the Centro Nacional de Investigaciones Cardiovasculares (CNIC) in Madrid.

I also declare that the work presented is novel and of great importance in the field, and of sufficient quality to merit to be presented in order to obtain a $\mathrm{PhD}$ degree by the Universidad Autonoma de Madrid.

Madrid, 17th January 2019

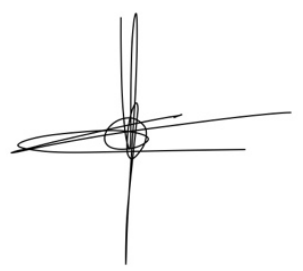

Miguel Torres Sánchez 

This work was performed in Miguel Torres' laboratory in the Cell and Developmental Biology Area at the Centro Nacional de Investigaciones Cardiovasculares Carlos III (CNIC) in Madrid.

The CNIC is supported by the Ministerio de Ciencia, Innovación y Universidades (MCNU) and the Pro CNIC Foundation, and is a Severo Ochoa Center of Excellence (SEV-2015-0505).

This study was funded by grants RD12/0019/0005 and RD16/0011/0019 (TerCel, RETICS); S2010-BMD-2315 (Comunidad de Madrid); BFU2012-31086 (MINECO); BFU2015-71519 (MEIC) and ref. 17CVD04 (Leudcq Foundation Transatlantic Networks).

Alejandra Cristina López Delgado was recipient of a fellowship from the MINECO (BFU2012-31086). 

"Las ideas no duran mucho.

Hay que hacer algo con ellas"

Santiago Ramón y Cajal 

Acknowledgements

$z$ 

No soy la autora de esta tesis, o al menos no la única. Vane e Irene, vuestros nombres deberían aparecer junto al mío. Sin vuestra ayuda, sobre todo en estos últimos meses, esta tesis sería la mitad de lo que es. Ha sido un placer trabajar con vosotras. Vane, gracias por hacer siempre nuestros favores con una eficiencia increíble, "Pon una Vane en tu vida"; e Irene, la mejor compañera de poyata! No solo porque así podía comentarte todas mis penas (¿Por qué me salen marrones las ISH?), si no también por compartir la afición por guardar cuerdecitas, papelitos marrones y demás cosas superútiles que el resto (ignorantes) considera "basura".

Gracias a todos los miembros de LAB_MT con los que he coincidido estos años, habéis sido mi familia. He intentado coger lo mejor de cada uno de vosotros para mejorar y aprender. He tenido la suerte de bromear y reír con todos y cada uno de vosotros, ésta es una de las mejores cosas que me llevo. Podría gastar botes de tinta agradeciendo vuestra colaboración, ayuda, ánimos, consejos, apoyo, tantos momentos; pero no es mi estilo enrollarme, y menos si estoy gastando papel, así que daré solo unas pinceladas.

Miguel, gracias por tus ideas que al fin y al cabo dan vida a los proyectos, por transmitir calma cuando parece que todo sale mal, por valorarnos (tal vez más de lo que merecemos) y por darme oportunidades para crecer en este mundo y aprender.

Noelia y Ghislaine, gracias por quererme. Habéis sido el punto de apoyo que me ha permitido mover mi mundo, en lo personal y profesional. Lin y Ester, gracias por vuestro positivismo y ser capaces de alegrar cualquier momento. Y Ester gracias por desahogarme en nuestros trayectos de tren ¡Menudas chapas te he dado! No sé si darte las gracias o pedirte perdón... José, gracias por ser capaz de sacarme una sonrisa incluso en el peor momento; por transmitirme tus ganas de trabajar y enseñarme que no hay que rendirse. Lorena e Isaac, habéis sido mis ejemplos de esfuerzo y dedicación. Rocío y Susana, gracias por vuestra ayuda desde que puse un pie en el CNIC (aunque no os hablase;P). Cris, gracias por tus consejos sobre cómo terminar una tesis. Cova, gracias por darme fuerza y apoyar mis ideas locas. Laura, la fuente de sabiduría, ¡Cuánto nos has faltado al equipo Meis! Kenzo, thanks for your different way of thinking and because I am happy to know that there is someone more antisocial than me ;P. Y a los más nuevos como mi compi de escalada Miquel, mi compi de mesa Morena (que siempre me espera para comer) y a Consuelo gracias por vuestra agradable compañía, consejos y apoyo.

Y a parte del grupo hay mucha más gente a la que agradecer. 
A Iván y las Beas, porque vuestra simpatía y buen rollo hizo que empezara a mostrar como soy (para vuestra desgracia...¡Lucy!).

A Pedro, gracias por esos paseos de $30 \mathrm{Km}$. Siempre tuve la sensación de que nos caíamos bien antes de conocernos.

A Marcos, por retarme y empujar mis limitados limites.

A la gente de la $3 \mathrm{~N}$ porque simplemente una sonrisa al cruzarse, un ¿qué tal? de vez en cuando o alguna conversación sin sentido en las lupas hacen que el día a día sea mucho más llevadero.

Al grupo de Miguel Manzanares, por ser todos tan majos! en especial a Mariajo, Claudio y Elena por ayudarme con ratones, ISH y sondas.

A todas aquellas personas que forman parte del CNIC y que facilitan nuestros días. Administración, mantenimiento, esterilización, genómica, bioinformática, microscopia, transgénesis, células pluripotentes (gracias Giovanna por estar siempre dispuesta a resolver dudas) y por supuesto a la gente del animalario y en especial a los que se han encargado directamente de nuestras colonias, Vir, Laura, Merche y a Guille que en este último tiempo le he estado dando algo de trabajo... Y ¡cómo no! a los/las AAZ, BRP, BZR (especialmente, BZR68 y 402), CBC, CZV, DD, DES, DGG, DYN, EZ, TUZ y unos cuantos más.

A mi familia, porque han sido, son y serán la única constante en mi vida. Por esos ratos en Valdemorillo en los que el mundo desaparece y solo importa que podemos comer juntos un día más.

$\mathrm{Y}$ a todos aquellos que han sido importantes para que yo haya podido llegar aquí, desde profesores, compañeros y demás personas con las que he compartido y vivido buenos y malos momentos durante estos años.

A todos muchas gracias, no sabéis lo orgullosa que me siento de tener tanto que agradecer y lo feliz que me hace saber cuánto os voy a echar de menos. 


\section{Index}

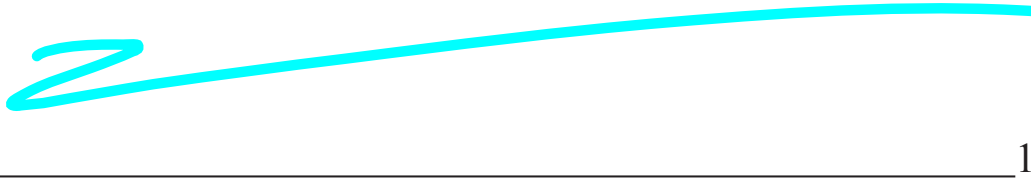

Abbreviations _ 15

Summary __ 17

Introduction _ 23

Cluster organization of Hox genes __ 25

Hox genes and early development __ 26

Axial elongation and segmentation __ 27

Axial skeletal patterning __ 30

Hox cofactors and DNA binding __ 32

Retinoic acid signaling in development __ 35

Meis genes and pattern formation in the mouse embryo ___ 37

Objectives _ 39

Materials and Methods __ 43

Mouse lines _ـ 45

Embryo harvest _ 46

Whole mount In situ hybridization __ 46

Probe synthesis _ 47

Skeletal and cartilage staining ___ 47

Immunostaining on gelatin sections __ 49

Image acquisition and processing _ 50

RNA sequencing _ 50

Results _ـ 53

Meis 1 and Meis 2 expression in early mouse embryo development ___ 55

Role of Meis in mouse development _ 56

Analysis of Hox gene expression in the absence of Meis $2 \_57$

Skeletal patterning in Meis-deficient mice __ 58

Analysis of Hox gene expression in the absence of Meis 1 and Meis $2 \_67$

Global gene expression analysis of Meis 1/2 double-knockouts recombined with Dll1Cre _ 68

Somite compartmentalization in Meis1/2 double-knockouts recombined with Dll1Cre

Expression of adhesion molecules in Meis 1/2 double-knockouts recombined with DlllCre _ 75

Myotomal FGF factors in Meis1/2 double-knockouts recombined with Dll1Cre 
Retinoic Acid signaling in Meis 1/2 double-knockouts recombined with DlllCre 75

Dll1Cre recombination pattern in control Meis mutant embryos 78

Skeletal pattern in Dll1Cre; Raldh2 ${ }^{-/}$embryos 80

Discussion 83

Meis 1 and Meis 2 expression in early mouse embryo development 85

Role of Meis in mouse axial skeletal development 85

Meis role in Hox regulation 91

Somite development in the absence of Meis 92

Involvement of Meis in retinoic acid metabolism 94

Conclusions 99

Supplementary Material 105

References 111 


\section{Abbreviations}

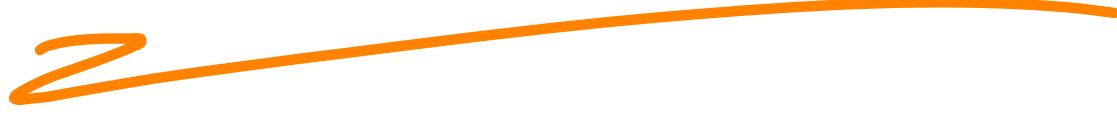

aaa: Anterior arch of the atlas

ANT-C: Antennapedia complex

AP: Antero-posterior

BX-C: Bithorax complex

Cdx: Caudal type homeobox

CNH: Chordo-Neural Hinge

Cyp26b1: Cytochrome P450 family 26 subfamily B member 1

DIl1: Delta-like 1

exd: Extradenticle

FGF: Fibroblast Growth Factor

FL: Forelimb

Hox: Homeobox

HD: Homeodomain

HL: Hindlimb

hth: Homothorax

Meis: Myeloid ecotropic viral integration site

Mesp1: Mesoderm Posterior BHLH Transcription Factor 1

NA: Neural arch

NSB: Node-Streak Border

Pax: Paired box

Pbx: Pre-B-Cell leukemia homeobox

PDGFRa: Platelet Derived Growth Factor Receptor Alpha

PS: Primitive Streak

PSM: Presomitic Mesoderm

RA: Retinoic Acid

Raldh2: Renialdehyde dehydrogenase 2

RAR: Retinoic Acid Receptor

RARE: Retinoic Acid-Responsive Element

RXR: Retinoid X Receptor

Sox2: Sex Determining Region Y-Box 2

Stra8: Stimulated by Retinoic Acid 8

TALE: Three Aminoacid Loop Extension

TGFB: Transforming growth factor beta

Zp3: Zona Pellucida Glycoprotein 3 

Summary 

Metazoan antero-posterior patterning is established during development and in vertebrates its organization can be studied through the specific morphologies of vertebrae depending on their position along the rostro-caudal axis. Hox genes encode DNA-binding homeodomain transcription factors essential for the specification of axial skeletal identities. The specificity and affinity of Hox proteins in DNA binding and axial identity specification depends on interactions with cofactors. Meis transcription factors form different molecular complexes required for Hox proteins to efficiently regulate their targets. In this thesis we show that Meis is involved in the specification of axial identities and skeletal patterning, by showing that the deletion of Meis produces anterior homeotic transformations and other skeletal defects affecting the occipital, cervical, thoracic and anterior lumbar region. The abnormalities observed in the skeleton of Meis-deficient mice do not involve changes in Hox gene expression, despite the extensive binding of Meis to Hox genetic complexes, and therefore, their role as Hox cofactors could underlie the homeotic functions described. Through molecular analyses, we found retinoic acid signaling deficiencies in Meis mutants and identified the gene Raldh2, which codifies for the main embryonic retinoic acid synthesizing enzyme, as a putative direct Meis target. A compared analysis of Meis and Raldh2 mutants identifies similar alterations of the skeletal pattern, which suggests that, at least in part, Meis roles in axial skeleton patterning are conveyed by regulation of the retinoic acid pathway. Besides homeotic transformation, we found defective patterning of the distal segments of ribs, which we correlated with defects in molecular pathways required for hypaxial muscle development. The results presented characterize the functions of Meis genes in axial skeletal patterning and identify molecular pathways by which they perform these functions. 

El patrón antero-posterior de los metazoos se establece durante el desarrollo y en el caso de vertebrados puede ser estudiado mediante la identificación de diferentes vertebras, ya que éstas presentan características específicas dependiendo de su posición en el eje. Los genes Hox codifican factores de transcripción que presentan un homeodominio mediante el que se unen al ADN y están implicados en la especificación de identidades axiales. Su especificidad y afinidad en la unión al ADN durante el establecimiento de identidades axiales depende de la interacción con otros cofactores. Este es el caso de los factores de transcripción Meis, que forman diferentes complejos para regular las dianas de los factores Hox. En esta tesis mostramos que Meis está implicado en el establecimiento del patrón axial, ya que la deleción de genes Meis produce transformaciones homeóticas anteriores y otros defectos esqueléticos que afectan predominantemente a las regiones occipital, cervical, torácica y lumbar anterior. Las anomalías observadas en el esqueleto de los mutantes de Meis no son debidas a cambios en la expresión de los genes Hox, por lo que, a pesar de la unión profusa de Meis a los complejos genéticos Hox, no podemos asignar a Meis una función en la regulación transcripcional de estos genes durante el desarrollo del eje principal de los vertebrados; sin embargo, dichos defectos si podrían ser debidos a la necesidad de la función de Meis como cofactor de los genes Hox. Mediante análisis molecular identificamos deficiencias en la ruta de señalización del ácido retinoico en los mutantes Meis, identificando el gen que codifica Raldh2, la enzima encargada de la mayor parte de la síntesis de ácido retinoico en el embrión, como posible diana directa transcripcional de Meis. El análisis comparado de los mutantes Meis y Raldh2 identifica alteraciones similares en el fenotipo esquelético, lo que sugiere que, al menos en parte, las funciones de Meis en la especificación axial están mediadas por la vía del ácido retinoico. Además de las transformaciones homeóticas, identificamos defectos en el patrón de la parte distal de las costillas, que se relacionan con defectos en el establecimiento de las vías moleculares que regulan el desarrollo de la musculatura hipaxial. Los resultados presentados caracterizan las funciones de los genes de la familia Meis en la asignación de identidades antero-posteriores en el esqueleto axial e identifican vías moleculares mediante las cuales se ejecutan estas funciones. 

Introduction 

Antero-posterior (AP) patterning is an essential feature of the bilaterian body plan and its principles have been under study for a long time. One of the most important breakthroughs in the understanding of antero-posterior axis patterning was the identification of Hox mutants in Drosophila, which cause the transformation of one part of the body into another, a phenomenon known as homeotic transformation (Lewis, 1978; Lewis, 1963).

\section{Cluster organization of Hox genes}

The discovery of Hox genes underlying these homeotic functions and their particular organization in clusters highlighted a relationship between genetic organization and the body plan. In most animals, Hox genes are organized in clusters. Classical studies in Drosophila identified 8 genes, found to be distributed in two different genetic complexes, the Antennapedia complex (ANT-C) and the Bithorax- complex (BX-C); both complexes were in the same chromosome but at a significant distance (Lewis, 1992; Kaufman et al.1990; Sánchez-Herrero et al. 1985a; Sánchez-Herrero et al. 1985b). In fact, Drosophila homeotic genes correspond with a single ancient complex that splitted during evolution, while it remained single in most other invertebrates (Montavon and Soshnikova, 2014; Duboule, 2007). Genes homologous to the invertebrate homeotic genes are also found in vertebrates (Krumlauf, 1994; Akam, 1989). Most vertebrates have Hox genes organized in 4 paralogous complexes (HoxA, B, C and D) that originated from two consecutive
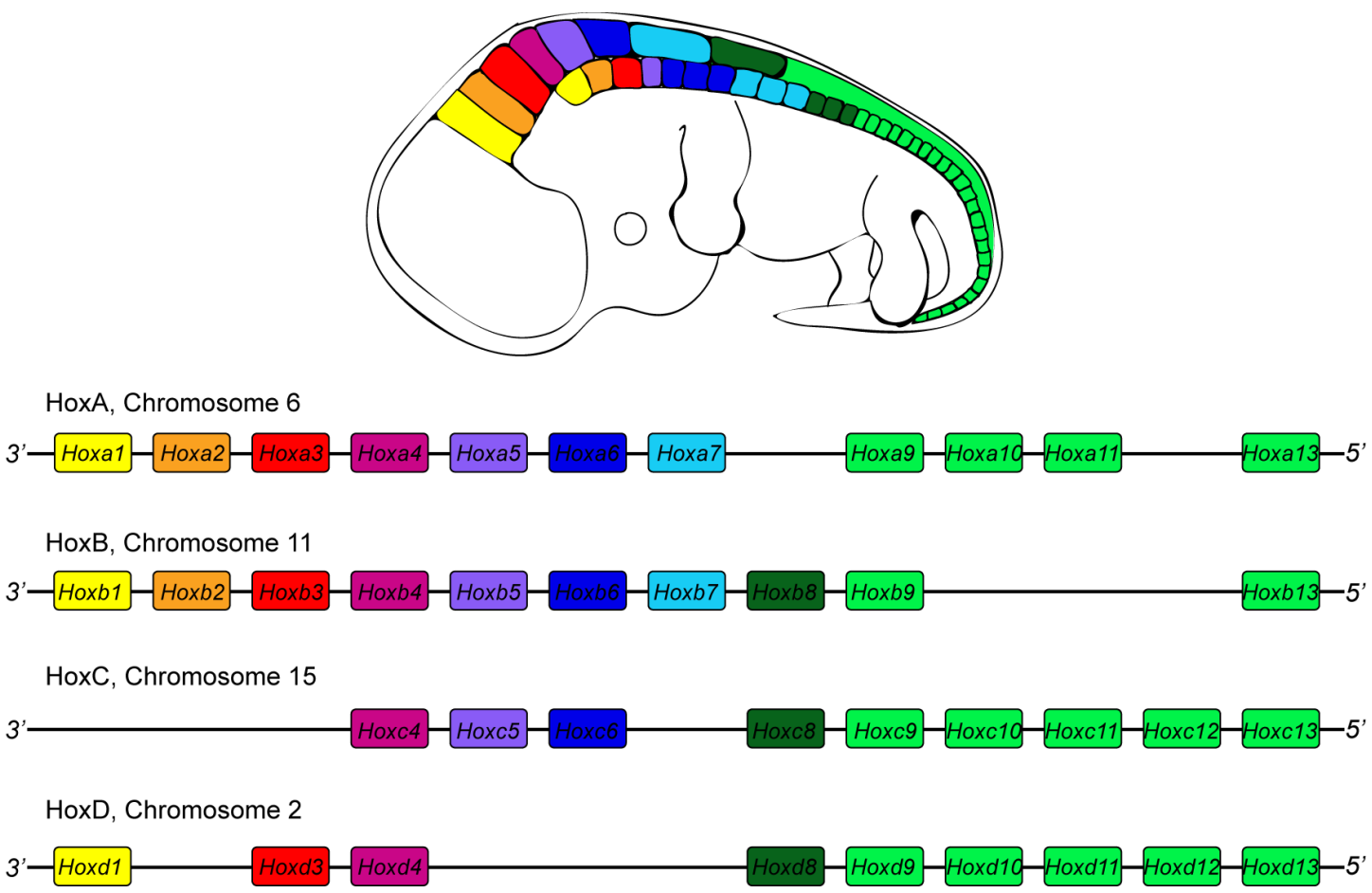

Figure 1: Spatial collinearity and organization of Hox gene complexes in the mouse embryo. 
rounds of genome duplication (Montavon and Soshnikova, 2014). This genomic organization confers unique characteristic to the dynamics of Hox gene expression such as spatial collinearity, which is the correspondence between the physical order of the genes in the chromosome and their antero-posterior boundary of expression in the embryo (Fig. 1). Spatial collinearity was first suggested by Lewis (1978) and then extended to vertebrates (Gaunt et al. 1988). In vertebrates, Hox cluster regulation shows as well temporal collinearity, which is a correlation between the order of genes in the complex and the timing of their expression onset (Izpisúa-Belmonte et al. 1991; Dollé et al. 1989). The timing of activation of a Hox gene depends on the position in the complex, so that 3 ' genes are expressed earlier than 5' genes. In vertebrates, gene clustering is needed for temporal collinearity and provides a coordinated system of axial signals generating different regional identities (Krumlauf, 1994). Despite these correlations, Hox complex organization is not strictly necessary for stablishing spatial domains, as species that do not show clustered Hox gene organization maintain spatial compartmentalization of Hox gene expression (Duboule, 2007). Furthermore, both types of collinearities, although coordinated, could be uncoupled since temporal collinearity depends on the relative location of the gene with respect to the centromeric/telomeric landscapes of the complex, while spatial collinearity depends on local regulation of enhancers (Tschopp et al. 2009). As demonstrated initially in flies, mutations in Hox genes produce homeotic transformations that in vertebrates are manifested in the axial skeleton (Krumlauf et al. 1994).

\section{Hox genes and early development}

Sequential activation of Hox genes starts at the late primitive streak stage (E7.2) and is tightly coupled with the process of gastrulation (Deschamps et al. 1999). In fact, experiments in the chicken suggest that Hox gene activation is responsible for the timing of ingression of epiblast cells through the primitive streak (PS) (Iimura and Pourquie, 2006). Prior to gastrulation, the mouse embryo epiblast is a cup-shaped columnar epithelium that surrounds the proamniotic cavity. The PS is formed at the onset of gastrulation at the extraembryonic/embryonic boundary of the proximal epiblast, defining the posterior pole of the embryo (Rivera-Pérez and Hadjantonakis, 2015). The initial expression of Hox genes starts in cells of the proximal-posterior region of the embryonic epiblast and as gastrulation proceeds, Hox expressing cells colonize the PS and reach the node, extending their expression anteriorly and distally in a process that does not involve cell migration. From this location and through asymmetric divisions, Hox expressing cells seed the trunk mesoderm and neuroectoderm in an antero-posterior sequence. At later stages, these precursors change position in the tail bud and lose their ability to generate 
lateral and intermediate mesoderm, keeping the ability to generate notochord, paraxial mesoderm and ectodermal derivatives (Cambray and Wilson, 2002). Hox genes are expressed sequentially in precursors, starting in the posterior epiblast up to their establishment as tail precursors, which helps establishing AP identity independently in the paraxial mesoderm, lateral mesoderm and in the neuroectoderm (Neijts and Deschamps, 2017; Deschamps and Wijgerde, 1993). Sequential activation of Hox genes has been shown to rely on a directional progressive transition from an inactive (closed) to an active (open) chromatin state allowing temporal regulation (Chambeyron and Bickmore, 2004). Close and open chromatin states correspond with a three-dimensional (3D) organization of the complex that is modified according to time and position in the embryo. Starting from a homogeneously inactive 3D structure, transcriptional activation starts at the 3' region of the complexes, establishing active and inactive regions (Noordermer et al. 2014; Noordermer et al. 2011). This bimodal state of the chromatin corresponds with H3K4me3 and H3K27me3 marks that can be found over the complex labelling active and inactive genes (Soshnikova and Duboule, 2009a), while in transition regions both histone marks could be seen simultaneously, indicating areas primed for activation (Soshnikova and Duboule, 2009b). This sequential chromatin activation model restricts the susceptibility of Hox genes to activation by environmental signals and provides a basis for experiments showing that induction of Hox genes can only be achieved in tissues that are already primed for expression at a given stage (Forlani et al 2003; Roelen et al. 2002), ensuring a proper sequence of transcriptional activation. The position of the Hox genes along the complex and the sequential chromatin activation mechanism thus imposes an important constraint on the order of Hox gene activation in the main embryonic axis and provides a basis for temporal/spatial collinearity.

\section{Axial elongation and segmentation}

While the opening of the Hox complex progresses continuously in the long-term progenitors at the posterior bud, their daughters fix their Hox expression code as they exit the progenitor region and colonize the embryonic axis. After the fixation of a Hox gene expression profile, as cells colonize the different AP segments, they carry the successive expression domains to the progressively forming main body axis, resulting in an AP nested pattern (Fig. 1). Thus, during axial elongation, temporal information is translated into spatial domains (Deschamps and Duboule, 2017). In fact, axial extension is controlled by Hox genes, as central Hox genes have been shown to stimulate axial elongation while posterior Hox genes arrest the extension (Young et al. 2009). Axial elongation is due to the addition of new cells from the posterior growth zone located in the node/primitive 
streak, and then later in the tail bud. Once the PS is mature, the position of the cells in the PS correlates with their final medio-lateral position in the embryo. Hence, cells in the rostral node generate the notochord but in the caudal end of the node and the most anterior region of the PS, neuroectoderm and somitic mesoderm forms. This region comprising the caudal node and the anterior most PS is called the node-streak border (NSB) and harbors bipotent progenitor cells, known as neuromesodermal progenitors able to generate stem cells of the neurectoderm and somitic mesoderm (Tzouanacou et al. 2009). Thus, neuromesodermal progenitors from the NSB and lateral epiblast of the anterior PS generate the neural tube and the paraxial mesoderm. Central positions of the PS generate the intermediate mesoderm and posterior-most regions of the PS produce the lateral mesoderm (Wilson et al. 2009; Sweetman et al. 2008). The derivative of the NSB at later stages is the chordo-neural hinge $(\mathrm{CNH})$ in the tail bud and neuromesodermal progenitors are maintained in this $\mathrm{CNH}$ until axis elongation has ceased around E13.5 (Wymeersch et al. 2016) (Fig. 2).

During differentiation, the paraxial mesoderm first segments into epithelial sacs known as somites, which then originate the trunk skeleton, skeletal connective tissues, muscles and somatic endothelium. The intermediate mesoderm generates the urogenital system and the lateral plate produces the heart, the limbs and the visceral mesoderm. Wnt signaling is an essential player in Hox regulation and promotion of mesoderm production. Wnt signaling is responsible for the initial activation of Hox genes around gastrulation and its continued signaling in the posterior bud stimulates neuromesodermal progenitors to produce the formation of new paraxial mesoderm (Martin, 2016; Jurberg et al. 2014; Wilson et al. 2009; Sweetman et al. 2008). From its birth in the progenitor region until its segmentation as it incorporates to the differentiating axis, the paraxial mesoderm transits through a phase in which it remains unsegmented and it is known as presomitic mesoderm (PSM). In the PSM, cells are continuously added posteriorly from the progenitor region and exit anteriorly, as its rostral part contributes to the formation of segmented paraxial mesoderm in the process called somitogenesis. Somites are generated at a regular pace that is regulated by a molecular oscillator involving several signals and known as the segmentation clock. The clock displays a coordinated cell-autonomous oscillatory gene expression pattern whose central regulation depends on the Delta/Notch and Wnt signaling pathways.

These oscillatory waves spread from the posterior to the anterior PSM. One proposed model, known as the clock and wave front model proposes that a determination front is established by an anterior threshold of Wnt and FGF signaling gradients spreading from the posterior PSM. The position of the determination front is influenced by an opposing 

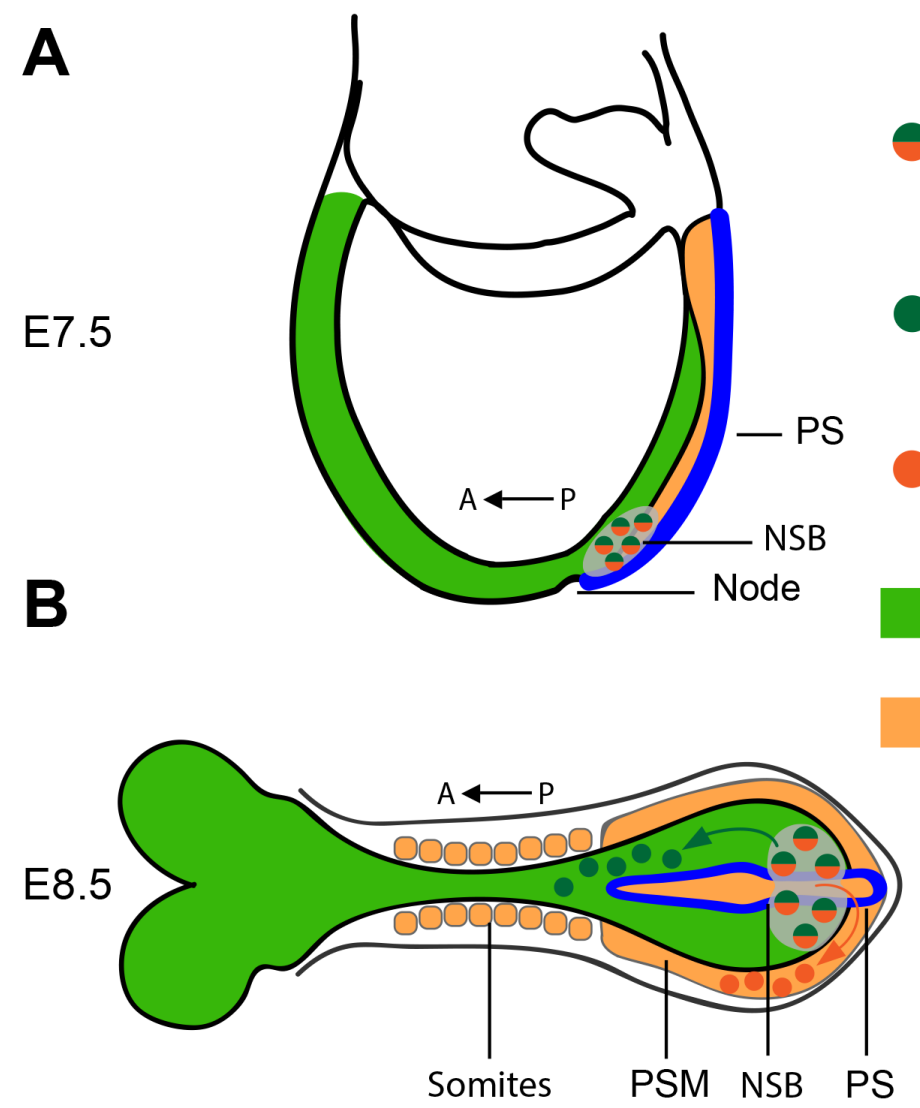

C

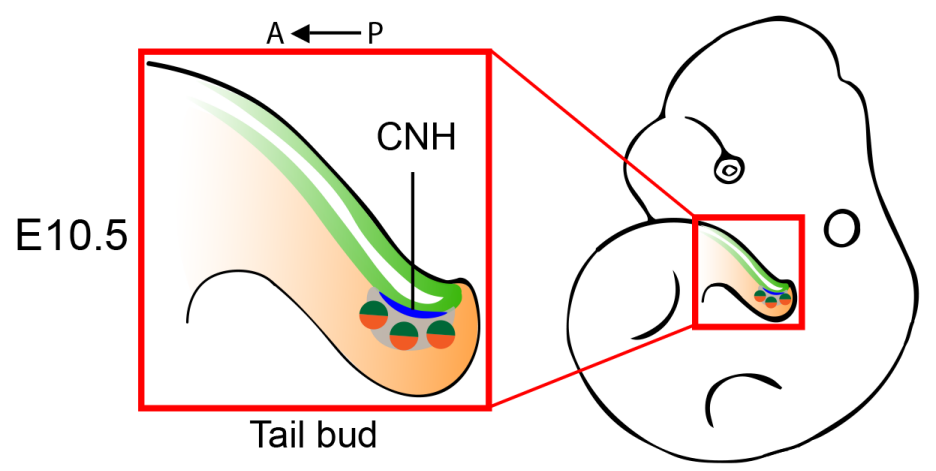

Figure 2: Axial elongation at E7.5 (A), E8.5 (B) and E10.5 (C). PS, Primitive Streak; NSB, Node-Streak Border; PSM, Presomitic Mesoderm; CNH, Chordo-neural Hinge; A, Anterior; P, Posterior.

gradient of retinoic acid (RA), which inhibits Wnt and FGF signaling (Aulehla and Pourquié, 2010). As the embryo extends posteriorly, cells that cross the determination front are able to respond to segmentation clock signals and express mesoderm segmentation genes, as Mesp 2 in the mouse, and a new physical boundary, and subsequently a new somite, is formed (Martin, 2016).

Coordination between segmentation and Hox gene activation in the PSM/somite tran- 
sition was described for the first time by Zákány et al. (2001). Additional experiments show that in the PSM the Hox code of the cells is not fully determined yet (Dubrulle et al. 2001) but remains sensitive to Wnt, FGFs, RA and signaling from the oscillatory clock (Deschamps and van Nes, 2005; Cordes et al. 2004).

A relevant question is then when during these phases of mesoderm production Hox genes exert their function in establishing the AP identity of skeletal elements. In this respect, Hox gene overexpression either in the PSM or in the already formed somites, gives rise to strikingly different phenotypes (Carapuço et al. 2005), with clear changes in vertebral identity only appearing after overexpression in the PSM but not in the formed somites. These experiments suggested that the Hox gene functions related to axial identity are defined in the PSM and affect cells before they form somites (Carapuço et al. 2005).

\section{Axial skeletal patterning}

The segmented paraxial mesoderm helps to precisely study Hox expression antero-posterior domains. Furthermore, the paraxial mesoderm gives rise to the vertebral column that is composed of a series of vertebrae. However, each vertebra is the result of the combination of two somite halves: the caudal half of one somite and the rostral half of the next somite join in a process known as resegmentation (Ward et al. 2017; Bagnall et al. 1988). In addition, each vertebra is composed of two parts: a vertebral body and a dorsal neural arch; with the spinal cord being enclosed ventrally by the vertebral body and elsewhere by the neural arch (Fig. 3 A). Vertebral bodies and neural arches show different shapes according to their position along the AP axis. These positional and morphological characteristics allow their classification in: cervical (C), in the neck; thoracic (T), forming ribs; lumbar (L), in the abdomen; sacral (S), connecting with the pelvic girdle and caudal $(\mathrm{Ca})$, in the tail. The number of vertebrae belonging to the different types varies depending on the vertebrate species. The mouse vertebral formula is 7 cervical, 13 thoracic, 6 lumbar, 4 sacral and 30 caudal (Mallo et al. 2009) (Fig. 3 B). Morphological diversity and axial position of the different types of vertebrae are sensitive to the positional cues given by the expression of different Hox genes (Burke et al. 1995; Gaunt et al. 1988). The first functional correlation between murine Hox genes and axial patterning was presented by Kessel et al. (1990), who reported vertebral homeotic transformations that resulted from the transgenic expansion of a Hox expression domain. Since then, several gain and lossof-function Hox mutants with different homeotic transformation have been described in mice (McIntyre et al. 2007; Wellik and Capecchi, 2003; Horan et al. 1995a; Horan et al. 1995b; Kostic and Capecchi, 1994; Condie and Capecchi, 1993; Ramírez-Solis et al. 
A

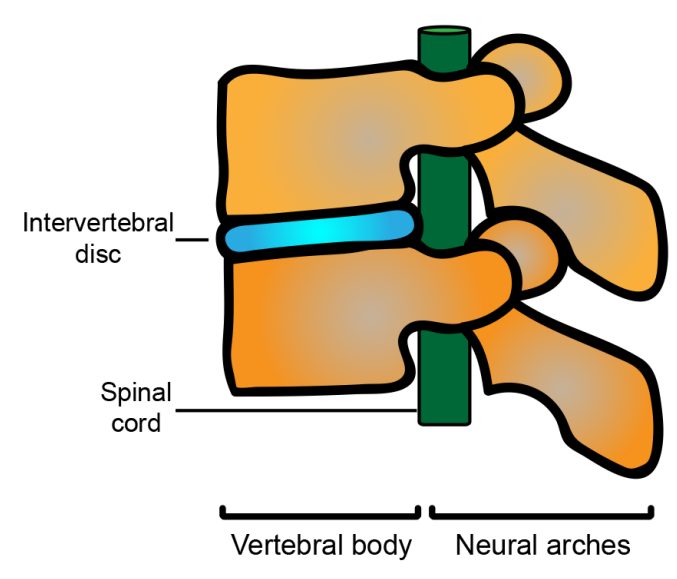

B

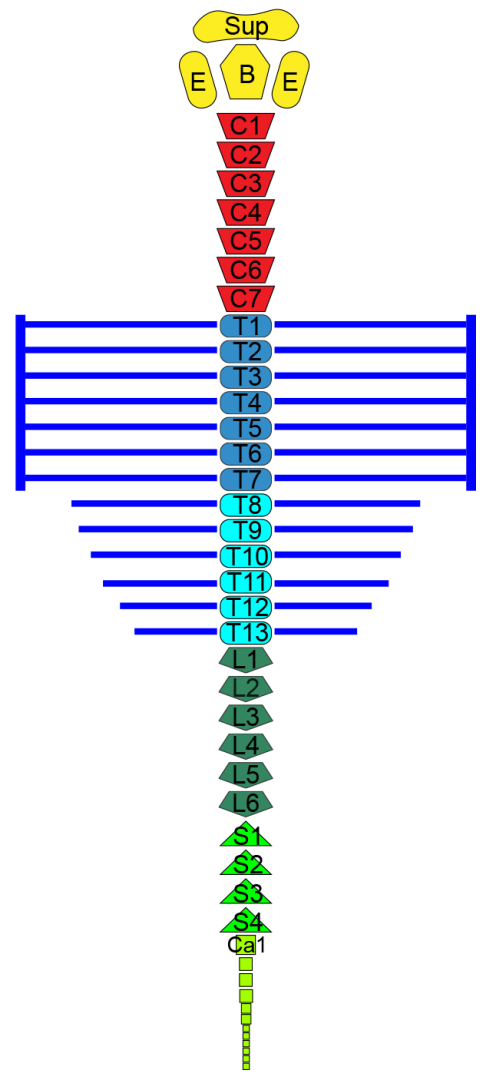

Figure 3: Schematic representation of a vertebra (A) and vertebral column (B). Sup, Supraoccipital; B, Basioccipital; E, Exoccipital; C, Cervical; T, Thoracic; L, Lumbar; $\mathrm{S}$, Sacral; $\mathrm{Ca}$, Caudal. Horizontal blue lines in $\mathrm{B}$ represent ribs and the vertical lines represent the sternum.

1993; Chisaka and Capecchi, 1991).

After segmentation from the PSM, somites are initially epithelial (Fig. 4 A) and in response to signals, ventro-medial cells close to neural tube and notochord lose epithelial characteristics and form the sclerotome (Fig. 4 B), which will give rise to the vertebrae and ribs. Somite lateral cells in contact with the ectoderm differentiate into the dermomyotome and cells from all four edges of the dermomyotome migrate internally and spread beneath its central region, forming the myotome (Cinnamon et al. 1999). The remaining central region of the dermomyotome then differentiates into the dermatome (Fig. $4 \mathrm{C}$ ) and gives rise to the dermis of the back and limbs. The myotome is dorso-ventrally continuous but there are molecular signatures that differentiate its dorso-medial/epaxial (deep muscle of the back) and ventro-lateral/hypaxial (intercostal, body wall and limb muscles) cell compartments (Musumeci et al. 2015; Ahmed et al. 2006). Although vertebrae and ribs have a sclerotomal origin, their development is dependent on interactions with other somitic compartments. Factors produced in the myotome have been shown to cause abnormalities 
A

Neural Surface Lateral plate

tube ectoderm mesoderm
B

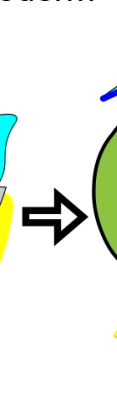

Dermomyotome

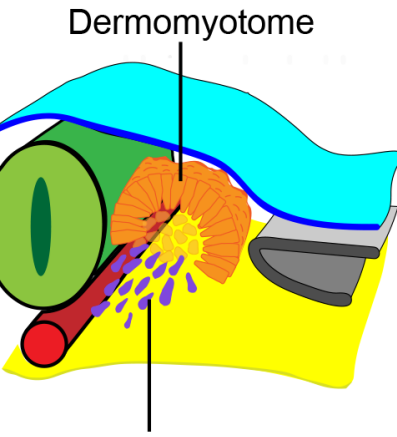

Sclerotome
C

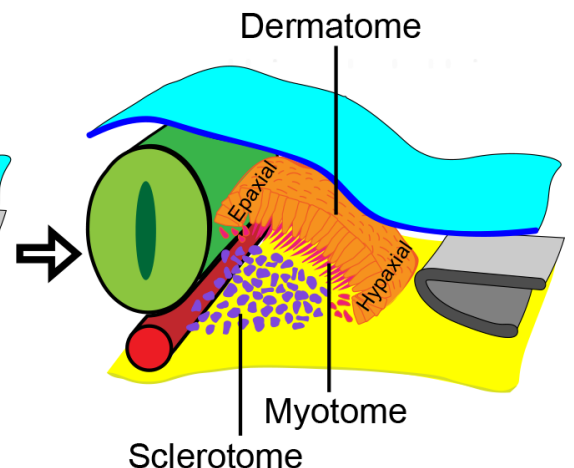

Figure 4: Somite differentiation from a spherical epithelial structure (A) until differentiation in three different layers: sclerotome, myotome and dermatome $(\mathrm{C})$.

in the skeleton and especially in the hypaxial region. Disruption of the muscle regulatory factors genes, Myf5, MRF4 and myogenin, leads to mice with absence of the distal part of the ribs (Vivian et al. 1999; Braun and Arnold, 1995; Zhang et al. 1995; Braun et al. 1992) and mutations in Pax3, expressed in the dermomyotome, and PDGFR , expressed in the sclerotome and the dermatome, show a very similar phenotype affecting ribs but also the sternum and neural arches of the vertebrae (Henderson et al. 1999; Soriano, 1997). Important signaling crosstalk between different compartments has been proposed involving different growth factors like PDGF $\alpha$, TGF $\beta$, FGF4 and FGF6, which are required for normal skeletal development (Tallquist et al. 2000; Vivian et al. 2000; Grass et al. 1996). Interestingly, Vinagre et al. (2010) propose a role of Hox genes in the control of Myf5 and MRF4 expression in the ventrolateral (hypaxial) somite through the control of PDGF $\alpha$ and FGF signaling. In this work, they correlated the Hox-controlled absence/presence of Myf5 and MRF4 in the hypaxial myotome with the absence/presence of ribs.

\section{Hox cofactors and DNA binding}

To generate positional identity, Hox proteins regulate different target genes by binding to their DNA regulatory sequences. Binding properties come from a $180 \mathrm{bp}$ region called homeobox (because it was discovered in homeotic genes) that encodes a homeodomain (HD) of 60 amino acids that functions as a DNA-binding domain. The HD is highly conserved in animals and plants and is not exclusive to homeotic genes but also present in a large number of transcription factors, many of them involved in developmental processes. The HDs of Hox proteins are very similar to each other and bind to similar DNA sequences, having low binding specificity and affinity for their target sequences (Bobola and Merabet, 2017; Gehrin, 1994). How Hox proteins are able to fulfill their diverse 
functions despite of their low sequence specificity has been a matter of study for many years. Additional flanking domains in the HD, DNA shape and sequence of the targets contribute to increase the specificity; but Hox proteins usually do not bind alone to enhancer or promoter regions and they gain specificity and affinity for binding sequences mainly through interactions with transcriptional cofactors of the TALE family (Mann and Affolter, 1998). TALE (Three Aminoacid Loop Extension) is a group of homeodomain factors which has a characteristic extra three-aminoacids between the first and second helix of the HD (Bertolino et al. 1995). Two TALE classes, PBC and MEIS, are important Hox cofactors (Mann and Affolter, 1998). PBC class are characterized by the presence of the PBC domain and comprises Pbx genes in mammals (Bürglin and Ruvkun, 1992; Nourse et al. 1990) and extradenticle (exd) in Drosophila (Chan et al. 1994; Rauskolb et al. 1993). MEIS class include Meis and Prep genes in mammals (Fognani et al. 2002; Chen et al. 1997; Moskow et al. 1995) and homothorax (hth) in Drosophila (Rieckhof et al. 1997). These TALE cofactors form dimers or trimers with the Hox proteins, conferring them with increased DNA specificity and affinity, although they also display also Hoxindependent functions (Bürglin and Affolter, 2016). Besides the HD, these two classes contain conserved protein-protein interaction domains allowing them to form MEIS-PBC dimers, even in the absence of DNA. This interaction increases the DNA-binding selectivity and affinity, through the binding of both HDs to the DNA. In addition, members of the PBC and MEIS classes can form dimers with Hox proteins, with Meis factors directly binding paralogs 9-13 (Shen et al. 1997), while Pbx factors directly binding paralogs 1-10 (Chang et al. 1996). In addition, DNA-bound heterotrimeric MEIS-PBC-HOX complexes can form with a representative of each class (Fig. 5 A). In these complexes, the homeodomain of the Hox protein and one of the TALE partners binds DNA, selecting sequences that are composites of each factor's isolated binding sites, while the second TALE factor participates as a non-DNA binding factor adding stability to the complex (reviewed in Longobardi et al. 2014). Penkov et al. (2013) identified the global repertoire of Meis, Prep and Pbx binding sites by ChIP-seq analysis in E11.5 mouse embryos. They reported specific DNA-binding sequences associated to the different complexes formed by combinations of Prep, Meis and Pbx proteins; and they show differences in the target sequences and interactions depending on the presence of Meis or Prep in the complex. These studies, identified Hox and Hox-PBC binding sites as the preferred sites of Meis interaction, above the Meis-only binding sites. Interestingly, Prep factors interacted only in a minority of their binding sites with PBC-Hox binding sites, suggesting that Meis factors represent the preferred Hox partner among the MEIS class. Interestingly, a large number of Meis binding sites was found within Hox complexes, and they were especially abundant in the HoxA complex (Fig. 7 B), which suggested a specific function of Meis factors in the 
transcriptional regulation of Hox genes, in addition to their Hox-cofactor functions. Later studies in zebrafish (Choe et al. 2014) and mouse (Amin et al. 2015) embryos showed that some of these binding sites represent Hox genes self-regulatory elements and that these elements contain pre-bound TALE factors, which prime the enhancer and recruits Hox proteins, necessary for activation of transcription. A striking observation regarding the Meis occupation of Hox complex DNA is that binding sites appear only distributed the paralog 1 to 9 region, whereas there are no binding sites in the paralogs 10 to 13 region (Penkov et al. 2013). This distribution suggests some relationship between Meis activity and collinear Hox complex activity, however this aspect has not been addressed functionally until now.

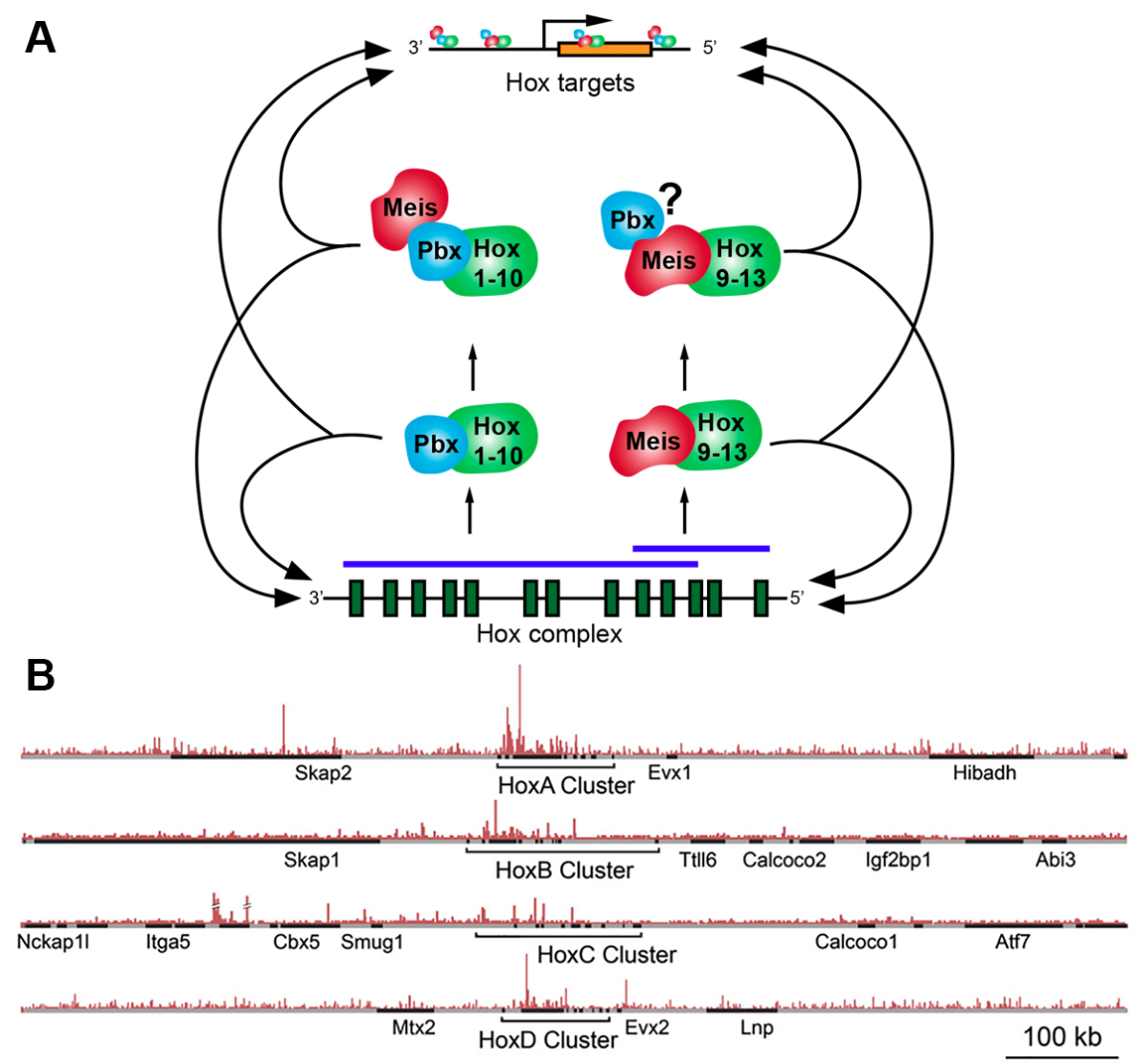

Figure 5: (A) Squematic representation of different Meis-Pbx-Hox complexes and their targets. (B) Chromatin immunoprecipitation of Meis in Hox complexes in E11.5 mouse embryos (Penkov et al. 2013). 


\section{Retinoic acid signaling in development}

Retinoic acid is the active derivative of vitamin A (retinol) and plays fundamental roles in a wide range of processes including axial patterning, cranio-facial development, patterning of the central nervous system, cell differentiation and development of multiple organs. RA is a lipophilic molecule, diffusible through cell membranes, that acts as a morphogen and exerts its functions by binding transcription factors of the nuclear receptor family. The first roles of RA have been studied on one hand in mice fed with a vitamin A-deficient diet; and on the other, by administering excess doses of RA that produced teratogenic effects. In placental embryos, retinol is introduced in the embryo from the maternal circulation and is metabolized to RA in two sequential reactions: retinol to retinaldehyde, which is catalyzed by alcohol dehydrogenases and retinol dehydrogenases; and a second reaction that is the oxidation of retinaldehyde to RA, which is carried out by retinaldehyde dehydrogenases. There are three retinaldehyde dehydrogenases, Raldh1, Raldh 2 and Raldh3 (encoded by genes Aldh1a1, Aldh1a2 and Aldh1a3, respectively) and their expression patterns closely correlate with the dynamics of RA signaling (Rhinn and Dollé, 2012). Raldh2 is responsible for almost all the RA production during early embryogenesis. At E7.5 its expression is restricted to the posterior half of the embryo, in the mesoderm lateral to the PS and then extends rostrally along each side of the node (Niederreither et al. 1997). This posterior expression domain is the origin of a RA diffusion gradient and represents a posteriorizing signal, since anterior structures are disrupted by an RA excess (Niederreither et al. 1997) and on the other hand, Raldh2-deficient mice present trunk and posterior defects (Niederreither et al. 1999).

The mechanism by which RA performs its action is binding to retinoic acid receptors (RARs). There are three RARs: RAR $\alpha, \operatorname{RAR} \beta$ and RAR $\gamma$, which form heterodimeric combinations with retinoid $X$ receptors $(\operatorname{RXR} \alpha, \operatorname{RXR} \beta$ and $\operatorname{RXR} \gamma)$. Some of these receptors present a complex tissue-specific expression (RAR $\beta, \operatorname{RAR} \gamma$ and $\mathrm{RXR} \gamma$ ) but most tissues are responsive to RA, due to the widespread expression and functional redundancy of the RAR/RXR heterodimers (Dollé, 2009). RAR/RXR heterodimers can bind DNA RA-responsive elements (RAREs) found in promoter or enhanced regions of the target genes, thereby regulating gene expression. Several members of the Hox gene family present RAREs (Marshall et al. 1996). RA effect on Hox gene expression has been largely studied, especially in hindbrain development due to its segmentation into rhombomeres, each with a Hox-coded AP identity. Absence of RA leads to loss of rhombomeric segmentation and alteration of segmental expression of different genes including Hox genes (Niederreither et al. 2000); on the other hand, RA induction alters the Hox code and produces 
homeotic transformation in the hindbrain (Marshall et al. 1992). But alterations of Hox codes and homeotic transformations in response to RA were also seen in the body axis (Kessel, 1992; Kessel and Gruss, 1991). In these works, the homeotic transformations produced opposite anterior or posterior transformation depending on the time of exposure to an RA excess. Posterior homeotic transformations were correlated with an anterior shift in the Hox boundary of expression. In addition, homeotic transformations were also seen in the absence of RA signaling, as is the case of $R A R \gamma$ mutants (Lohnes et al. 1993), whereas other studies suggest that $R A R \gamma$ and Hox genes act in parallel to regulate targets genes (Folberg et al. 1999) and may impact Hox expression by regulating $C d x$, which codes for a homeodomain transcription factor that regulates the timing and anterior expression borders of Hox genes (Allan et al. 2001). Further evidence on Hox regulation by RA comes from experiments in embryonic stem cells in which induction with RA produces a rapid epigenomic reorganization dependent of RAR $\gamma$ that consists of an increase in active histone marks in Hox genes, especially in the anterior Hox genes (Kashyap et al. 2011).

The regional distribution of RA, therefore, has to be highly controlled in the embryo; which is achieved by the regulation of a degradation pathway consisting on cytochrome P450 subfamily-26 enzymes (Cyp26a1, Cyp26b1 and Cyp26c1), which catalyze the oxidation of RA in to 4-hydroxy-RA and 4-oxo-RA, which inactivates RA. Cyp26 enzymes present an expression pattern complementary to the Raldh domains and they have a role protecting proliferative or progenitor cell zones from RA differentiating effects (Rhinn and Dollé, 2012). Cyp26 subfamily genes are direct targets of RARs transcriptional activity and are activated when embryonic cells are exposed to a RA excess or in regions that require absence of RA for proper development.

RA also has a role regulating the induction and patterning of the limb. RA is produced by Raldh 2 in the flank mesoderm and extends into the proximal limb domain whereas it is antagonized by FGF signaling from the apical ectodermal ridge in the distal part of the limb, generating proximo-distal information that is interpreted by regionally expressed genes, including Meis and Hox genes. Meis expression is restricted to the proximal domain of the developing limb bud and it is essential for proximo-distal specification. Experiments in chicken (Mercader et al. 2000), axolotl (Mercader et al. 2005) and mouse (Yashiro et al. 2004) showed that RA promotes Meis expression in the limb bud, while experiments in the chick (Mercader et al. 2000) and mouse (Mariani et al. 2008) showed that FGF inhibits Meis expression. On the other hand, it has been described that Meis has an inhibitory effect on Cyp26bl expression, which is activated in the distal limb bud by FGF and is responsible for RA degradation in this region (Roselló-Díez et al. 2014). The- 
se results integrate Meis proximo-distal function with RA and FGF signaling pathways.

The crosstalk between TALE, Hox and RA signaling is, however, more complex. The TALE-PBC-HOX network has a wide spectrum of targets outside the Hox complexes and this includes the gene encoding Raldh2, the enzyme responsible for RA synthesis. Analysis of binding sites in Raldh2 locus identified an enhancer bound by Hoxa1-PbxMeis2 complex required for normal Raldh2 expression levels and AP patterning in the hindbrain (Vitobello et al. 2011). Further evidence was found in a human neuroblastoma cell line where Meis2 activates Raldh2 but decreases Cyp26al expression (Groß et al. 2018). Altogether, the knowledge in the field depicts a complex scenario in which multiple and tissue-specific regulatory interactions shape the TALE-PBC-HOX network and its relationship to RA signaling.

\section{Meis genes and pattern formation in the mouse embryo}

Three different genes were identified in the Meis family, Meis1, Meis 2 and Meis3. Meis1 is the acronym of myeloid ecotropic viral integration site 1 because it was identified as a common site of viral integration (Moskow et al. 1995). Afterwards, two Meis 1-related genes, Meis2 and Meis3, were identified showing high homology with Meis1 (OuladAbdelghani et al. 1997; Cecconi et al. 1997; Nakamura et al. 1996).

Meis1 deficient mice die around E14.5 (Azcoitia et al. 2005; Hisa et al. 2004) because of defects in hematopoiesis (Azcoitia et al. 2005). Meis 1 expression was detected in different structures of the head such as the eye, external ear primordium but also in other regions of the embryo such as the spinal cord, mediastinum, mid gut, cardiac chambers, lung, paraxial mesoderm (González-Lázaro et al. 2014; Hisa et al. 2004) and in the proximal domain of the limb primordium (Mercader et al. 1999).
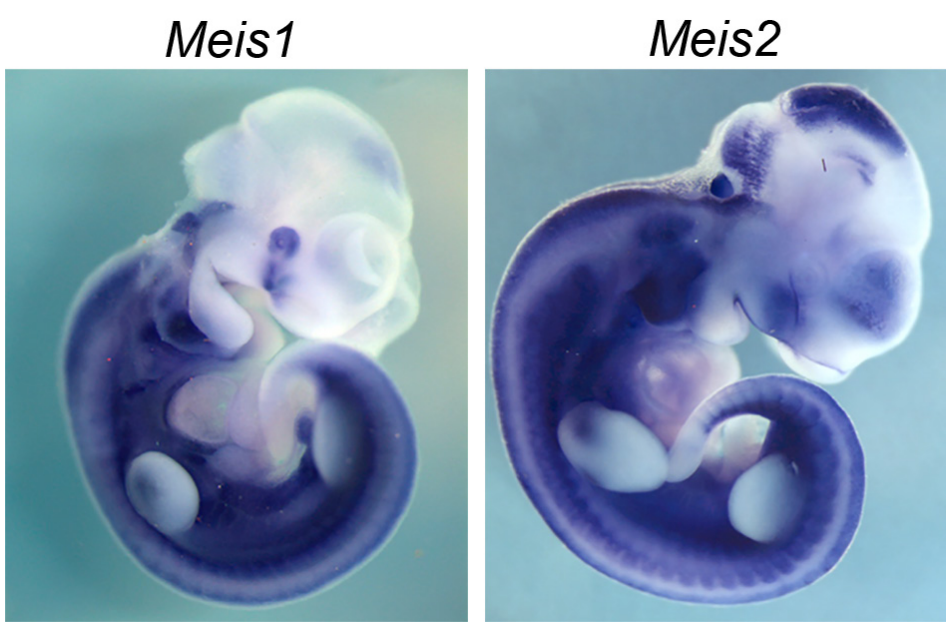

Figure 6: In situ hybridization of Meis1 and Meis 2 in E10.5 embryos. 
Meis2 mutants die between E13.5-E14.5 and suffer from hemorrhaging that induces apoptosis in liver cells and that may be the cause of embryonic lethality (Machon et al. 2015). Meis 2 is expressed at early stages in the neural tube midline and in the somitic mesoderm corresponding to the presumptive cervical and trunk segments. At later stages it labels the developing brain, including the rhombomere 2 and 3, part of the midbrain and forebrain. It was also detected in branchial arch derivatives and in heart, lung, gut and kidney. In relation with the trunk, Meis 2 is expressed in the lateral compartments of the somites but at later stages the expression is excluded from the sclerotome persisting only in the myotome and in the overlying dorsal ectoderm (Oulad-Abdelghani et al. 1997; Cecconi et al. 1997). Like Meis1, Meis 2 is also expressed in the proximal limb bud (Mercader et al. 1999).

Meis3 deficient mice have not been generated but experiments in Xenopus and zebrafish suggest a role of Meis 3 in the differentiation and patterning of the hindbrain (Vlachakis et al. 2001; Salzberg et al. 1999). This is consistent with the expression detected by Northern blot at high levels in the brain, although some expression also appeared in the heart, spleen and lung (Nakamura et al. 1996).

The three Meis genes present different expression pattern although they present overlap in some regions. This overlap occurs mainly between Meis1 and Meis2 expression (Fig. 6), being Meis3 expressed more specifically in the neural tube and dorsal root ganglia (Yokoyama et al. 2009). In addition, unlike Meis 1 and Meis2, which are expressed from early stages, Meis3 is first detected at E11 (Nakamura et al. 1996).

As it was mentioned above, Meis family members act as cofactors of Hox proteins to increase binding specificity in their targets. Axial patterning is one of the most known function of Hox genes; however, the role of Meis transcription factors in the establishment of axial skeleton specification remains unknown. Since Meis 3 is expressed in the nervous system at late stages, Meis 1 and Meis2 are the factors of this family that could form the Hox-Meis complex and have a role in the establishment of the axial skeleton identity. Defects in the axial skeleton have not been reported neither in Meis1 (Azcoitia et al. 2005) nor in Meis 2 deficient mice. However, both factors could present redundant functions so single knockout could not present skeletal transformation and the generation of Meis 1/2 double knockout is necessary. 


\section{Objectives}



Meis transcription factors are known to play roles as cofactors of Hox proteins during development, however, their roles in axial patterning have not been studied before.

Furthermore, Meis factors bind extensively to the chromatin of Hox complexes during development, however the role of Meis in Hox transcription has not been established. In this thesis we devised the following specific aims to analyze whether and how Meis regulates antero-posterior organization during mouse development.

1- Analysis of Meis 1 and Meis 2 expression pattern during early mouse develop mental stages

2- Description of the axial skeletal pattern in the absence of Meis function through the study of Meis 1 and Meis 2 conditional deletion models

3- Analysis of Hox gene antero-posterior transcription patterns in Meis 1 and Meis 2 conditional deletion models

4- Elucidate the timing and tissue of Meis function during mouse axial skeletal patterning

5- Identification of molecular pathways and mechanisms involved in Meis functions during axial skeletal patterning 



\section{Materials and Methods}





\section{Mouse lines}

To generate Meis1 and Meis2 conditional knock-outs, Meis1-flox and Meis2-flox lines combined with different Cre lines have been used. Meisl-flox mice (Unnisa et al., 2012) have loxp sites flanking exon 8. Meis2-flox mice (Alberto Roselló and Giovanna Giovinazzo, unpublished), and in this locus, loxp sequences surround exon 3.

Raldh2-flox line (Vermot et al. 2006) which present loxP sites flanking the fourth exon was used to generate Raldh2 conditional knock-outs.

Cre lines used recombine at different stages in development, so Sox2Cre line (Hayashi et al., 2002) induces recombination in all epiblast cells by E6.5; whereas Mesp1Cre (Saga et al. 1999) recombines later in the early anterior mesoderm; and finally, Delta-likel Cre (Dll1Cre) line (Wehn et al., 2009) starts to recombine at E7.5 and expresses the Cre in the paraxial mesoderm, lateral plate and intermediate mesoderm.

To completely delete Meis 1 and Meis 2 from the beginning of development, male and female germ line Cre lines, Stra8Cre (Sadate-Ngatchou et al., 2008) and Zp3Cre (de Vries et al., 2000) respectively, were crossed with Meis1-flox;Meis2-flox mice.

To visualize Cre recombination pattern, Gt(ROSA) ${ }^{26 S o r t m 14(C A G-t d T o m a t o) H z e}$ reporter line (Madisen et al., 2010) has been used.

Stra8Cre Meis1flox/flox; Meis2flox/flox

Adult mice

not recombined
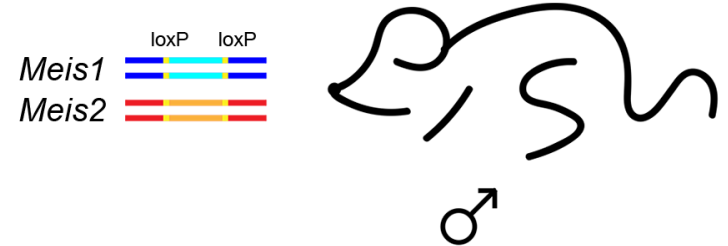

Gametes
recombined

Zygote recombined

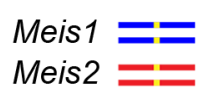

Figure 5: Schematic representation of Stra8;Meis $1^{\text {flox } f f l o x} ;$ Meis $2^{\text {floxfflox }}$ and Zp3Cre;Meis $1^{f l o x}$ fflox $;$ Meis $2^{\text {floxfflox }}$ mating. 


\section{Embryo harvest}

Mice were mated in the afternoon and females were checked every morning for the presence of a vaginal plug; noon of the day the plug was observed was considered as gestational day 0.5 (E0.5). Pregnant females were euthanized by carbon dioxide inhalation and the uterus was extracted through an incision of the abdominal cavity and transferred to PBS. In a culture dish containing $1 x$ PBS, the uterus was ripped with forceps to extract the decidua and each deciduum was dissected to obtain the embryo. After isolation, extraembryonic tissue from transgenic embryos was dissected for genotyping and embryos were fixed. Fixation process varied depending on the method to be used. Usually, 4\% paraformaldehyde (PFA) was used except for immunostaining and for embryos with endogenous fluorescence from the Gt(ROSA) 26 Sortm14(CAG-tdTomato)Hze reporter line in which 2\% PFA was used.

\section{Whole mount In situ hybridization}

Embryos were fixed in 4\% PFA overnight at $4^{\circ} \mathrm{C}$. Next day, embryos were washed with $1 x$ PBS containing $0.1 \%$ Tween 20 (PBT) at least three times and dehydrated washing them with increasing concentrations of methanol in PBT $(25 \%, 50 \%$ and $75 \%)$. Finally, embryos were stored in $100 \%$ methanol overnight at $-20^{\circ} \mathrm{C}$, although they can be stored for several months.

For hybridization, embryos were rehydrated washing them with decreasing concentrations of methanol in PBT and finally with PBT. Once rehydrated, embryos were bleached in 6\% $\mathrm{H} 2 \mathrm{O} 2$ in PBT during one hour and after several washes in PBT they were digested with proteinase $\mathrm{K}(10 \mu \mathrm{g} / \mathrm{ml})$ (Sigma). Time of proteinase $\mathrm{K}$ treatment depends on the stage of the embryo (Table 1).

After proteinase K permeabilization, embryos were washed with PBT during 5 minutes and fixed with glutaraldehyde $0.05 \%$ in $4 \%$ PFA. After 20 minutes, fixative was removed and embryos were washed twice with PBT during 10 minutes before prehybridization. For prehybridization, embryos were incubated in pre-warmed hybridization buffer $(50 \%$ Formamide, 4x SSC pH 4.5, 1\% SDS, $50 \mu \mathrm{g} / \mathrm{ml}$ heparin (Sigma), $10 \mu \mathrm{g} / \mathrm{ml}$ tRNA from

\begin{tabular}{|l|l|}
\hline Stage & Time \\
\hline E7.5 & $3 \mathrm{~min}$ \\
\hline E8.5 & $5 \mathrm{~min}$ \\
\hline E9.5 & $9 \mathrm{~min}$ \\
\hline E10.5 & $13 \mathrm{~min}$ \\
\hline
\end{tabular}

Table 1: Time of proteinase $\mathrm{K}$ treatment depending on the embryo stage. 
baker's yeast (Sigma), 1\% w/v Blocking reagent (Sigma) during 2 hours at $65^{\circ} \mathrm{C}$. Afterwards, embryos were hybridized with the probe overnight at $65^{\circ} \mathrm{C}$. Before hybridization, probes were resuspended in prehybridization buffer at different concentrations depending on the probe. Next day, the probe was removed and several washes were performed with posthybridization buffer I (0.1\% CHAPS w/v (Sigma), $2 x \mathrm{SSC}$ pH 5.5) and posthybridization buffer II ( $0.1 \%$ CHAPS w/v, $0.2 x$ SSC) during 3 hours at $65^{\circ} \mathrm{C}$. After posthybridization, embryos were washed with TBST (5mM Tris-HCl pH 7.5, $15 \mathrm{mM}$ $\mathrm{NaCl}, 0.1 \%$ Triton X-100 (Sigma) 3 times during 30 minutes and incubated in blocking solution (20\% Goat serum, 1\% Blocking reagent in TBST) during 2 hours. Then, embryos were incubated overnight at $4^{\circ} \mathrm{C}$ with 1:2000 anti-digoxigenin AP antibody (Roche) in blocking solution. Next day, embryos were washed with TBST several times during the day at room temperature and overnight at $4^{\circ} \mathrm{C}$. Finally, 3 washes of 10 minutes each with NTMT (125mM Tris-HCl pH 9.5, 125 mM NaCl, 62.5mM MgCl2, 0.5\% Triton X-100) were made and embryos were stained with BMPurple (Roche) at room temperature until the signal was optimal. After the staining, embryos were washed with TBST, fixed in $4 \%$ PFA and stored at $4^{\circ} \mathrm{C}$.

Occasionally, after in situ hybridization embryos were sectioned in the cryostat. Tissue processing for sectioning was done as described below for immunostaining.

\section{Probe synthesis}

RNA antisense probes were synthesized by transcription of linearized DNA from plasmids or from DNA amplified with specific primers and purified using a Gel DNA recovery kit (Zymoclean) (see Table 2). Transcription was carried out with digoxigenin labelled nucleotides (Roche) and T7 RNA polymerase (Roche). Synthesized RNA was precipitated with $0.8 \mathrm{M}$ ammonium acetate in $75 \%$ ethanol or $0.1 \mathrm{M} \mathrm{LiCl}$ in $75 \%$ ethanol and finally resuspended in 50\% formamide-50\% RNase free water. Probes were stored at $-20^{\circ} \mathrm{C}$.

\section{Skeletal and cartilage staining}

Embryos at E14.5 were prepared for cartilage staining with Victoria Blue and at lategestation stages embryos were prepared for Alcian Blue and Alizarin Red staining to dye cartilage and bone, respectively.

Victoria Blue

Embryos were eviscerated and fixed in 10\% formaldehyde overnight and then washed in acid alcohol $(3 \% \mathrm{HCl}$ in $70 \%$ ethanol) several times. Embryos were stained during 3 


\begin{tabular}{|c|c|c|}
\hline Probe & & 5'-3' Sequence \\
\hline \multirow[t]{2}{*}{ Hoxal } & Forward & ATTTAGGTGACACTATAGAATGCCATCAGACATTTGCAGG \\
\hline & Reverse & GTAATACGACTCACTATAGGGACAGTGTGGAAGGAAAGGGT \\
\hline \multirow[t]{2}{*}{ Hoxa3 } & Forward & ATTTAGGTGACACTATAGAATGCTGGAAAGGCTGTCAGTA \\
\hline & Reverse & GTAATACGACTCACTATAGGGTTAGCGTTCAGTTTGGCCAG \\
\hline \multirow[t]{2}{*}{ Hoxa4 } & Forward & ATTTAGGTGACACTATAGAATATACCCGGCAGCAAGTCTT \\
\hline & Reverse & GTAATACGACTCACTATAGGGAGTACATGTCCCCAGTCAGC \\
\hline \multirow[t]{2}{*}{ Hoxd4 } & Forward & ATTTAGGTGACACTATAGAATTCGGTGAACCCCAACTACA \\
\hline & Reverse & GTAATACGACTCACTATAGGGGCCTCCAACCTTCATTTGCA \\
\hline \multirow[t]{2}{*}{ Hoxa5 } & Forward & ATTTAGGTGACACTATAGAA GCTGCACATTAGTCACGACA \\
\hline & Reverse & GTAATACGACTCACTATAGGG GCAACACACAACATTGGCAC \\
\hline \multirow[t]{2}{*}{ Hoxa6 } & Forward & ATTTAGGTGACACTATAGAACGGACAAGACATACACCTCAC \\
\hline & Reverse & GTAATACGACTCACTATAGGGCTGCGTGGAGTTGATGAGTT \\
\hline \multirow[t]{2}{*}{ Paxl } & Forward & ATTTAGGTGACACTATAGAA AGATGGCTGCGTTCTCCTAA \\
\hline & Reverse & GTAATACGACTCACTATAGGG CGCGGATTGAAGAAGTCGAG \\
\hline \multirow[t]{2}{*}{$\operatorname{Pax} 3$} & Forward & ATTTAGGTGACACTATAGAA CAATGGCCTTTCACCTCAGG \\
\hline & Reverse & GTAATACGACTCACTATAGGG TCTGTGTCCTGGGCTTATCC \\
\hline \multirow[t]{2}{*}{$\operatorname{Pax} 9$} & Forward & ATTTAGGTGACACTATAGAAATGGATTGGAGAAGGGAGCC \\
\hline & Reverse & GTAATACGACTCACTATAGGGGCACGTTTCGAAAGTTCAGG \\
\hline \multirow[t]{2}{*}{ Myf5 } & Forward & ATTTAGGTGACACTATAGAATACCATGGATCGGCGCAA \\
\hline & Reverse & GTAATACGACTCACTATAGGGGTATTCTGCCCAGCTTGTC \\
\hline \multirow[t]{2}{*}{ Myogenin } & Forward & ATTTAGGTGACACTATAGAACATCCAGTACATTGAGCGCC \\
\hline & Reverse & GTAATACGACTCACTATAGGGGTCAGGGCACTCATGTCTCT \\
\hline \multirow[t]{2}{*}{ MRF4 } & Forward & ATTTAGGTGACACTATAGAATCTGATCTGGGCTTGCAAGA \\
\hline & Reverse & $\begin{array}{l}\text { GTAATACGACTCACTATAGGGACTTGAGGTGGTGAGAAGTTTC } \\
\end{array}$ \\
\hline \multirow[t]{2}{*}{ MyoD } & Forward & ATTTAGGTGACACTATAGAATGGTTCTTCACGCCCAAAAG \\
\hline & Reverse & GTAATACGACTCACTATAGGGAGGGCTCCAGAAAGTGACAA \\
\hline \multirow[t]{2}{*}{$F G F 6$} & Forward & ATTTAGGTGACACTATAGAATCCACGACGAATGCAAGTTC \\
\hline & Reverse & GTAATACGACTCACTATAGGGTACACACCATGCAGTCCAGT \\
\hline \multirow[t]{2}{*}{ Eyal } & Forward & ATTTAGGTGACACTATAGAAACCGTGTCTGGGATTCTTGT \\
\hline & Reverse & GTAATACGACTCACTATAGGGGGCCATTTCTGTCTGCATCA \\
\hline \multirow[t]{2}{*}{ Eya2 } & Forward & ATTTAGGTGACACTATAGAAGGCCCTAGACACCAGAAACT \\
\hline & Reverse & GTAATACGACTCACTATAGGGCCTACAACACAAGATGGCGG \\
\hline \multirow[t]{2}{*}{ Sim1 } & Forward & ATTTAGGTGACACTATAGAAGGAAAGGGCAGAGCAGAGTA \\
\hline & Reverse & GTAATACGACTCACTATAGGGGCCTTCAGACCAGATAGCCA \\
\hline \multirow[t]{2}{*}{ Cdh15 } & Forward & ATTTAGGTGACACTATAGAA CCCTACGACACAGCTCTCAT \\
\hline & Reverse & GTAATACGACTCACTATAGGG GCCTAGTCCATGCTCCAGAT \\
\hline \multirow[t]{2}{*}{ Palld } & Forward & ATTTAGGTGACACTATAGAACTAGAGGTAGGTGCCGAGTG \\
\hline & Reverse & GTAATACGACTCACTATAGGGGAGATAGGCCCATGAGACCC \\
\hline \multirow[t]{2}{*}{ Shisa2 } & Forward & ATTTAGGTGACACTATAGAACGATCTTGAACTCCGACCCT \\
\hline & Reverse & GTAATACGACTCACTATAGGGAGTGACAGCGGACAACCTAT \\
\hline Probe & & Reference \\
\hline Meis1 & & Generated previously in the lab \\
\hline Meis2 & & Generated previously in the lab \\
\hline Cyp26b & & Generated previously in the lab \\
\hline Raldh2 & & Provided by Bovolenta \\
\hline$R A R \beta$ & & Provided by Zuniga \\
\hline FGF4 & & Provided by de la Pompa \\
\hline
\end{tabular}

Table 2: Primer sequences and references of the probes used. SP6 and T7 RNA polymerase transcription start sequence was included in the primer sequence of forward and reverse primers, respectively. 
hours with $0.5 \% \mathrm{w} / \mathrm{v}$ Victoria Blue (Sigma) in acid alcohol and after staining embryos were washed in acid alcohol until the embryos were white, then they were washed in $70 \%$ ethanol and $95 \%$ ethanol. Finally, embryos were clarified with increasing concentrations of Methyl salicylate in ethanol $(30 \%, 50 \%)$ and stored in $100 \%$ Methyl salicylate.

\section{Alcian Blue and Alizarin Red}

Embryos were eviscerated and the skin and soft tissues were removed as much as possible. Embryos were fixed overnight with $95 \%$ ethanol and after fixation were submerged in Alcian Blue solution (0.03\% w/v Alcian Blue (Sigma), 80\% ethanol, 20\% glacial acetic acid) overnight. Alcian Blue solution was removed and several washes with $70 \%$ ethanol were made during the day; incubating the embryos in $95 \%$ ethanol overnight. Once the tissue becomes whiter, embryos were cleared with 1\% KOH during 3-6 hours depending on the stage and the amount of soft tissue that the embryos have. Once cleared, Alizaren Red solution (0.005\% Alizarin Red (Sigma), 1\% w/v KOH) was added until the bones were stained. Another clarification step with $1 \% \mathrm{KOH}$ could be done if necessary after staining with Alizarin Red solution, if not embryos were transferred to increasing concentrations of glycerol (20\% and 50\%) and finally placed in $100 \%$ glycerol for long term storage.

\section{Immunostaining on gelatin sections}

Embryos were fixed in 2\% PFA and after several washes with PBS were left in 15\% sucrose in PBS overnight at $4^{\circ} \mathrm{C}$. On the following day, embryos were included in a gelatin solution (15\% sucrose, $7.5 \%$ gelatin from porcine skin (Sigma) in PBS) at $37^{\circ} \mathrm{C}$ and after 1-2 hours, gelatin blocks were made and frozen for 1 minute in isopentane at $-70^{\circ} \mathrm{C}$ and stored at $-80^{\circ} \mathrm{C}$. Cryosections were made using a Leica CM1950 Automated Cryostat and stored at $-20^{\circ} \mathrm{C}$.

For immunostaining, removal of the gelatin is required so sections were incubated in PBS for 15 minutes at $37^{\circ} \mathrm{C}$. After several washes with PBT, sections were permeabilized with 0 '5\% Triton X-100 in PBS for 20 minutes and blocking was performed with $20 \%$ goat serum in PBS for 1 hour. Primary antibodies used were a rabbit polyclonal anti-Aldh1a2 (ab96060) and an anti-Meis-a antibody generated in rabbits with a synthetic peptide corresponding to the conserved C-terminal domain of Meis1a and Meis2a/ Meis2b isoforms (GMNMGMDGQWHYM). Primary antibody was incubated overnight at $4^{\circ} \mathrm{C}$ and after several washes; secondary antibody was incubated during 45 minutes at room temperature. Secondary antibodies were an Alexa-488 (1:500) for anti-Meis-a and an anti-HRP (1:200) for anti-Aldh1a2. After anti-HRP incubation, amplification with Tyr- 
FITC (1:100) during 3 minutes at room temperature was performed. Secondary antibody and tyramides were washed with PBT several times and DAPI incubation (1:1000) was done during 3 minutes at room temperature. Then, sections were mounted in Vectashield or Dako fluorescent mounting media for acquisition.

\section{Image acquisition and processing}

Images were acquired using a Nikon A1R confocal microscope using 405, 488 and 561 nm wavelengths and Plan Apo 10x DIC L or Plan Apo VC 20x DIC N2 dry objectives and a Zeiss LSM 780 upright microscope fitted with a W Plan-Apochromat 20x/1.0 DIC M27 $75 \mathrm{~mm}$ objective in confocal mode and using 405, 488 and 561nm wavelengths. Acquisitions were commonly $1024 \times 1024$ pixels.

In situ hybridization and skeletal preparations images were acquired with a Nikon DXM1200F coupled to a Leica MZFLIII scope with a Plan Apo 1x objective.

Images were processed using Image J (https://imagej.nih.gov/ij/), Imaris and Adobe Photoshop CC.

\section{RNA sequencing}

Differential gene expression analysis was carried out among Meis1 and Meis 2 Dl11Cre conditional double knockout and control embryos at E9. Four embryos were used for each condition and were staged by somite number, choosing the embryos with 20-24 somites.

$\underline{\text { RNA isolation }}$

Embryos were dissected separating the anterior trunk containing the first 10-12 somites and the posterior trunk with the rest of the somites and the tail bud (head was excluded). Tissue was frozen in liquid nitrogen and stored at $-80^{\circ} \mathrm{C}$ until all the samples were collected and total RNA was performed using the RNeasy Micro Kit (Qiagen).

RNA-seq library production and sequencing

20ng of total RNA were used to generate barcoded RNA-seq libraries using the NEBNext Ultra RNA Library preparation kit (New England Biolabs). Briefly, poly A+ RNA was purified using poly- $\mathrm{T}$ oligo-attached magnetic beads followed by fragmentation and then first and second cDNA strand synthesis. Next, cDNA ends were repaired and adenylated. The NEBNext adaptor was then ligated, followed by uracile excision from the adaptor and PCR amplification. Finally, the size and the concentration of the libraries was checked using the TapeStation 2200 DNA 1000 chip. 
Libraries were sequenced on a HiSeq2500 (Illumina) to generate 60 bases single reads. FastQ files for each sample were obtained using bcltofastQ softaware 2.20

\section{$\underline{\text { RNA-seq data analysis }}$}

Sequencing reads were pre-processed by means of a pipeline that used FastQC (http:// www.bioinformatics.babraham.ac.uk/projects/fastqc/), to asses read quality, and Cutadapt (Martin, 2011) to trim sequencing reads, eliminating Illumina adaptor remains, and to discard reads that were shorter than $30 \mathrm{bp}$.

The resulting reads were mapped against the mouse transcriptome (GRCm38, release 91; dec2017 archive) and quantified using RSEM v1.2.20 (Li and Dewey, 2011). Data were then processed with a pipeline that used Bioconductor package Limma (Ritchie et al. 2015) for normalization and differential expression analysis, using a blocking strategy to consider gender and developmental stage (number of somites).

Genes with at least 1 count per million in at least 4 samples (14,731 genes) were considered for further analysis. We considered as differentialy expressed those genes with Benjamini-Hochberg adjusted $\mathrm{p}$ value $<0.05$. Fold change and $\log$ (ratio) values were calculated to represent gene expression differences between conditions.

Gene Set enrichment analysis was performed with the genes differentially expressed using the Broad Institute GSEA "Molecular Signatures Database" (http://software.broadinstitute.org/gsea/msigdb/index.jsp). For pathways analysis, the Ingenuity Pathway Analysis software was used. 



\section{Results}





\section{Meis 1 and Meis 2 expression in early mouse embryo development}

Meis1 and Meis2 have been shown to play different roles during development in different organs/tissues but early embryonic functions remain unknown. We studied the expression dynamic of both genes at early stages of mouse development starting at E6.5, at the onset of gastrulation (Fig. 8). We detected the earliest expression of Meis2 at E7 in the proximal and posterior region of the embryo, in the boundary with extraembryonic mesoderm (Fig. 8 F). This expression extended distally and anteriorly as development progresses (Fig. 8 G-I, P) and at early headfold stage, a stripe of Meis 2 transcripts was found bilaterally in the embryo, below the extraembryonic region, and continuous with its posterior expres-
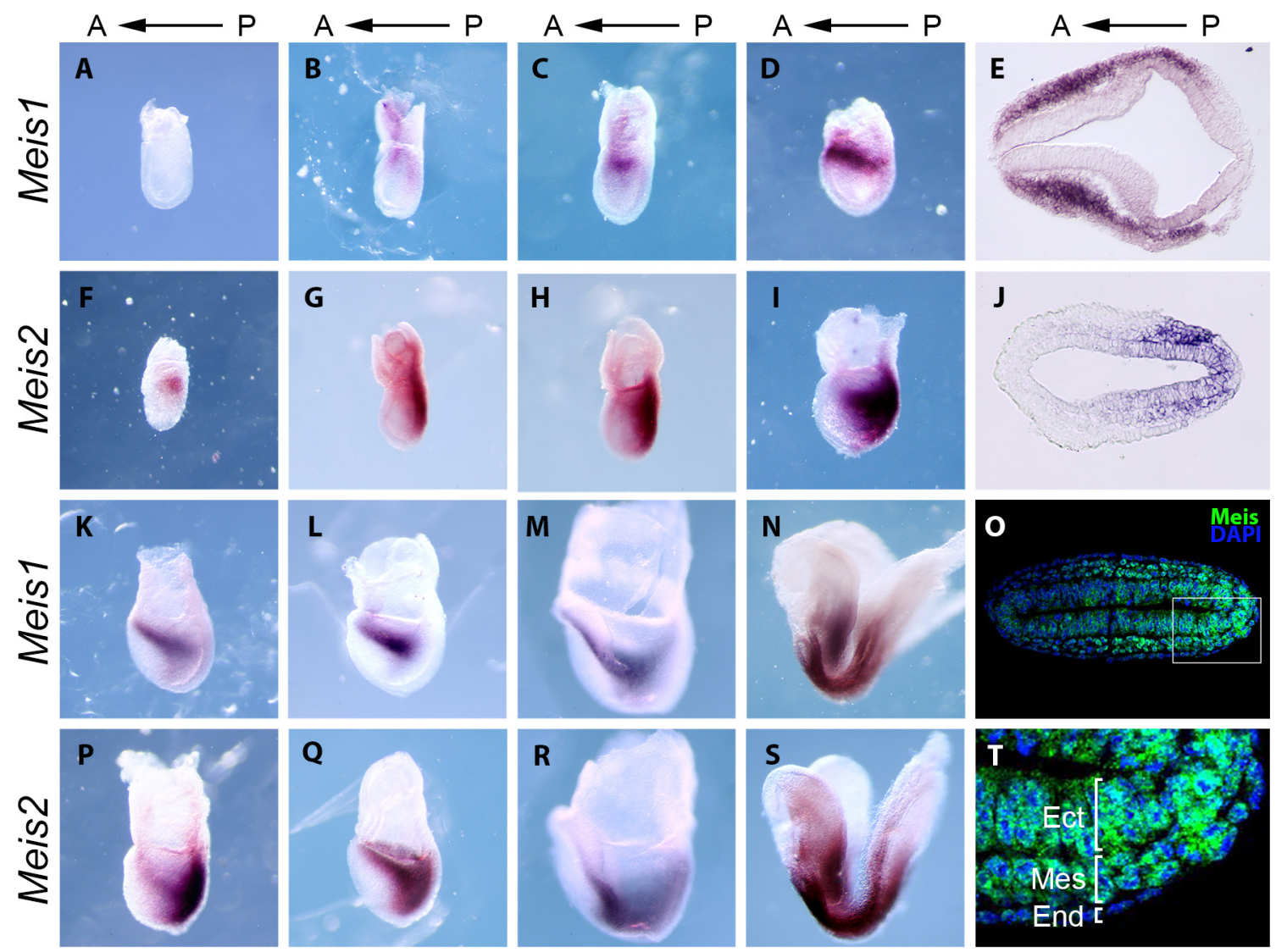

Figure 8: In situ hybridization of Meis genes in early development. Meis1 (A-D) and Meis2 (F-I) expression from E7 to E7.5. (E and J) Transverse section of Meis1 (E) and Meis2 (J) at E7.5 embryo. Meis1 (K-N) and Meis2 (P-S) expression from E7.5 to E8. ( $\mathrm{K}$ and $\mathrm{P}$ ) late allantoic bud, (L and $\mathrm{Q}$ ) early headfold embryos, ( $\mathrm{M}$ and $\mathrm{R}$ ) late headfold and ( $\mathrm{N}$ and $\mathrm{S}$ ) E8 embryos. (O and T) Meis1 and Meis2 immunostaning of a late bud embryo. (T) Magnification of the region marked in $\mathrm{O}$ with the three germ layers indicated: Ect, ectoderm; Mes, mesoderm and End, endoderm. All images are orientated with the anterior, A, region to the right and posterior, $\mathrm{P}$, to the left. 
sion (Fig. 8 Q). At later stages, Meis 2 started to disappear from the posterior region (Fig. $8 \mathrm{R}$ ) and at E8, the posterior embryonic bud was devoid of Meis 2 transcripts (Fig. 8 S). On the other hand, we observed Meis 1 expression starting slightly later than Meis 2 and the first signal arose bilaterally in the proximal mesoderm (Fig. $8 \mathrm{~A}-\mathrm{C}$ ) and later extended anteriorly forming a stripe of expression, similar to Meis 2 pattern (Fig. 8 D, K-L). Meis 1 expression extends slightly posteriorly at the early headfold stage and more intensely in late headfold stage (Fig. 8 L-M) but high levels of Meis 1 transcripts were never observed in the posterior embryonic bud. Finally, at E8 Meis1 and Meis2 expressions converge to a similar expression pattern. (Fig. $8 \mathrm{~N}$ ).

To confirm the presence of Meis1 and Meis2 proteins at early stages, we performed immunostaining in transverse sections of late bud embryos (Fig. 8 O). To detect Meis proteins we used an antibody that recognizes the isoform "a" of Meis1 protein, and the isoforms "a" and "b" of Meis2 protein. These isoforms contain an alternative shorter c-terminus and predominate during development (Azcoitia and Torres, unpublished). Meis proteins were detected in the posterior epiblast, in the posterior and lateral mesoderm and in the endoderm (Fig. 8 T). As we were unable to discriminate Meis1 from Meis2 protein by immunostaining, we sectioned Meis 1 and Meis2 in situ hybridizations in E7.5 embryos. We observed Meis 2 expression in the posterior epiblast and in the mesoderm (Fig. $8 \mathrm{~J}$ ); suggesting that the early expression of Meis 2 starts in epiblast cells before they migrate through the primitive streak and form the mesoderm and definitive endoderm. In contrast, Meis 1 transcripts were found only in the mesoderm (Fig. 8 E).

We observed a different timing and pattern between Meis 1 and Meis2 genes at the onset of their expression but as development progresses, both expression patterns became more similar. This difference in timing at early stages suggests that Meis1 and Meis2 have different roles in early embryogenesis.

\section{$\underline{\text { Role of Meis in mouse development }}$}

The onset of Meis2 expression coincides in time and space with the activation of Hox genes. This observation together with the high number of Meis binding sites in the HoxA cluster (Penkov et al. 2013), and the well-known role of Pbx and Meis as Hox cofactors (Ryoo et al. 1999; Mann and Affolter, 1998) led us to think of a possible function of this early expression in the activation and regulation of Hox genes. To investigate this function we followed two different approaches: analysis of Hox gene expression pattern and observation of the axial skeleton in Meis 2 conditional knockouts, in order to see if the absence of Meis 2 produces changes in the expression and/or skeletal pattern. 


\section{- Analysis of Hox gene expression in the absence of Meis 2}

To delete Meis 2 early in development, we used a Sox2Cre allele crossed to a Meis2floxed allele, eliminating Meis2 in the epiblast from E5. By in situ hybridization in Sox 2 Cre; Meis $2^{--}$embryos, we analyzed the expression of the Hox genes that are activated at early stages (Fig. 9).

Hoxal is activated at the posterior end of the embryo and its expression spreads anteriorly both in mesoderm and in the overlying ectoderm (previously described in Murphy and Hill, 1991 and in Sundin et al. 1990), presenting a very similar pattern to that of Meis2 (Fig. 9 A'). Expression of Hoxal in Sox2Cre;Meis $2^{-/-}$at E7.75 is unchanged with respect to controls (Fig. 9 A).

Hoxa 3 was analyzed at E8 when the first somites appeared and the expression of this gene is restricted to the PSM and the neuroectoderm, however no changes in the expression of Hoxa 3 with respect to controls were found in Sox2Cre;Meis2 $2^{-/}$embryos at this stage, remaining the boundary of expression at the anterior border of the PSM, similar to control embryos (Fig. 9 B and B').

Similar to Hoxa3, Hoxa4 was also found in the PSM and in the neuroectoderm and, again, we did not see any difference between control and Sox2Cre;Meis $2^{-/}$embryos (Fig. 9 C and $\left.C^{\prime}\right)$.

Regarding Hoxa5, we analyzed embryos at E8.5, when Hoxa5 expression was present in
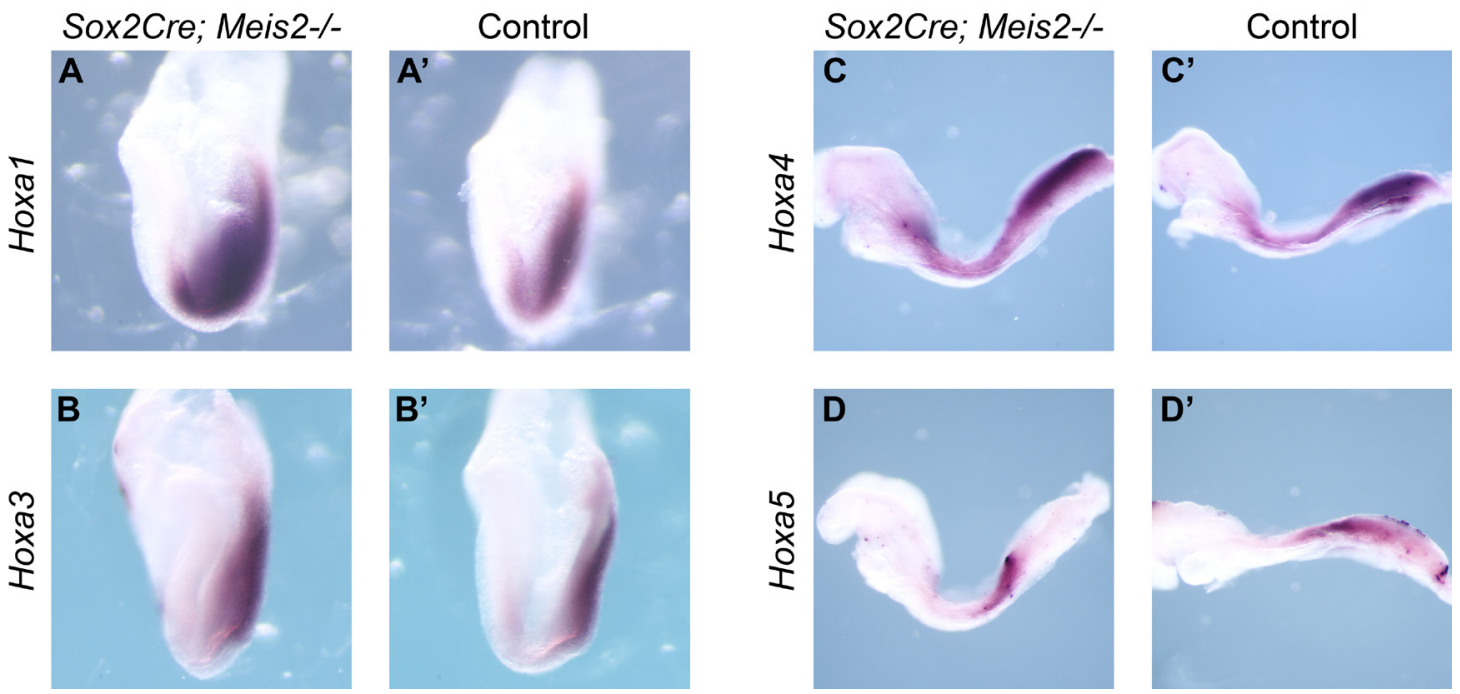

Figure 9: In situ hybridization of Hox genes in Sox2Cre;Meis2 $2^{-/}$embryos (A-D) and control (A'-D'). All images are oriented with the anterior region to the left. 
the rostral PSM and in the most recently formed somites. The anterior most somite with a faint Hoxa 5 expression was somite 5 in both the Meis2-deficient and control embryos (Fig. 9 D and D').

These results indicate that deletion of Meis 2 from the early epiblast using Sox 2 Cre does not alter the expression pattern of the anterior genes of the HoxA cluster.

\section{- Skeletal patterning in Meis-deficient mice}

The mouse vertebral formula is 7 cervical, 13 thoracic, 6 lumbar, 4 sacral and 30 caudal (Mallo et al. 2009) and we have examined if changes in this axial organization are seen in the absence of Meis, using different Cre lines.

- The skeletal pattern of Sox 2 Cre;Meis $2^{-1} \underline{\text { mice }}$

To investigate if the early expression of Meis 2 described above could have a role in skeletal patterning, we analyzed the skeleton in the same mouse line used in the Hox expression analysis. Lethality of these Sox2Cre;Meis2 $2^{-/}$embryos around E14.5-E15.5 due to cardiac defects (Carramolino and Torres, unpublished) did not allow us to study the pattern at later stages but despite specific structures are not completely developed at E14.5, the verteral formula can be determined. Skeletal defects are summarized in Supplementary Table 1 .

\section{-Occipital region abnormalities:}

Due to the early stage and cartilage staining we could not observe the basioccipital and supraoccipital bones at this stage. However, exoccipital cartilage condensations are already formed at this stage and presented a normal position and morphology, except for the fact that its posterior part was fused to the neural arch (NA) of the first cervical vertebra (Fig. 10 A). In addition, we observed a severe hypoplasia of the otic capsule, suggesting a failure in inner ear development.

\section{-Abnormalities in the cervical region:}

The first cervical vertebra (C1 or atlas) of all Sox 2 Cre;Meis $2^{-/-}$fetuses studied was fused to the exoccipital ( $n=14 / 14)$; This fusion involves a change in the angle and shape of the first vertebra that becomes aligned and similar to the exoccipital in its ventral part, while its most dorsal part was not formed. These changes correlated with a change in the shape of the second vertebra (C2 or axis), which acquired a C1-like morphology ( $n=13 / 14)$ (Fig. $10 \mathrm{~A}$ ). With less penetrance, the $\mathrm{C} 3$ vertebra presented a morphology that resembles $\mathrm{C} 2$ $(n=2 / 14)$. 
Other abnormalities found in this cervical region were the presence of disconnected chondrogenic condensations that could not be assigned to any vertebra (asterisk Fig. $10 \mathrm{~A}$ ).

-Abnormalities in the thoracic region:

The thoracic vertebrae did not show any defect in shape; however, defects were observed in their associated ribs. We found that the first rib (R1) was short (open arrowhead in Fig. $10 \mathrm{~A}$ and $\mathrm{A}^{\prime}$ ) and sometimes fused to the second rib in one or both sides of the embryo ( $n=13 / 14$ taking into account both defects). In posterior ribs, fusions and splits were found (arrowheads in Fig. 10 A') and in 6 of 14 embryos the last thoracic rib, T13, was short and in some cases $(n=4 / 14)$ an extra short rib is present in the first lumbar vertebra (named here as T14). In addition, in wild type mice the first seven thoracic vertebrae have ribs that reach the sternum and the next six vertebrae have floating ribs (T7/6 formula); however, the proportion between sternal and floating ribs was changed from the normal $7 / 6$ pattern to a $6 / 7$ pattern (named T6/7; $\mathrm{n}=3 / 14$ ) in Sox2Cre; Meis $2^{-/-}$fetuses. In the thoracic region, absence of fusion between both halves of the sternum was also observed $(\mathrm{n}=5 / 14)$ (arrows in Fig. 10 A").

Further defects in the lumbar or sacral regions were not observed in Sox2Cre;Meis2-/mice.

\section{- The skeletal pattern of Mesp1Cre;Meis 2 -- $\underline{\text { mice }}$}

To investigate if these defects, especially those observed in occipital and cervical region, are due to the elimination of the very early expression of Meis 2 in the posterior epiblast or to the lack of Meis 2 in the mesoderm, we combined Mesp1Cre with Meis2-flox mice to eliminate Meis 2 from the early mesoderm. While Mesp 1 activates in the early embryo in a similar pattern to Meis2, because of the time lag between Cre expression and effective recombination, the recombination pattern of MesplCre affects only the anterior mesoderm down to the forelimb level (Saga et al. 2000). As it occurred with Sox2Cre;Meis $2^{-/}$mice, lethality due to cardiac defects only allowed us to study the phenotype at E14.5.

In Mesp1Cre;Meis $2^{-/}$fetuses, we found the same kind of defects described above for Sox2Cre;Meis $2^{--}$, although with reduced penetrance and severity, with the exception for the inner ear, which was largely normal (Fig. 10 B, B' and B" and Supplementary Table 1). Transformation of $\mathrm{C} 1$ and its fusion to the exoccipital was found in $6 / 9$ embryos, but half of them presented this defect in only one side, while in Sox2Cre;Meis $2^{-/}$fetuses, this defect appeared bilaterally in most cases $(n=13 / 14)$. Nonetheless, in those fetuses in which a fusion between exoccipital and C1 was not observed, C1 was found in a position close to the exoccipital and adopted an angle and shape similar to the exoccipital, 
although it was dorsally truncated. As observed in Sox2Cre;Meis $2^{-/}$fetuses, there was also a change of $\mathrm{C} 2$ to a $\mathrm{C} 1$-like morphology, as well as extra-elements in the cervical region. However, we did not observe the shortening of the first rib in Mesp1Cre;Meis $2^{-/-}$ fetuses and other posterior defects appeared at a very low frequency, consistent with the recombination pattern of MesplCre (Fig. 10 B' and Supplementary Table 1). Regarding
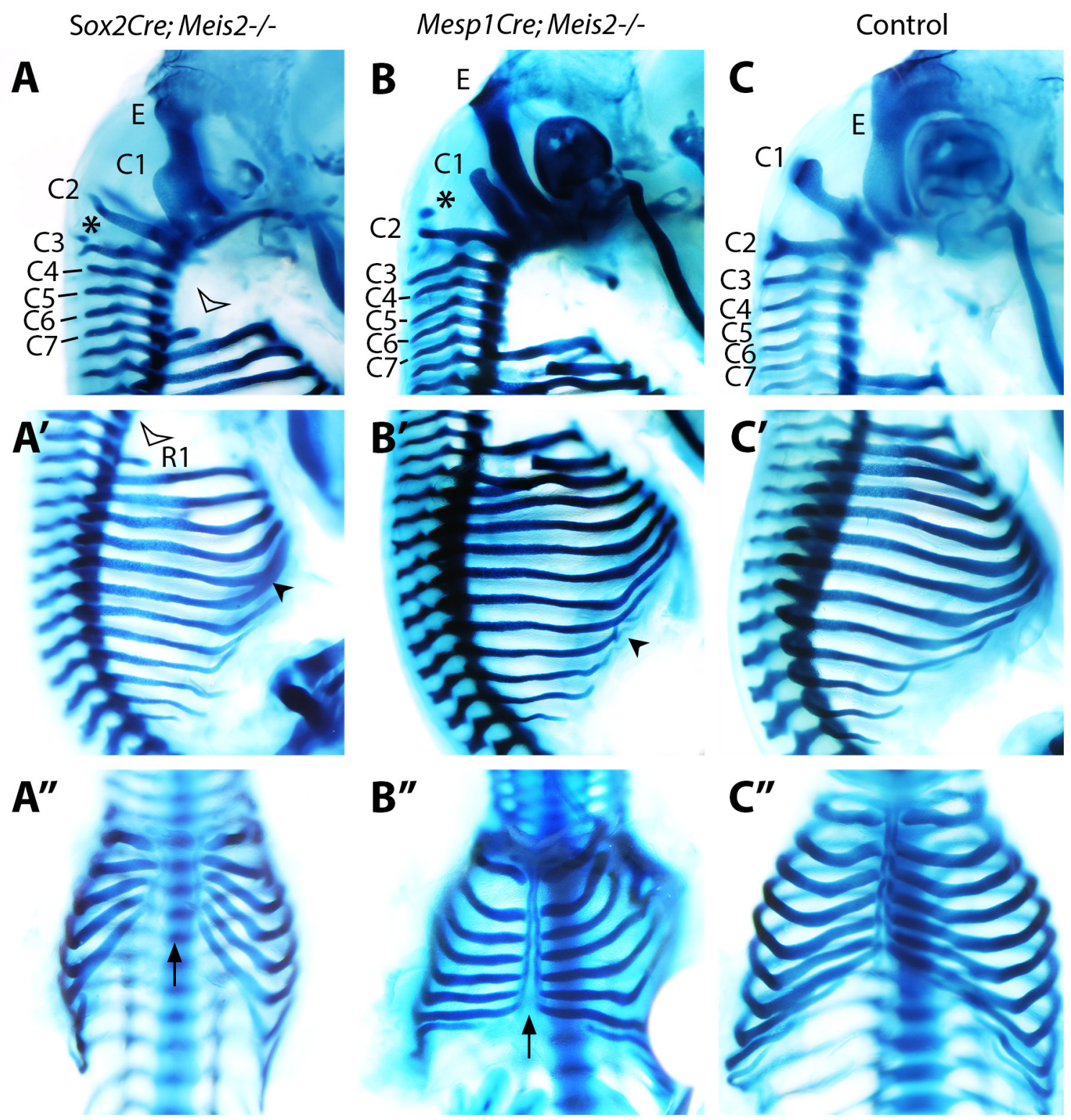

Figure 10: Cartilage staining at E14.5 in Sox2Cre; and Mesp1Cre;Meis $2^{-/-}$mutants. (A-C) Lateral view of the cervical region. Asterisk indicate chondrogenic condensations. Open arrowheads in A and A' points shortening of the first rib. (A'-C') Lateral view of the thoracic region. Arrowheads point fusion and split of ribs. (A"-C") Ventral view of the sternum. Arrows indicate defects in the sternum. E, exoccipital; $\mathrm{C}$, cervical vertebra; $\mathrm{R}$, rib. 
the sternum, only one embryo presented the sternum separated and in another there was only a small separation of the sternum (arrow in Fig. 10 B").

We have shown that the deletion of Meis2 induced by either Sox2Cre or Mesp1Cre at early stages produces skeletal defects in the occipital/cervical region consistent with an anterior transformation of the first two vertebrae. In addition, skeletal patterning was defective at the cervical/thoracic and thoracic/lumbar transitions with apparent anterior transformations of incomplete penetrance and rib/sternum misspatterning. The changes observed in the skeletal pattern, however were not accompanied by shifts in the expression of Hox genes in Sox 2 Cre; Meis $2^{-/}$fetuses.

\section{- The skeletal pattern of Dll1Cre;Meis $1^{-1-}$; Meis $2^{-1-}$ mice}

Redundant functions of Meis 1 and Meis 2 have been observed during the development of several organs, like the heart and the limb (Delgado, López-Delgado, Carramolino and Torres, unpublished). Even though we observed differences in the early expression patterns between both genes, there was a weak expression of Meis 1 in the posterior region at E7.5 (Fig. 8 L-M) that could compensate for the lack of Meis2 and we cannot exclude a possible compensatory activation of Meis 1 in Meis 2 mutants. For these reasons, we wanted to eliminate both genes and analyze both Hox expression and axial skeleton. However, Meis1;Meis2 double heterozygous animals recombined with Sox2Cre or Mesp1Cre are not viable due to cardiac defects. To be able to generate double-homozygous mutants we used the DlllCre deleter strain. This deleter strain recombines the paraxial and lateral mesoderm mostly without affecting the cardiac mesoderm (Wehn et al. 2009). In addition, it recombines axial precursors at a later phase of their incorporation to the embryo AP axis compared to Sox2Cre or Mesp1Cre. While Sox2Cre recombines the epiblast precursors before they become mesodermal, MesplCre recombines as they adopt the mesodermal fate and DlllCre just before they enter the segmentation program. Meis 1 -flox and Meis2-flox lines were crossed with Dll1Cre to generate different combinations of mutant alleles, fetuses of different genotypes were obtained and the phenotypic analysis was performed at E14.5 and E18.5 (Supplementary Table 2).

-Abnormalities in the occipital region:

The basioccipital bone presented abnormalities when two Meis 2 alleles, any three Meis alleles or the four Meis1/2 alleles were deleted (Fig. 11 A, B, C, E); however, we did not find basioccipital defects in single or double heterozygous mice or Meis 1 knockouts (Fig. $11 \mathrm{D})$. The basioccipital posterior border normally is indented in controls (Fig. 11 F) but showed posterior aberrant protrusions in mutants of the different genotypes (Fig. 

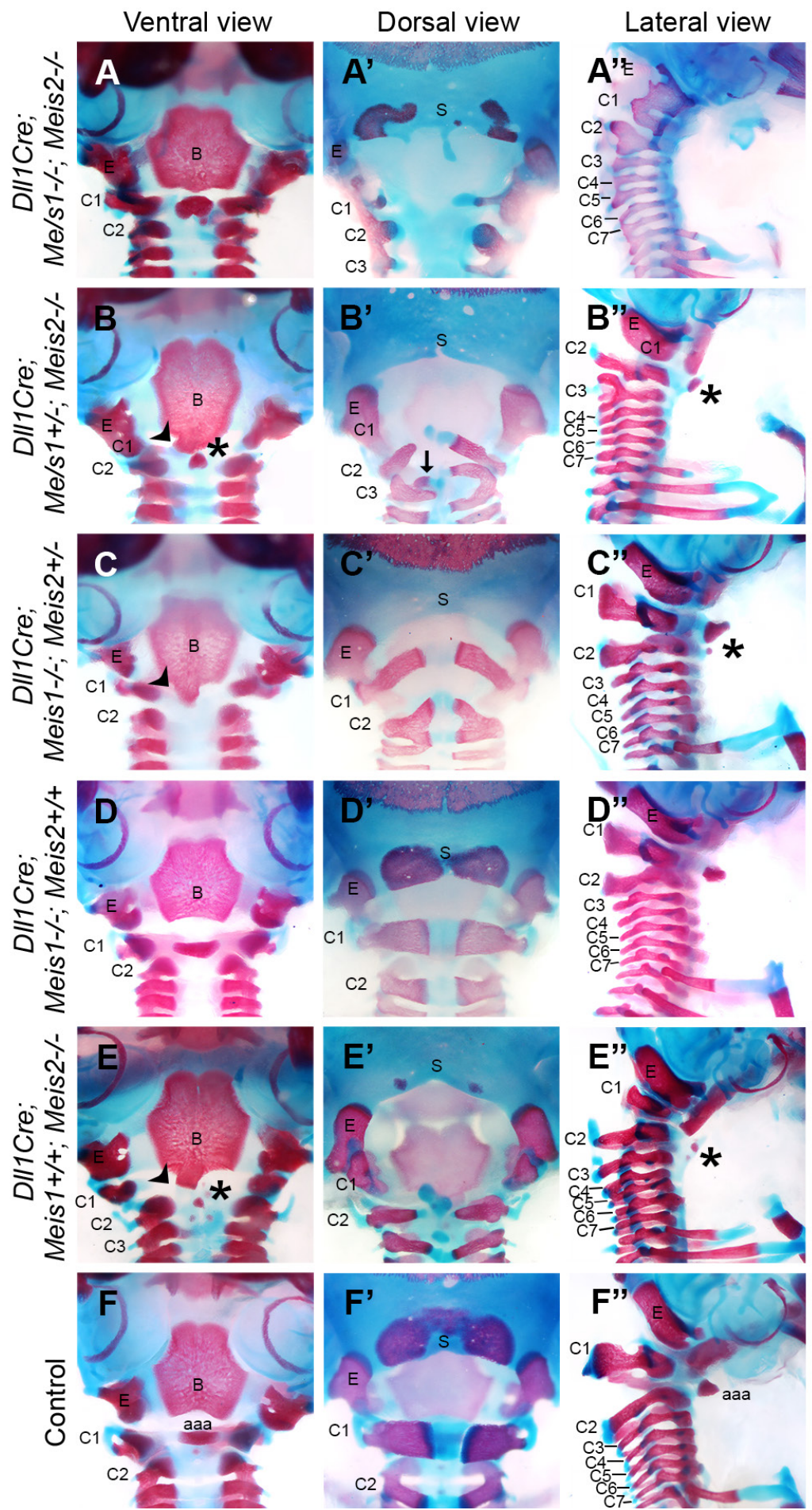

Figure 11: Skeletal staining at E18.5 of Meis mutants with Dll1Cre. (A-F) Ventral view of the basioccipital. Arrowheads indicate fusion of the basioccipital with the aaa. (A'-F') Dorsal view of the supraoccipital and cervical vertebrae. Arrow in B' points an extraelement in the cervical region (A"-F") Lateral view of the cervical region. Asterisk indicate aaa formed by C2. B, basioccipital; S, supraoccipital; E, exoccipital; $\mathrm{C}$, cervical vertebra; aaa, anterior arch of the atlas. 
$11 \mathrm{~A}-\mathrm{E})$. In extreme cases, the basioccipital is fused to the anterior arch of the atlas (aaa) (arrowheads in Fig. 11) that is a osified protrusion formed in the ventral part of the first cervical vertebra. These fusions were observed most frequently in Dll1Cre;Meis ${ }^{+/-}$ ;Meis $2^{-/}$mice $(\mathrm{n}=7 / 11)$. Abnormalities in the supraoccipital bone were more frequent than those in the basioccipital bone. We observed a reduction in supraoccipital ossification of Dll1Cre;Meis $1^{-/} ;$Meis $2^{-/-}(\mathrm{n}=3 / 3)$ and Dll1Cre; Meis $1^{+/+} ;$Meis $2^{-/-}$mice $(\mathrm{n}=4 / 4)$ (Fig. 11 A' and E') and a complete lack of supraoccipital ossification when three Meis alleles are deleted ( $\mathrm{n}=7 / 11$ in Dll1Cre;Meis ${ }^{+/} ;$Meis2 $2^{-/}, \mathrm{n}=3 / 4$ in Dll1Cre;Meis $1^{-/} ;$Meis2 $2^{+-}$) (Fig. 11 B' and C'). The exoccipital bone presented abnormal shapes in Dll1Cre;Meis ${ }^{-1 /} ;$ Meis $^{-/-}$ $(\mathrm{n}=7 / 7)$ and Dll1Cre;Meis $1^{+-}$;Meis2 $2^{-/}(\mathrm{n}=5 / 22)$ mice, being either shorter or rounder (Fig. 11 A", B" and E"). In most of the cases, these abnormalities concur with the fusion of the neural arch of the first vertebra to the exoccipital bone, as previously observed in deletions using Mesp1Cre or Sox2Cre.

-Abnormalities in the cervical region:

Defects in C1 resembled those observed in the Sox2Cre and Mesp1Cre-deletion. In Dll1Cre;Meis $2^{-/}$mice, the neural arch appears in a shape and position similar to and immediately porterior to the exoccipital, with absence of its dorsal part $(n=4 / 4)$ (Fig. 11E', E"). In Dll1Cre;Meis $1^{-/} ;$Meis $2^{-/}$and Dll1Cre;Meis $1^{+/} ;$Meis $2^{-/}$mice, this phenotype was even more severe, since $\mathrm{C} 1$ appeared completely fused to the exoccipital ( $n=11 / 22$ and $\mathrm{n}=6 / 7$, respectively). In some cases, this fusion led to the lack of the aaa formed by $\mathrm{C} 1$, resulting in a ventrally incomplete $\mathrm{C} 1$ (Fig. $11 \mathrm{~B}$ and $\mathrm{E}$ ).

We also found that in several genotypes, the $\mathrm{C} 2$ acquired a $\mathrm{C} 1$-like morphology, forming the aaa (asterisks in Fig. 11 B, E, B", C" and E"), although it maintained the ventral odontoid process characteristic of this C2 vertebra (Fig. 11 E). Moreover, we noticed that the neural arches of the second cervical vertebra also were larger and present angles that approximate those of C1 (Fig. 11 A", B" and E"). These transformations of the axis often correlated with the fusion of the exoccipital and $\mathrm{C} 1$. In the same way, $\mathrm{C} 3$ also presented a C2-like appearance with larger neural arches (Fig. 11 B" and E") and in some cases, the ventral part of the vertebra is fused to the $\mathrm{C} 2$ (Fig. $11 \mathrm{E}$ ). We also found neural arches of the second and third cervical vertebrae fused.

In wild type mice, cervical vertebra 3 to 7 present a similar morphology with the exception of C6 that presents a ventral protrusion called tuberculi anterior; this structure seems not to be affected in the absence of Meis. The rest of the cervical vertebrae remain normal in the mutant, although some fusions and splits of the neural arches were also frequent (Fig. 11 A" and E"). These splits and fusions, together with the presence of disconnected skeletal elements in the cervical region (arrow in Fig. 11 B'), produced a mismatch bet- 


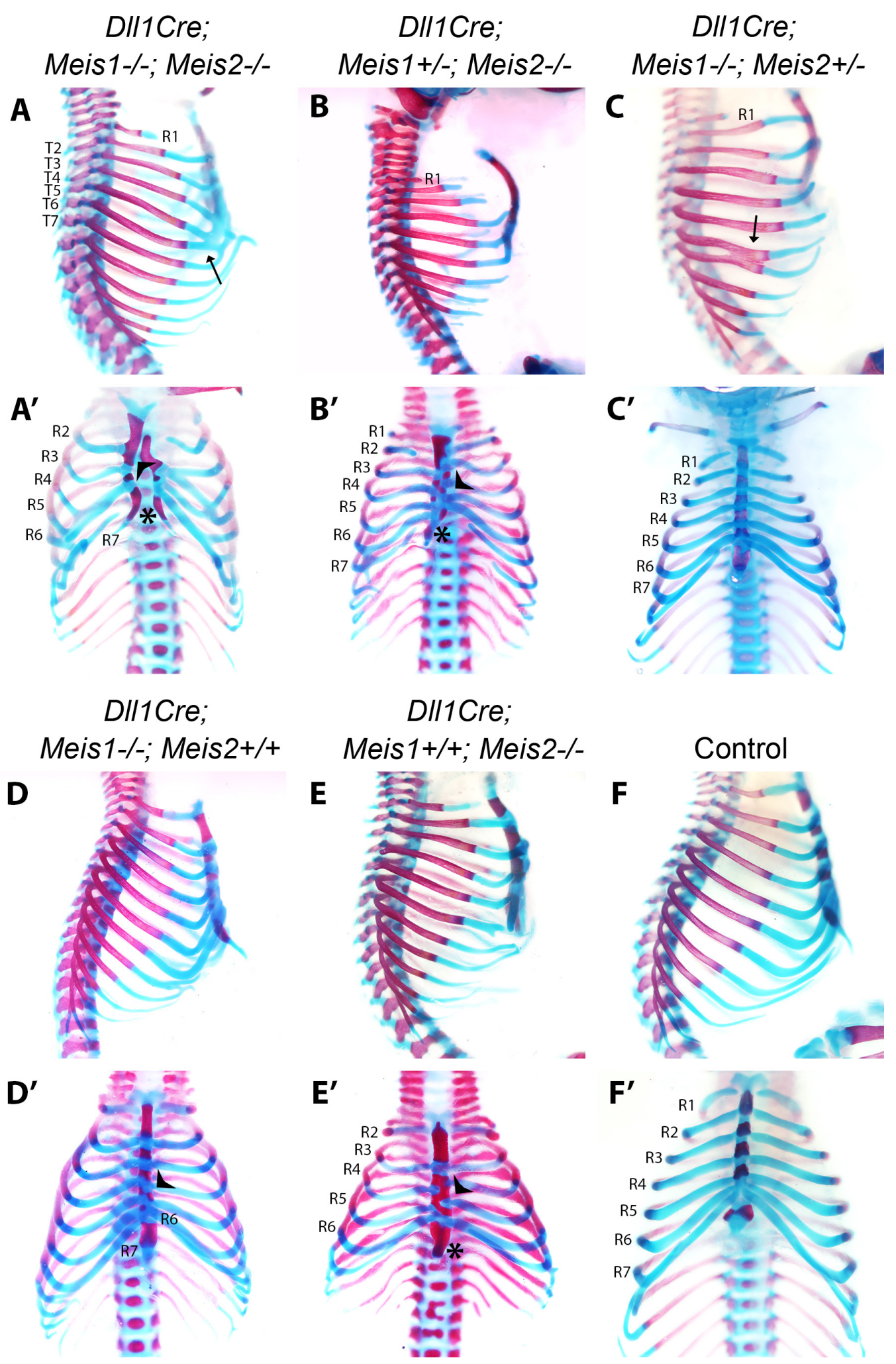

Figure 12: Skeletal staining at E18.5 of Meis mutants with Dll1Cre. (A-F) Lateral view of the thoracic region. Arrows point fusion and splits of ribs. (A'-F') Ventral view of the sternum. Arrowheads indicate defects in the sternebrae and intersticial cartilage and asterisk mark abnormal xiphoid process. $\mathrm{T}$, thoracic vertebra; $\mathrm{R}$, rib. 
ween the neural arches of both sides of the vertebra in the dorsal part (Fig. 11 A', B' and E').

-Abnormalities in the thoracic region:

Mutants presented changes in the sternal/floating formula, with a T6/7 pattern in one or both sides of the embryo (Fig. 12 B' and E'). Although, we ocassionally detected this defect unilaterally in control embryos $(n=4 / 46)$, the frequency was higher and included bilateral affection in Dll1Cre;Meis $1^{+/+} ;$Meis $2^{-/-}$mice (n=4/4), DlllCre;Meis $1^{+/-} ;$Meis2 $2^{-/-}$ mice $(\mathrm{n}=5 / 22)$ and Dll1Cre;Meis $1^{-/} ;$Meis $2^{+/-}$mice $(\mathrm{n}=3 / 12)$. In DlllCre;Meis $1^{-/} ;$Meis2 $2^{-/-}$ mice, we observed that most of the ribs did not join to the sternum due to a truncation of the cartilaginous distal part of the rib; however in all cases of these double-knockout mice collected at E18.5 presented the seventh rib joined to the sternum (Fig. 12 A'). This distal rib truncation was also observed in the absence of any three alleles of Meis and less frequently in the single knockouts of Meis1 and Meis2 (Fig. 12 B, C, E). The first rib was most frequently affected by truncations and sometimes appeared fused to the second rib in the absence of three/four Meis 1/2 alleles and in Meis 2 mutant mice (Fig. 12 A, B, C and E). Moreover, different sternal and floating ribs presented fusions and splits at different penetrances according to the genotype (arrows in Fig. $12 \mathrm{~A}, \mathrm{C}$ ).

Sternum defects were observed in Dll1Cre;Meis ${ }^{-/} ;$Meis $^{-/-}(\mathrm{n}=5 / 7)$ and Dll1Cre;Meis $1^{+-}$ ;Meis $2^{--}(\mathrm{n}=2 / 22)$ mice. The most severe sternum defects detected were the split of the sternum in two halves (Fig. 12 A'); in these cases, ribs from each side fused to each half. On the other hand, we observed fusions between ribs and shortening of the costal cartilage of the rib was related with the malformation of sternebrae, the intersternal cartilage and with an abnormal xiphoid process formation (arrowheads and asterisks in Fig. 12 A', B', C', D' and E').

In general, skeletal defects were more severe as the number of Meis alleles deleted increases, being the absence of Meis 2 more detrimental than Meis 1. However, E18.5 Dll1Cre;Meis 1${ }^{\prime}$;Meis $2^{-/-}$mice appeared less affected in comparison with DlllCre;Meis ${ }^{+/-}$;Meis $2^{-/}$mice , which was paradoxical. We observed, however that the viability of Dll1Cre;Meis $1^{-1-}$

\begin{tabular}{|l|r|r|r|r|}
\hline Stage & E18.5 & E14.5 & \multicolumn{1}{|c|}{ E10.5 } \\
\hline $\mathbf{N}^{\circ}$ Dll1Cre; Meis1-/-; Meis2-/- expected & 8,13 & 7,47 & 11,95 \\
\hline $\mathbf{N}^{\circ}$ Dll1Cre; Meis1-/-; Meis2-/- observed & 3 & 5 & 12 \\
\hline \% Viability & 36,9 & 66,9 & 100,4 \\
\hline
\end{tabular}

Table 3: Viability of Dll1Cre;Meis $1^{-/}$;Meis $2^{-/-}$fetuses at different stages. 
;Meis $2^{-/}$mice at E18.5 was reduced to $37 \%$, which suggested that mice of this genotype represent escapers at this stage and thus missing mice could be more affected than appreciated at E18.5 (Table 3). We then studied the phenotype of Dll1Cre;Meis $1^{-/} ; \mathrm{Meis}^{2^{--}}$ fetuses at E14.5 and observed a fraction of embryos with the same defects as at E18.5 (Fig. 13 B) and, in addition, we found very strongly affected fetuses with all the cervical vertebrae fused and with ribs not correctly developed, showing widespread fusions and not reaching the sternum (Fig. $13 \mathrm{C}$ ).

\section{Control}

A

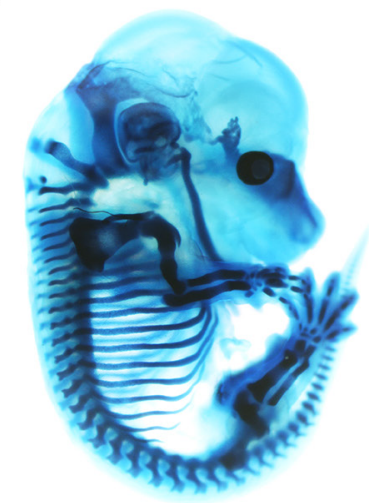

DII1Cre; Meis 1 -/; Meis 2 -/-

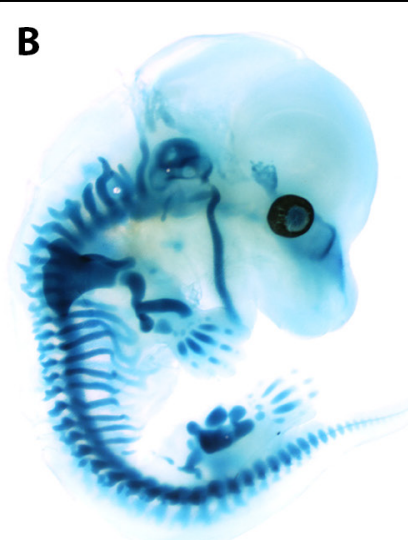

C

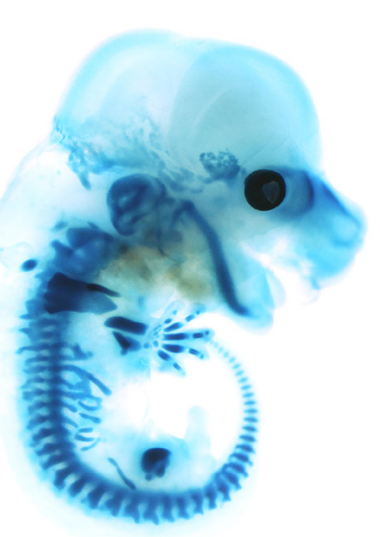

Figure 13: Cartilage staining at E14.5. (A) Control. (B-C) Dll1Cre;Meis $1^{-/} ;$Meis2 $2^{-/}$.

In summary, we observed similar defects comparing Dll1Cre;Meis2 $2^{-/}$mutants with equivalent mutants induced with Sox2Cre and Mesp1Cre (Supplementary Table 1 and Fig. 10 ), although the penetrance of the phenotypes was lower. This results suggest that most Meis 2 functions involve relatively late functions of the gene, starting the earliest in the presomitic mesoderm. Additional evidence for this conclusion derives from the observed excacerbation of the phenotypes upon deletion of Meis 1 copies, provided Meis 1 is not coexpressed with Meis 2 expression in at the earliest stages of axial precursor development.

\section{-Limb defects:}

Limb defects also appeared in Meis mutants lacking at least three copies of Meis. Hindlimb (HL) defects were more frequent than those in the forelimb (FL) and affected FLs were detected mainly in E14.5 fetuses (Fig. 13), appearing normal in E18.5 fetuses (Fig. 13 ; 14 A-D). HL defects observed were shortening of the stylopod and pelvic bones,

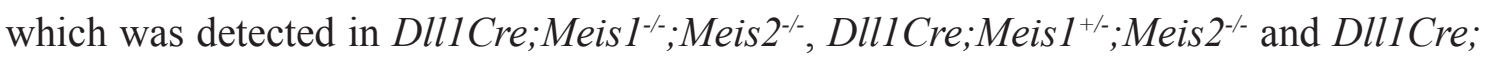
Meis $1^{-/} ;$Meis2 $2^{+/}$(Fig. 14 A'-D'), while in the Dll1Cre;Meis $1^{-/-} ;$Meis $2^{-/-}$mutants, defects in the zeugopod were also observed (Fig. 14 A'). The autopod remained normal in all the cases (Fig. 14). 

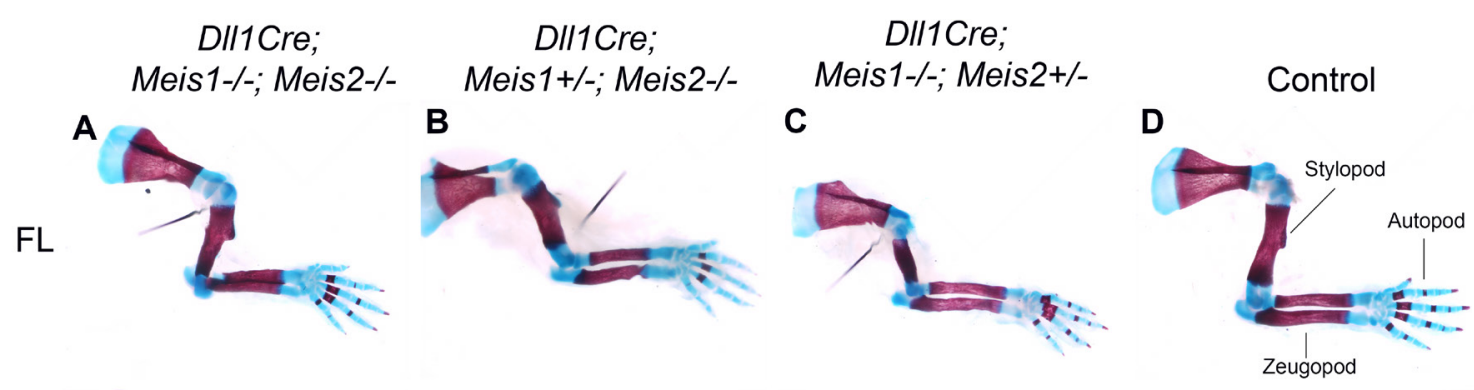

$A^{\prime}$

B'
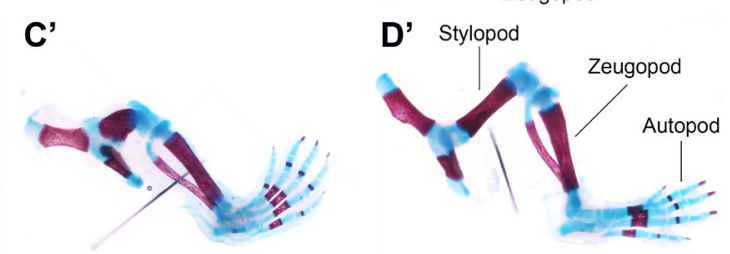

Figure 14: Limb defects observed in Meis mutants with Dll1Cre at E18.5. (A-D) Forelimb and (A'-D') hindlimb.

\section{- Analysis of Hox gene expression in the absence of Meis 1 and Meis 2}

The stronger skeletal phenotype of Meis1/2 double-knockouts compared to Meis2-only deletions, and their similarity with previously described Hox mutants prompted us to study Hox gene expression in these embryos. Some examples of Hox mutants with similar phenotypes to Meis mutants are the paralogous group 4, which present different anterior transformation such as $\mathrm{C} 3$ to $\mathrm{C} 2$ and $\mathrm{C} 2$ to $\mathrm{C} 1$ with the presence of the aaa in $\mathrm{C} 2$ (Horan et al. 1995b), fusion between the exoccipital and $\mathrm{C} 1$ and defects in the basioccipital (Lufkin et al. 1992), fusions of the basioccipital with the aaa were shown in Hoxd3 mutants (Condie and Capecchi, 1993). We examined the early expression of Hoxal and Hoxa3 and no differences were found between controls and double-knockout embryos (Fig. 15 A, A', B, B').

We also studied Hoxd4, as mutant mice for this gene present malformations in the cervico-occipital joint (Horan et al. 1995a) and to Hoxa6, because it plays a role in the cervicothoracic transition (Kostic and Capecchi, 1994). However, we have not observed any difference in the expression pattern at E10.5 in either Hoxd4 or Hoxa6, which show an anterior boundary of expression at somites 5 and 14, respectively, both similar to those observed in control embryos (Fig. 15 C-D and C'-D').

Therefore, we have not found any differences in the Hox gene expression domains after eliminating both Meis 1 and Meis 2 genes with Dll1Cre, even though we observed an evident skeletal phenotype, including AP transformations. 

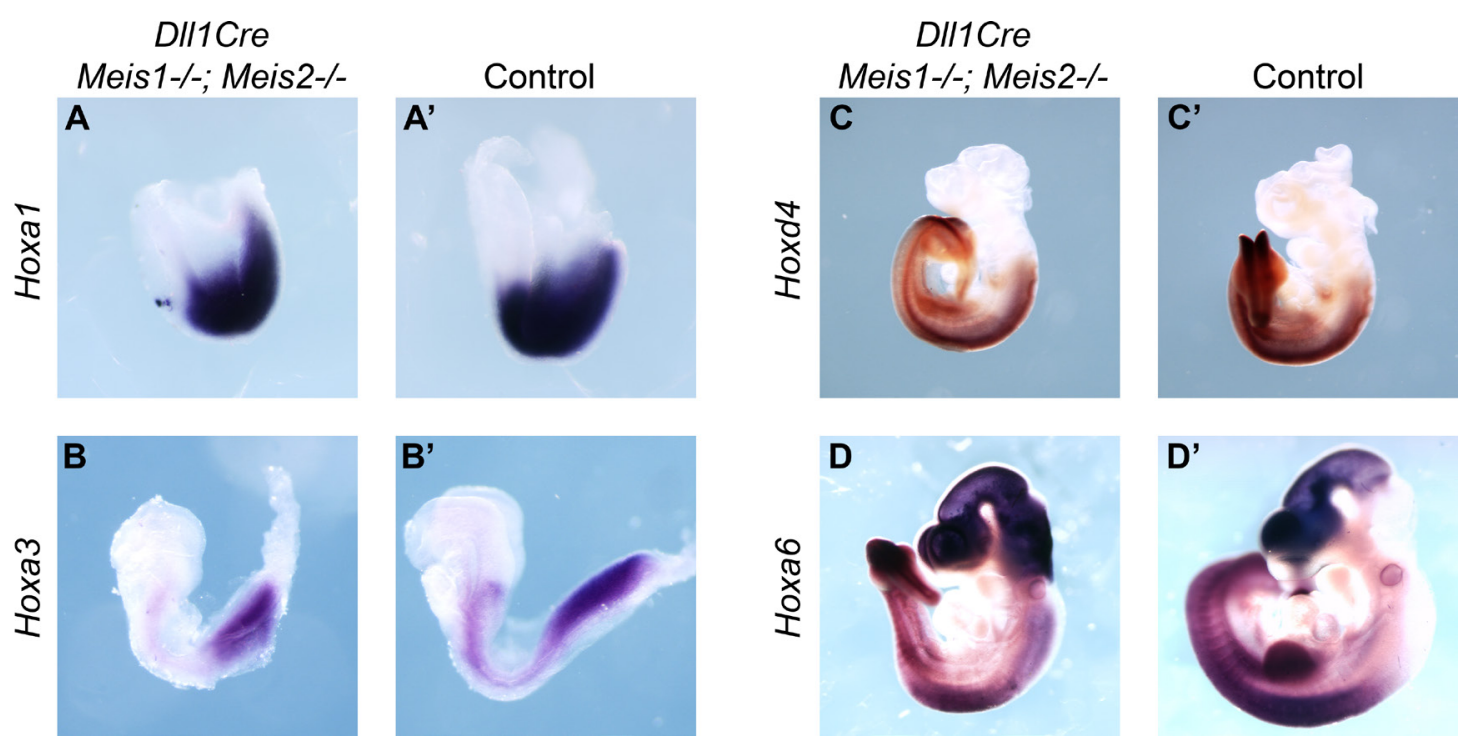

Figure 15: In situ hybridization of Hox genes in control (A-D) and DlllCre;Meis $1^{-1-}$ ;Meis $2^{-/-}$embryos (A'-D'). All images are oriented with the anterior region to the left.

\section{Global gene expression analysis of Meis $1 / 2$ double-knockouts recombined with Dll1Cre}

To unravel the molecular mechanism underlying the skeletal phenotype observed we performed a gene expression analysis in E9 Dll1Cre;Meis ${ }^{-\leftarrow}$;Meis $2^{--}$embryos. As we were unable to reveal any qualitative change in Hox gene expression by in situ hybridization, we wanted to confirm if quantitative changes in their expression levels occurred. Furthermore, we wanted to independently determine putative changes in gene expression in differentiating and pre-differentiating axial precursors and in anterior and posterior $H o x$ genes. To achieve this, we dissected and analyzed separately the posterior axial bud together with the 10-12 newly formed somites and the rest of the trunk.

We identified 9 upregulated genes and 25 downregulated genes in the analysis of the anterior region; whereas in the posterior region there were 58 upregulated and 58 downregulated genes differentially expressed (p-value $\leq 0.05$ ) (Fig. 16 B and Supplementary Table 4).

Ingenuity Pathway Analysis showed that developmental processes were affected, and it is worth mentioning that skeletal and muscular system development and function was significantly disturbed. Differences in other processes such as cell death, cell-to-cell interactions, cell assembly and organization were also found in this analysis (Fig. 16 A). Complementary studies using Gene Set Enrichment Analysis in the "Molecular Signatures 
Database" (http://software.broadinstitute.org/gsea/msigdb/index.jsp) showed correspondence with similar processes such as skeletal development, adhesion, cell differentiation, proliferation and death. In addition, processes related with urogenital and neural system, Polycomb Repressive Complex 2 (PRC2) targets and endoplasmic reticulum were significantly detected (Supplementary Table 3).

However, no significant differences in Hox gene expression between the control and the mutant embryos either in anterior or posterior region were found. These results show that Meis 1/2 function does not affect Hox gene expression in the AP embryonic axis.

Among the genes sensitive to Meis function there were several representatives of the Notch and Retinoic Acid signalling pathways (Fig. 16 C).

We next focused on genes potentially involved in skeletal and muscular system development, such as development of the myotome, sclerotome, paraxial mesoderm and formation of vertebrae and ribs. Characterization of the expression pattern of some of these genes was carried out by in situ hybridization in E9.5-E10.5 Dll1Cre;Meis ${ }^{-/-}$;Meis2 $2^{-/-}$ embryos.

\section{- Somite compartmentalization in Meis $1 / 2$ double-knockouts recombined with Dll1Cre}

To study the compartmentalization of Meis-deficient somites, we selected misexpressed genes from the RNA-seq analysis that are known to have a restricted expression pattern in sub-domains of somites. Eya1 and Eya2 are transcription factors with phosphatase activity expressed in the ventrolateral (hypaxial) and mediolateral (epaxial) compartment of the somites (Fig. 17 A'), and are required for hypaxial somitic myogenesis (Grifone et al. 2007). In the RNA-seq analysis Eyal was downregulated, while Eya2 was upregulated in mutant mice. In situ hybridization of Eyal showed that its ventrolateral signal was reduced (white arrow in Fig. $17 \mathrm{~A}$ ); however, anterior somites presented an abnormal expression in the epaxial region that was not observed in the control (black arrow in Fig. 17 A). On the other hand, Eya2 did not show any alteration in somitic expression (Fig. $17 \mathrm{~B}$ and B'), although its expression in dorsal root ganglia appeared more intense in mutant embryos. This expression pattern allowed to demonstrate fusions between dorsal root ganglia, indicating a segmentation defect in peripheral nervous system patterning (arrowhead in Fig. 17 B). We conclude that the hypaxial gene Eyal is specifically reduced in Meis $1 / 2$ double-knockouts.

We next analyzed Sim1, a gene encoding a transcription factor homologous to Drosophila 
A

Embryonic Development

Tissue Development

Cell Death and Survival

Skeletal and Muscular System

은 Vitamin and Mineral Metabolism

Cellular Growth and Proliferation

Cell Morphology

Post-Translational Modification

Cell Cycle

Cell-To-Cell Signalling and Interaction

Cellular Movement

Connective Tissue Development
and Function

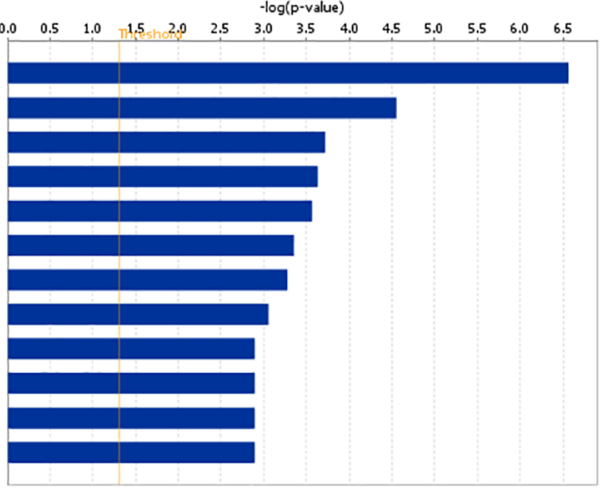

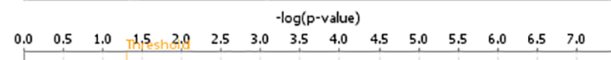

Embryonic Development

Connective Tissue Development

Skeletal and Muscular System
Development and Function

Tissue Development

Cell-To-Cell Signalling and Interaction

Cellular Growth and Proliferation

Cell Death and Survival

Cell Cycle

Post-Translational Modification

Protein Synthesis

C

- Upregulated

- Downregulated

- Shared
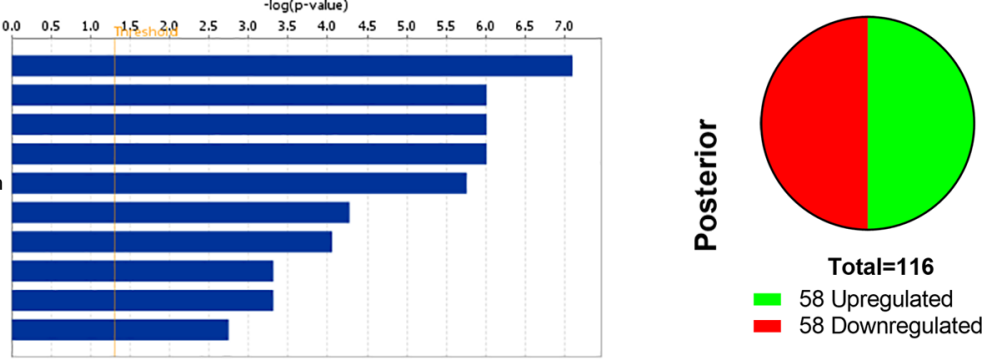

Rpn2

Sdf4
Tmed9

Rab3gap1

Tspan7

Tspan7
Tmem97
The

Thoc6

Mkrn1

Bsg

Ly6e

Cd63
Sdf2

Anapc16

Cst3
Atg4d
Ptn

Gadd45a

H2-Q4

Gm44215

lgfbp3

Erp29

Gm21992

Pth1r

Npde1

Cpt1c

Irx1
Pltp

Ppp1r1a
Phlda3

Ccng1

Azin2

Gdnf

Hes5
Ctgf
Dcxr

DCXr

D2-K1
Trp53inp1
Spon2

Spon2
Ddit4l

Yjefn3

Sap25
Cdkn1a

Zfp365

Gper1
Tap1

Tap1
Qrfpr

Ptprv

Fam212b

Tmod4
A930024N18Rik

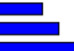

Nr1h5

$\log \mathrm{FC}$

$\log \mathrm{FC}$

Anterior

\section{Posterior}

Figure 16: Transcriptome analysis of Dll1Cre;Meis $1^{-/} ;$Meis $2^{-/}$embryos at E9. (A) Functions affected in Dll1Cre;Meis ${ }^{-/} ;$Meis $2^{-/}$embryos from the Ingenuity Pathway 
analysis ( $\mathrm{p}$-value $\leq 0.05$ ) in anterior and posterior region of the embryonic trunk. (B) Representation of the number of genes differentially expressed in both anterior and posterior samples ( $p$-value $\leq 0.05)$. (C) Fold change representation ( $p$-value $\leq 0.05$ ) from anterior and posterior samples (upregulated and downregulated genes are coloured in dark and light blue, respectively). Genes coloured in red are differentialy expressed in both, anterior and posterior.

single-minded and expressed in the lateral hypaxial dermomyotome (Ikeya and Takada, 1998). We found that the dermomyotomal expression is strongly reduced in mutant mice, which was in accordance with the RNA-seq results (Fig. 16 C; 17 C and C').

Another downregulated gene in the mutants was Shisa2, which is expressed in the dorsolateral part of the dermomyotome and encodes an endoplasmic reticulum protein that inhibits FGF and Wnt signaling (Nagano et al. 2006). In the anterior region of control embryos, down to the forelimb, we found expression in the dorsal part of the dermomyotome, while in the interlimb region the expression extended along the hypaxial region as well (Fig. 17 D'). In Meis mutants this hypaxial expression was abolished and in the anterior region, we could not detect a properly segmented expression as it was the case in control embryos. In addition, the ventral extension of the expression was reduced in
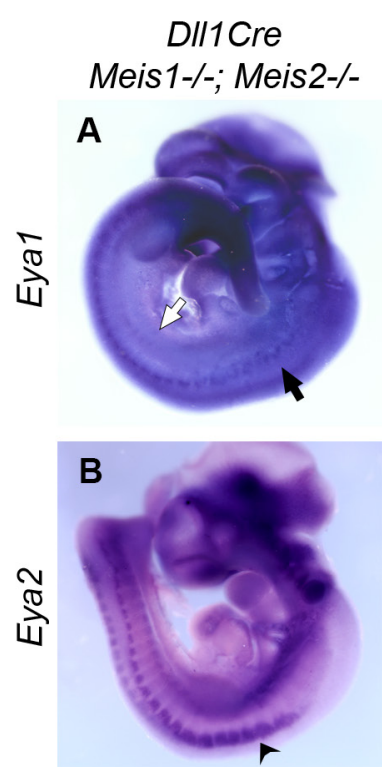
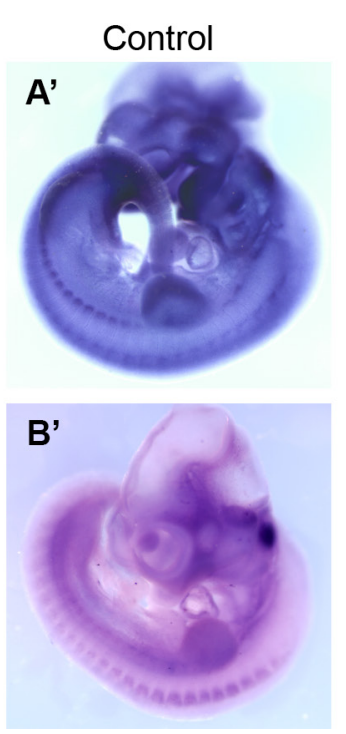
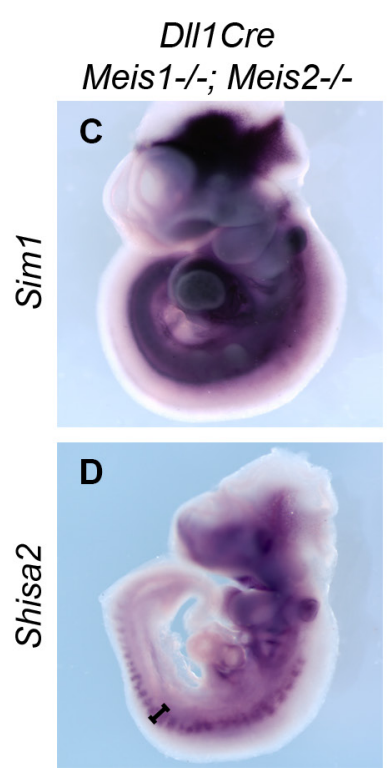
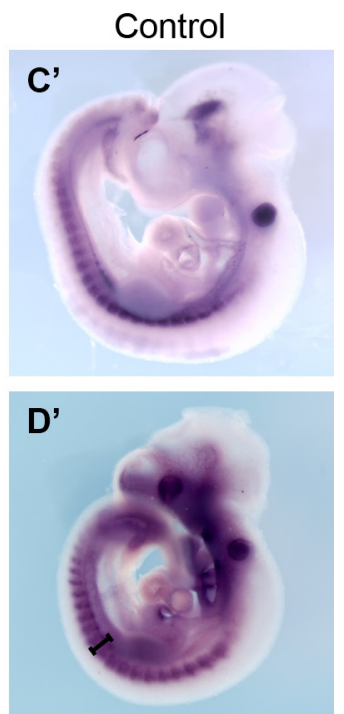

Figure 17: In situ hybridization of Eyal (A and A'), Eya2 (B and B'), Sim1 (C and C') and Shisa2 (D and D') in Dll1Cre;Meis $1^{-/} ;$Meis2 $2^{--}$(A-D) and control (A'- D') embryos at E10.5. Black arrow in A indicates abnormal expression of Eyal in the anterior somites and white arrow points reduced hypaxial expression of Eyal in interlimb somites. Arrowhead in B points fusion of the dorsal root ganglia. Brackets in D and D' shows the dorso-ventral extension of Shisa2 expression in the trunk. 
mutants (brackets in Fig. 17 D and D').

Differentially expressed genes studied in this section, with the exception of Eya2, exhibit altered expression in the different somite compartments, with the hypaxial dermomyotome being specially affected (Fig. 17). These results, together with the similarities of the skeletal phenotypes in Meis mutants with those previously described in the literature affecting sclerotomal, myotomal and dermomyotomal development (Vivian et al. 2000; Henderson et al. 1999, Soriano, 1997; Wallin et al. 1994; Braun et al. 1992), led us to extend the study to other genes expressed in different components of somite development, even if their expression was were not found differentially expressed in the transcriptome analysis.

Regarding the sclerotome, we checked $\operatorname{Pax} 1$ and $\operatorname{Pax} 9$, members of the paired-box transcription family and involved in sclerotome development. Paxl expression was not altered in E10.5 mutants (Fig. 18 A and A'), however, an abnormal expression of $\operatorname{Pax} 9$ was observed in the anterior sclerotomes, which appeared not fully segmented (Fig. 18 B and B').

Another member of the family, Pax3, is expressed in the hypaxial dermomyotome and is

DII1Cre

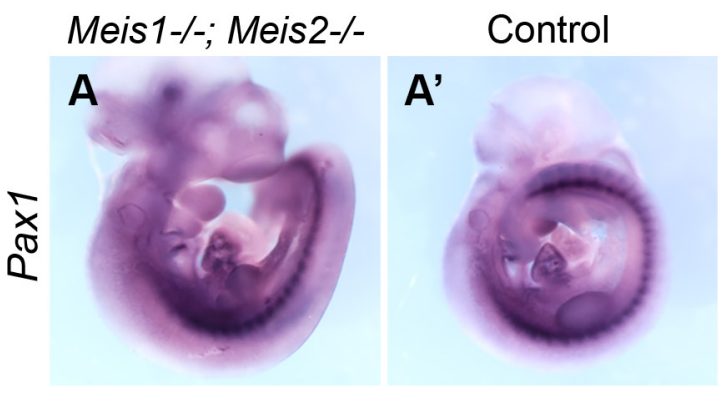

DII1Cre

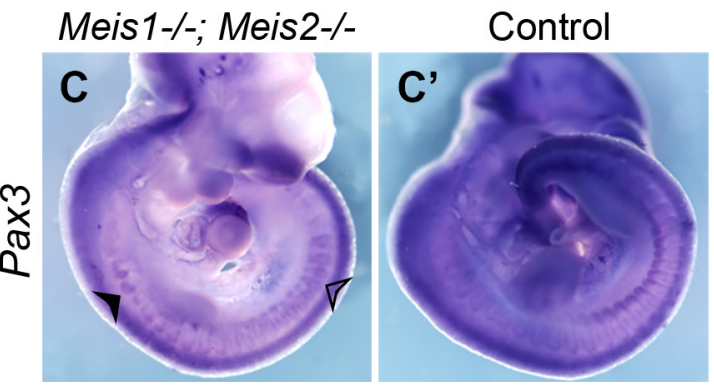

DIl1Cre

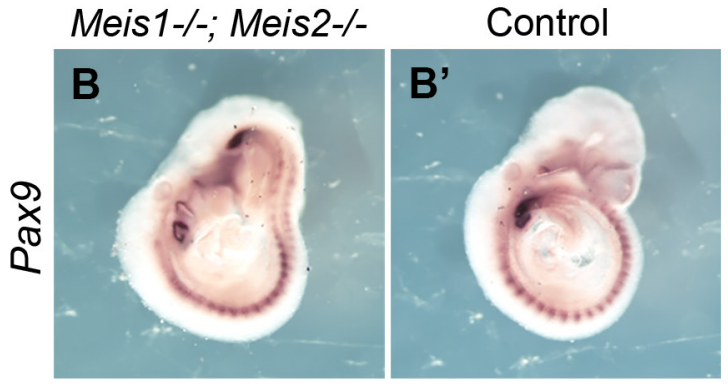

Figure 18: In situ hybridization of $\operatorname{Pax} 1$ (A and $\mathrm{A}^{\prime}$ ), $\operatorname{Pax} 9$ (B and $\mathrm{B}^{\prime}$ ) and $\operatorname{Pax} 3$ (C and C') in Dll1Cre;Meis $1^{-/} ;$Meis2 $2^{-/}$(A-C) and control (A'-C') embryos. Arrowhead and open arrowhead in $\mathrm{C}$ point ectopic dorso-medial expression in anterior and interlimb somites, respectively. 
involved in myotomal cell migration (Fig. 18 C'). Pax3 presented strongly reduced and mispatterned expression in mutant embryos in regions posterior to the forelimb at E10.5 (open arrowhead Fig. $18 \mathrm{C}$ ), further indicating a strong affection of hypaxial dermomyotome development. However, an apparent ectopic Pax3 expression in the dorso-medial region of the anterior somites was observed in the mutants but did not appear in controls (arrowhead Fig. $18 \mathrm{C}$ and C').

Provided that it has been described that crosstalk between myotome and sclerotome is essential for development of the ribs, we have studied the main myogenic factors: Myf5, MRF4, myogenin and MyoD (Fig. 19). Early expression of Myf5 arises in the epaxial myotome at E9 (Fig. 19 A'). At later stages, Myf5 signal also appears hypaxially from the forelimb to the caudal region of the embryo (Fig. 19 B'). In mutant mice, this epaxial early expression showed incomplete segmentation (arrowhead in Fig. 19 A). At E10.5, Myf 5 expression in myotomes anterior to the forelimb extended ventrally in a pattern that
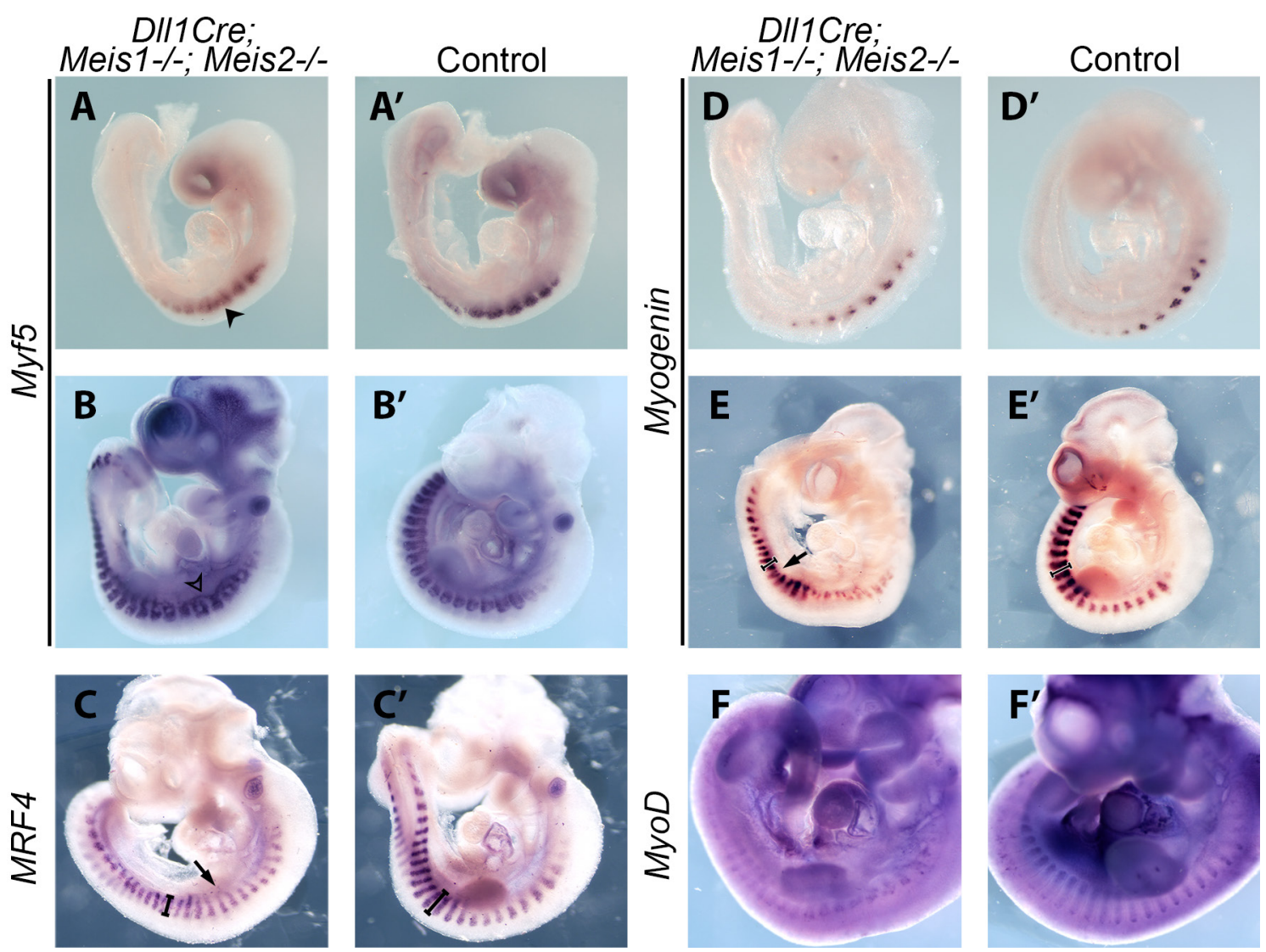

Figure 19: In situ hybridization of myotomal markers in Dll1Cre;Meis $1^{-/} ;$Meis2 $2^{-/}(\mathrm{A}-$ F) and control (A'-F') embryos at E9 (A, A', D and D') and E10.5 (B, B', C, C', E, E', $\mathrm{F}$ and $\left.\mathrm{F}^{\prime}\right)$. Arrowhead in $\mathrm{A}$, open arrowhead in $\mathrm{B}$ and arrow in $\mathrm{C}$ indicate fusion of the somites. Arrow in E points to a split of a somite. Brackets in C, C', E and E' mark the dorso-ventral extension of the signal. 
was not detected in control embryos. The extended expression appeared to fuse between adyacent myotomes, forming a continuous band (open arrowhead in Fig. 19 B).

MRF4 and myogenin presented a similar pattern to Myf5 and again we found that in the anterior and interlimb regions of mutant embryos, the expression pattern showed missegmentation and splitted patterns (arrows in Fig. $19 \mathrm{C}$ and E). In addition, the ventral hypaxial extension of the signal was reduced as observed before for other hypaxial markers (brackets in Fig. 19 C, C', E and E'). In contrast, defects in the early expression of myogenin at E9 were not as evident as for Myf5 (Fig. 19 D).

In addition, $M y o D$ expression in the anterior somites of the mutants was not restricted to the medial region as it occurs in the control embryos and appeard disorganized and less extended hypaxially (Fig. $19 \mathrm{~F}$ and F').

In summary, resegmentation of the paraxial mesoderm appears defective in Meis mutants, with defects in the separation of adjacent sclerotomal/myotomal domains and bifurcated myogenic domains. These defects affected mainly to the anterior region although defects were also seen in the interlimb region. During dermomyotome formation and myotome further development, the hypaxial developmental program seems especially affected and hypaxial migration fails in correlation with an inability to activated $\operatorname{Pax} 3$ expression.
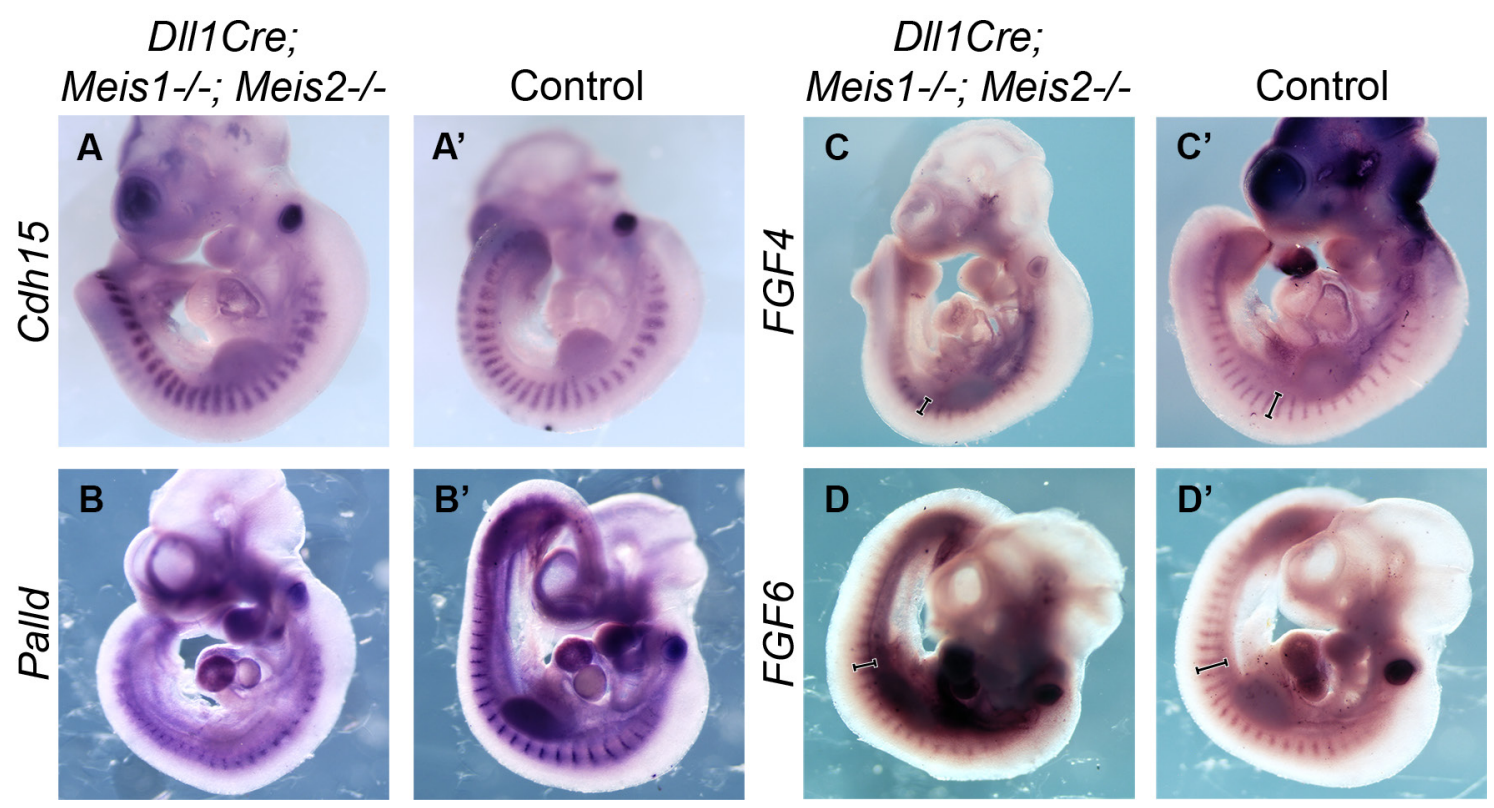

Figure 20: In situ hybridization of different markers at E10.5 in control (A'-D') and Dll1Cre;Meis $1^{-/} ;$Meis2 $^{-/-}$(A-F) embryos. Brackets in C, C', D and D' indicate the dorso-ventral extension of the signal. 


\section{- Expression of adhesion molecules in Meis $1 / 2$ double-knockouts recombined with}

\section{$\underline{\text { DllCre }}$}

Another group of genes differentially expressed were related with cell adhesion such as Cdh15 in the anterior region or Palld, Itga8 and Itga9 in the posterior. In situ hybridization of Cdh15 showed mild defects in the anterior somites of mutant mice at E10.5. Abnormal expression appeared in the anterior somites, and some ectopic patches of expression were found in the ventral part of this region (Fig. 20 A and A'). Palld signal was strongly reduced in the absence of Meis compared with the control. In control embryos, a stripe of expression appeared in the intersomitic boundary, which is not well-formed in the mutants (Fig. 20 B and B').

\section{- Myotomal FGF factors in Meis1/2 double-knockouts recombined with Dll1Cre}

FGF4 and FGF6 are involved myogenesis, though their expression in the medial myotome. We found that expression of FGF4 and FGF6 appeared highly reduced in mutant embryos. Both genes presents a similar pattern in the medial myotome extending from the dorsal to the ventral region in controls. This expression is reduced (almost absent in some embryos) and surprisingly, the reduction affects predominantly the epaxial region (Fig. 20 E, F, E' and F').

\section{- Retinoic Acid signaling in Meis $1 / 2$ double-knockouts recombined with Dll1Cre}

In the transcriptomic analysis of Meis mutants, Raldh2, the gene encoding the main embryonic enzyme responsible for synthesis of RA, and Cyp26b1, the gene encoding the main embryonic enzyme responsible for RA degradation, appeared downregulated in the anterior region (Fig. 16 C). In situ hybridizations for both genes were consistent with the transcriptomic analysis. Raldh2 expression in the somites appeared reduced at E9.5 (Fig. $21 \mathrm{~A}$ and A') and E10.5 (Fig. 21 B and B'). Dorsal and medial signals from the anterior and interlimb region were severely reduced; while ventral expression in the interlimb region appeared unaltered. Strikingly, the reduction in Raldh 2 transcript showed a mosaic appearance. In control embryos at E9.25, Cyp26b1 was expressed in the hindbrain and in the endothelium of the dorsal aortae and intersomitic vessels. While the hindbrain signal was preserved in mutants, the endothelial signal in the somitic region was abolished (Fig. $21 \mathrm{C}$ and $\left.\mathrm{C}^{\prime}\right)$.

Cyp26b1 is a direct target of the RA pathway that gets activated in response to RA. The concomitant downregulation of Raldh2 and Cyp26b1 thus suggest that Meis mutant embryos are defective in RA. We then studied the expression of the gene encoding the RA receptor beta $(R A R \beta)$, which has been described as a RA-responsive gene. Contrary to 

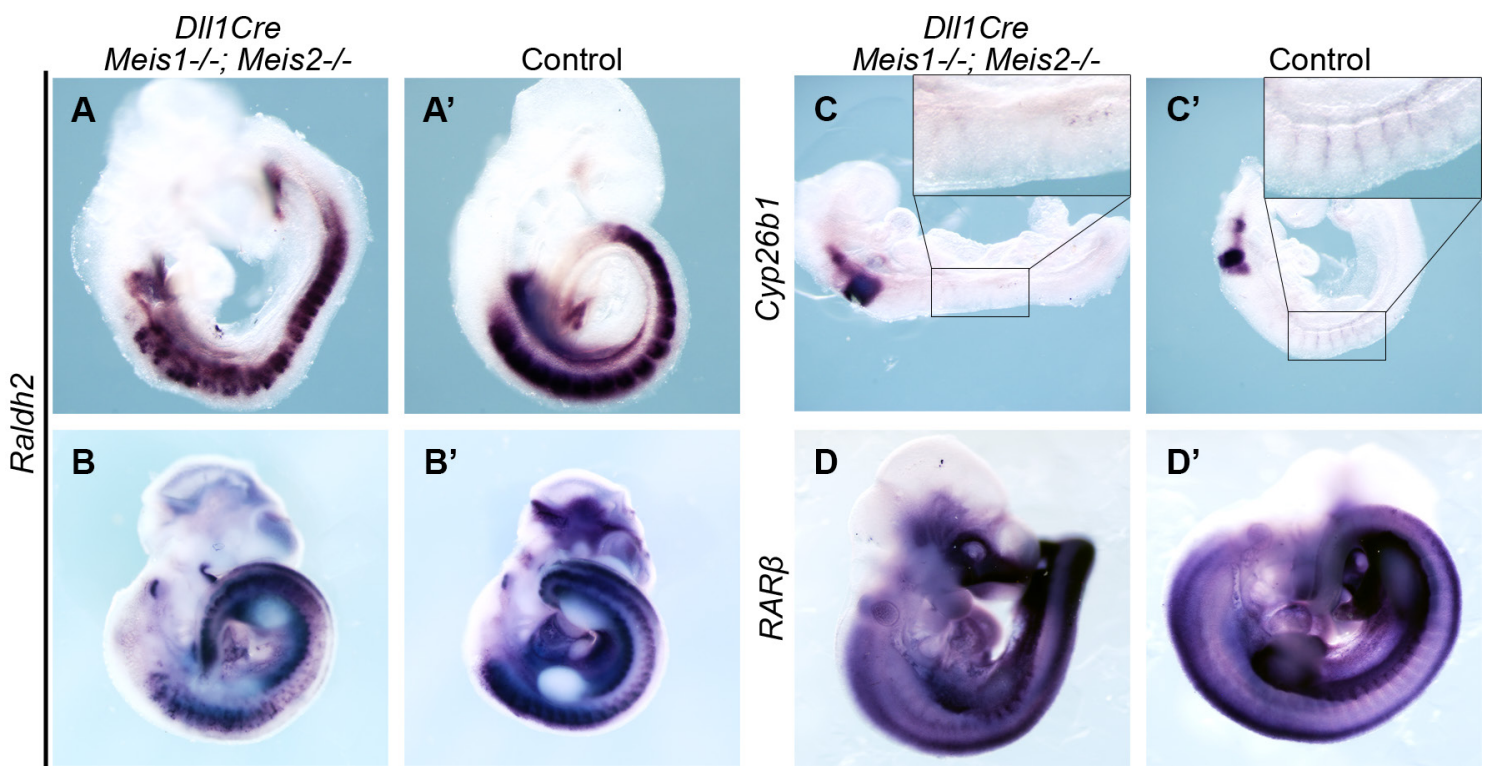

Figure 21: In situ hybridization of different genes of retinoic acid signalling in

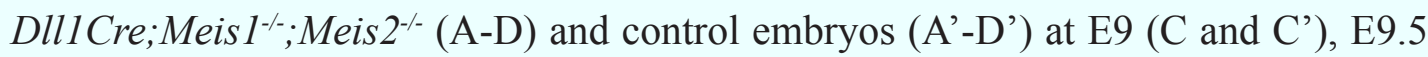
(A and A') and at E10.5 (B, B', D and D').

expectations, no change in the pattern of $R A R \beta$ was seen between controls and Meis mutants (Fig. 21 D and D'), which is consistent with the RNAseq data, where there were no differences in $R A R \alpha, R A R \beta$ or $R A R \gamma$.

We then studied the expression of Raldh2 in Meis mutants from the onset of its expression. As it was previously described, Raldh2 expression starts around E7 and at E7.5 is restricted to the mesoderm in the posterior half of the embryo (Niederreither et al. 1997). Interestingly, its expression pattern at early stages is very similar to that of Meis 2 in the mesoderm. We then performed a time-course expression analysis during the stages of onset of Meis 1 and Meis 2 expression (Fig. 22 A-D and F-I). We found a weak lateral signal in the E7 embryo (Fig. 22 C) and, as the embryo developed, this signal extended more posteriorly and distally (Fig. $22 \mathrm{D}$ and F-I). Immunostaining of Raldh2 was also performed at E7.5 and the signal corresponds with that seen by in situ hybridization. Unlike Meis 2 expression, which appeared in the three germ layers, ectoderm, mesoderm and endoderm, Raldh2 signal was restricted to the mesoderm (Fig. 22 E and J).

This initial expression of Raldh2 in the lateral mesoderm coincides with the early expression of Meis 1 , although Meis 1 start to express slightly before. To investigate if Meis could regulate Raldh2 at these early stages we could not use the DlliCre, as it recombines at later stages. Generating early double Meis mutants is a challenge, provided that double heterozygous mutants affecting anterior mesoderm are lethal. We therefore designed a 

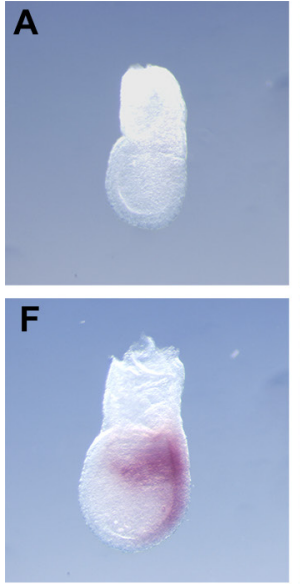

Stra8Cre;Zp3Cre; Meis1-/-; Meis2-/-

$\mathrm{K}$

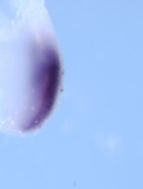

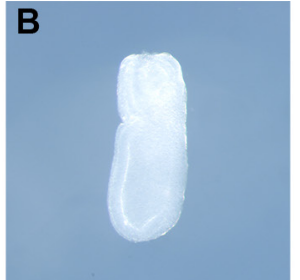

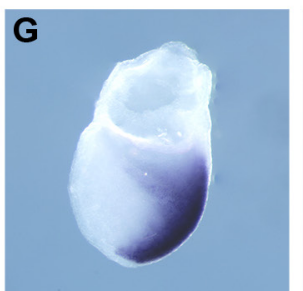

Control

$\mathbf{L}$

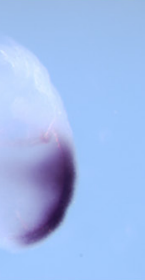

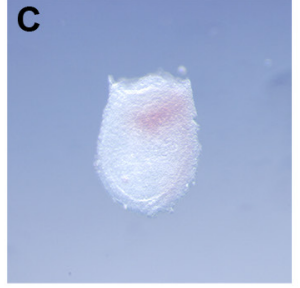

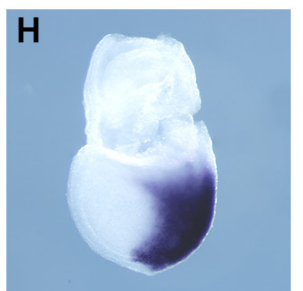

Stra8Cre;Zp3Cre; Meis1-/-; Meis2-/-

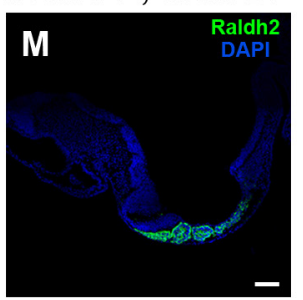

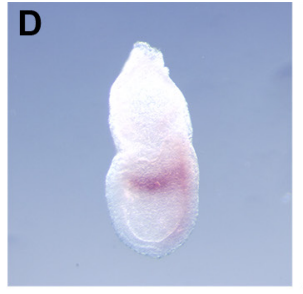

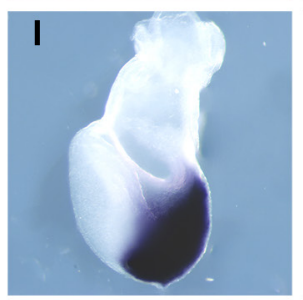

DII1Cre;

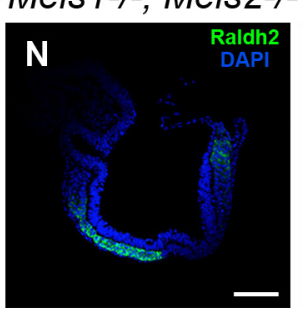

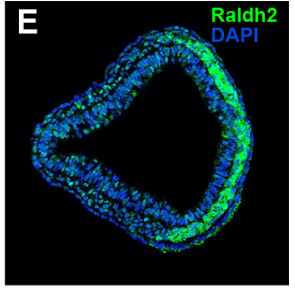

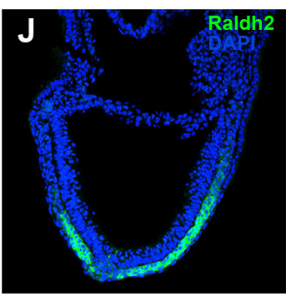

Control

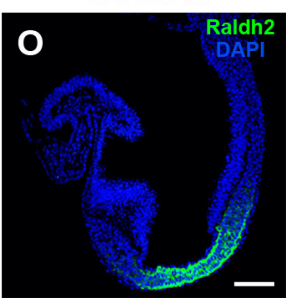

Figure 22: In situ hybridization of Raldh2 genes in early development from E7 to E7.5 (A-D), early allantoic bud (F), late allantoic bud ( $\mathrm{G}$ and $\mathrm{H}$ ) and late headfold (I) embryos. (E) Transverse (E) and sagittal (J) section of Raldh2 immunostaining at E7.5 embryo. (K and L) Raldh2 expression in Stra8Cre;Zp3Cre;Meis $1^{-1 /} ;$ Meis $2^{-/-}$and control embryo. (M-O) Raldh2 immunostaining in double-knockouts using Stra8Cre;Zp3Cre $(\mathrm{M})$ and DlliCre $(\mathrm{N})$ and in control embryos $(\mathrm{O})$. All images are orientated with the anterior region to the right. Scale bar (M-O), $100 \mu \mathrm{m}$.

strategy in which we used simultaneous paternal and maternal germline-specific deletion of Meis alleles. For this strategy, we used the Zp3Cre and Stra8Cre delete strains, which recombine in the female and male germ line, respectively. We crossed Zp3Cre;Meis f $^{\text {fox } /}$ ${ }^{f l o x}$;Meis $2^{f l o x / f l o x}$ females with Stra8Cre;Meis $1^{\text {flox/flox}}$;Meis $2^{\text {floxfflox }}$ males, to recombine Meis alleles in the parental gametes and obtain Meis double- zygotic knockouts (zMeisDKO). In situ hybridization of Raldh2 in zMeisDKOs at E7.5 did not show any defect in Raldh2 early posterior expression. However, the lateral expression that corresponds with the earliest expression, was not detected in mutants (Fig. $22 \mathrm{~K}$ and L). Immunostaining at E8.5 of Raldh2 in zMeisDKOs did not show alterations in the paraxial and proximal lateral mesoderm (Fig. $22 \mathrm{M}$ ). We were not able to study Raldh2 expression at later stages in zMeisDKOs, due to lethality after E8.5 related to cardiac defects.

In situ hybridization at E7.5 and immunostaining in zMeisDKOs suggests that Meis is not responsible for the early posterior expression of Raldh2 but regulates an early lateral 
domain probably related to cardiac precursors. At later stages, reduced Raldh2 expression was detected when Dll1Cre was used to delete Meis 1/2 alleles. The reduction in Raldh2 correlated with a reduction in Cyp26b1 expression, however other RA targets like $R A R \beta$ do not show changes in the mutants, suggesting a complex scenario in the relationship between Meis and the RA pathway.

In conclusion, our data support a role for Meis in regulating Raldh2 expression in the embryo, however this regulation is context dependent and does not affect all expression domains/stages.

\section{$\underline{\text { Dll1Cre recombination pattern in control and Meis mutant embryos }}$}

The mosaic pattern observed in Raldh2 expression downregulation suggested incomplete Dll1Cre recombination. We therefore aimed to study the distribution of DlllCrerecombined cells and compared their distribution in control embryos and Meis-deleted embryos. For that purpose, we combined Meis1 and Meis2 floxed alleles with Dll1Cre and a Rosa26RtdTomato reporter allele. In these embryos, Dll1Cre recombines the Meisfloxed alleles and removes the stop cassete of the Rosa26RtdTomato reporter, producing lineage-labelled double-knockout cells, while unrecombined cells remain unlabelled.

The Tomato ${ }^{+}$cell distribution was widespread in the trunk and the presomitic mesoderm at E8 and no differences were found between control and Meis mutant embryos (Fig. 23 A and B). At E10.5 we observed a mosaic pattern of Tomato ${ }^{+}$cell distribution in both control and Meis mutant embryos (Fig. 23 C-F). This mosaicism had not been described for this line before (Wehn et al. 2009) and therefore it might depend on the genetic background. To determine whether the observed mosaicism results from inefficient recombination in all cells or from random mosaic inactivation of Dll1Cre expression, we studied the correlation between Meis immunodetection and Tomato expression in Dll1Cre;Rosa 26RtdTomato; Meis $1^{\text {floxffox }}$;Meis $2^{\text {floxffox }}$ embryos. We found that Tomato ${ }^{+}$cells were devoid of Meis, while their neighbouring Tomato- cells showed Meis expression (Fig. 23 G-N). Image profiling shows the anti-correlation between Tomato and Meis detection (Fig. 23 L) whereas this correlation did not exist in control embryos (Fig. $23 \mathrm{~N}$ ). These results indicate that the mosaic Tomato distribution results from mosaic inactivation of DlllCre and therefore the Tomato $^{+}$cell distribution reports the distribution of Meis-deficient cells. We did not find any reproducible difference in the distribution of Tomato $^{+}$cell patches between mutant and control embryos and the proportion of Tomato ${ }^{+}$cells was variable between different embryos. However, in the mutant there is a tendency of knockout cells to agregate forming patches that are more evident in the mutants compare with the con- 
DII1Cre;

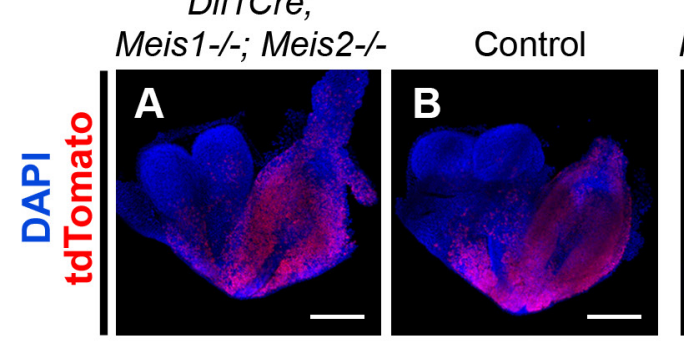

Control

DII1Cre;

DII1Cre; Meis1-/-; Meis2-/-
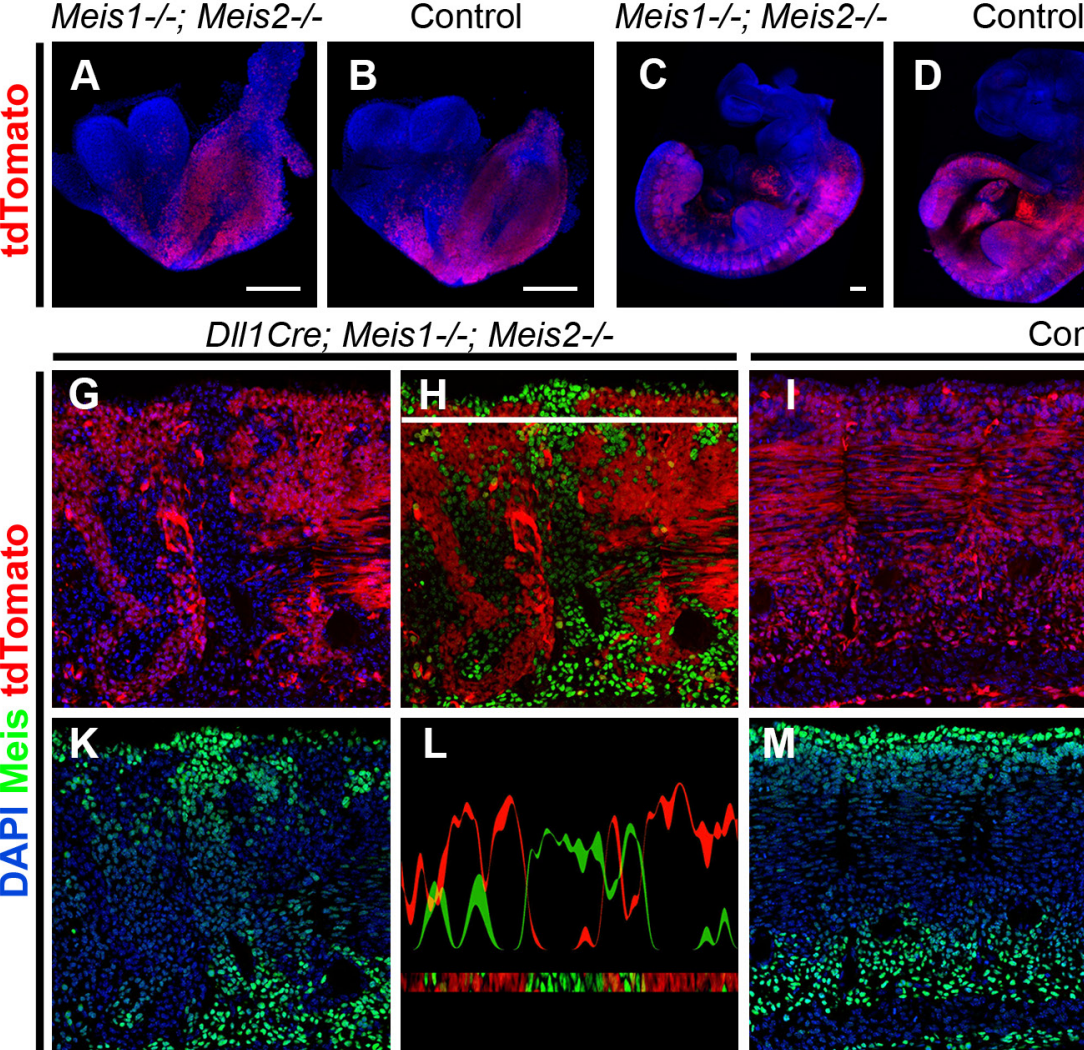

Control
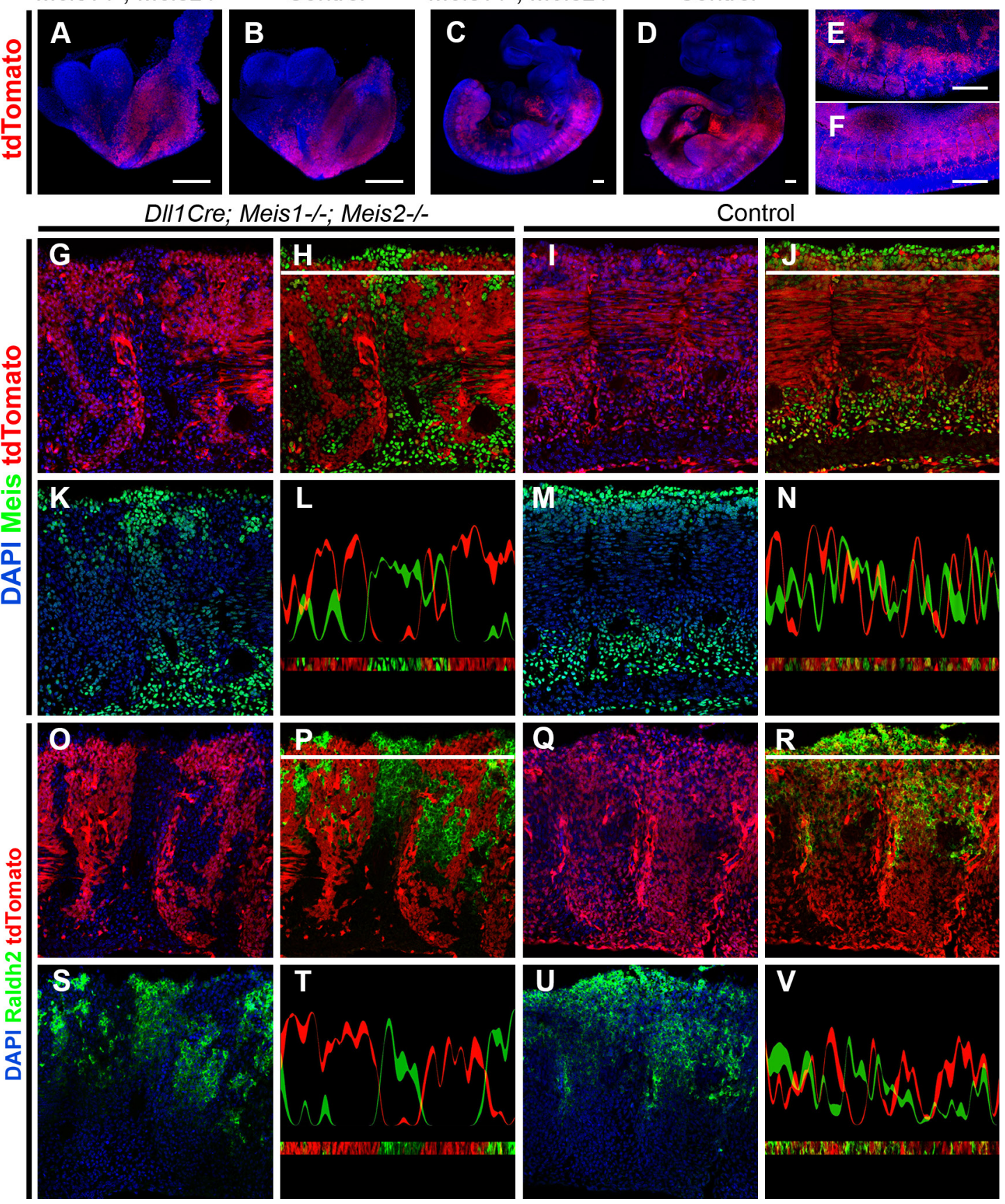

Figure 23: 3D reconstruction of Dll1Cre;tdTomato lineage in double-knockout (A, $\mathrm{C}$ and E) and control (B, D and F) embryos at E8 (A-B) and E10.5 (C-F). (E and F) Detail of the trunk under the forelimb of Dll1Cre;Meis $1^{-/} ;$Meis2 $2^{-/-}$(E) and control (F) embryos at E10.5. Meis (G-K and M) and Raldh2 (O-S and $\mathrm{U}$ ) immunostaining in anterior somites from E10.5 sections of Dll1Cre;Meis $1^{-/} ;$Meis $2^{-/} ;$R26tdTomato and $^{2}$ control embryos. (L, N, T and V) Representation of Meis ( $\mathrm{L}$ and N) or Raldh2 (T and $\mathrm{V})$ signal in green and tdTomato signal in red from the region of the section depicted

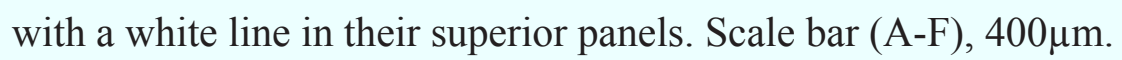


trols (Fig. 23 E-F). The anterior-most border of Tomato ${ }^{+}$cell distribution was established at the occipital level and was also unchanged between control and mutant embryos.

We therefore used the mosaic inactivation of Meis alleles to study the regulation of Raldh2 by Meis. We performed Raldh2 immunostaining and correlated this signal with that of tdTomato. We found that Tomato $^{+}$cells lacking Meis function did not show Raldh2 signal, while their Tomato- neighbours, Meis-expressing cells showed normal Raldh2 expression (Fig. $23 \mathrm{O}-\mathrm{V}$ ). The result was similar to that observed for Meis immunostaining, being the signal of Raldh2 and tdTomato mutually exclusive in the mutant mice but not in controls (Fig. $23 \mathrm{~T}$ and V). These results indicate that Raldh2 is a confirmed target of Meis in the differentiating paraxial and lateral plate mesoderm, however this relationship does not take place in the undifferentiated nascent mesoderm, with the possible exception of the early cardiogenic mesoderm. These conclusions correlate with the observed downregulation of Raldh2/Cyp26b1 in the transcriptome of anterior trunk but not the posterior trunk of E9.5 embryos (Fig. 16 C).

\section{Skeletal pattern in Dll1Cre; Raldh $2-\underline{-}$ embryos}

The relation of Meis and Raldh2 expression described above prompted us to study whether defects observed in Meis mutants may derive from a deficiency in Raldh2/RA. Despite the role of RA in regulating Hox expression and skeletal patterning (Kessel, 1992; Marshall et al. 1992; Kessel and Gruss, 1991), there is no published description of the consequences to AP axial patterning of Raldh2 deletion. For that purpose, we generated Dll1Cre;Raldh2floxfflox embryos and analyzed the axial skeleton (Supplementary Table 2 and Fig. 24).

In the occipital region, abnormalities in the basiocciopital were observed ( $n=14 / 43)$, including fusion of this structure with the aaa (arrowhead Fig. 24 A). However, these abnormalities were also found in the control embryos although in a lower proportion $(n=5 / 39)$ (Fig. 24 G). The supraoccipital did not present any malformation (Fig. 24 B) and the exoccipital appeared normal (Fig. $24 \mathrm{E}$ and F) except in the cases in which $\mathrm{C} 1$ is fused to it and shows a rounder appearance similar to that found in Meis mutants.

In the cervical region, abnormalities were found at a low frequency. In the mutants, the $\mathrm{C} 1$ was fused to the exoccipital $(\mathrm{n}=5 / 49)$ or appeared close to and showed a similar angle and shape as the exoccipital, with reduction or absence of the neural arch $(n=2 / 49)$ (Fig. $24 \mathrm{~F}$ ). When $\mathrm{C} 1$ it was fused to the exoccipital, $\mathrm{C} 2$ changed its morphology to C1-like, and this can be observed in the morphology of the neural arch and in the formation of 
the aaa at the level of the C2 (asterisk in Fig. 24 E and F). In Dll1Cre;Raldh2- fetuses, fusions were also common between neural arches of the cervical vertebrae and, in some cases, tuberculi anterior was found in C7 instead of C6 ( $n=5 / 21)$ (Fig. $24 \mathrm{E}$ and F).

Altogether, the alterations found in Raldh2 mutants were similar to those observed in Meis mutants but were present at a lower frequency.

In the thoracic region, rib fusions and splits were observed in similarity to those found in the Meis mutants (Fig. $24 \mathrm{~J}$ ), and shortening of the first rib or its fusion with the second rib was also found (Fig. $24 \mathrm{E}$ and F).
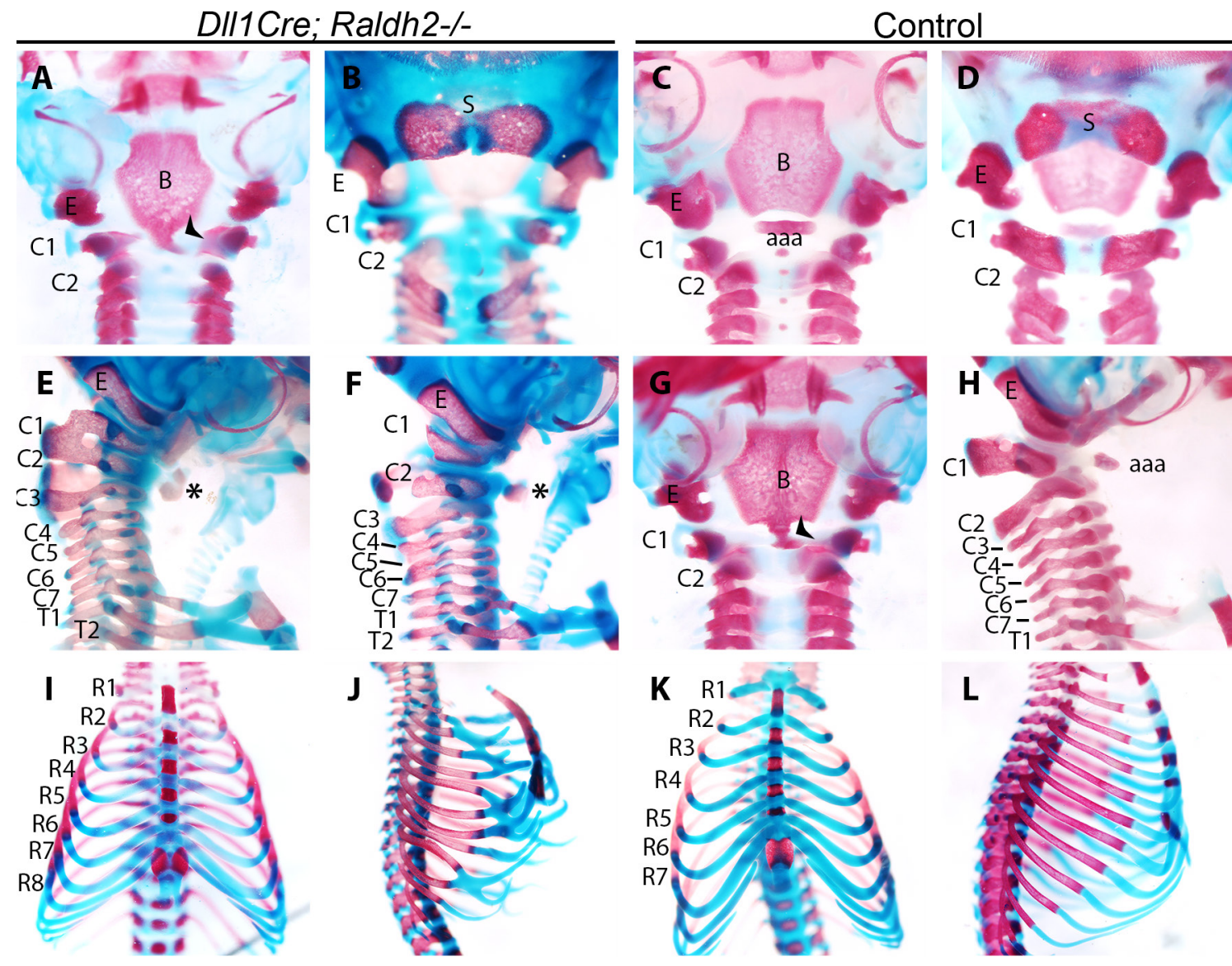

Figure 24: Dll1Cre;Raldh2-/ embryos skeletal staining at E18.5. (A, C and G) Ventral view of the basioccipital in control (C and $\mathrm{G}$ ) and knockout (A) embryos. Arrowheads point to the fusion between the basioccipital and the anterior arch of the atlas. $(\mathrm{B}, \mathrm{D})$ Dorsal view of the cervical region. (E, F and $\mathrm{H}$ ) Lateral view of the cervical region in knockout $(\mathrm{E}$ and $\mathrm{F})$ and control $(\mathrm{H})$ embryos. Asterisk indicated the aaa formed by C2. (I-L) Ventral (I and K) and lateral ( $\mathrm{J}$ and L) of knockout (I and J) and control (K and L) embryos. aaa, anterior arch of the atlas; B, basioccipital; E, exoccipital; S, supraoccipital; C, cervical vertebra; T, thoracic vertebra; R, rib. 
We detected a change as well in the number of sternal versus floating ribs in Raldh2 mutants $(n=15 / 49)$ but also in control embryos $(n=14 / 42)$. Eight sternal ribs and five floating ribs were found in both cases in a similar proportion (Fig. 24 I). In the most affected mutant embryos, we observed defects in the intersternal cartilage and the sternebrae, although we did not observe a split sternum.

The defects observed in rib formation are partially coincident with those observed in Meis mutants and suggest a especial affection of hypaxial development as it was observed in Meis mutants. In both Meis and Raldh2 mutants, the abnormalities observed were restricted to the occipital, cervical and thoracic region, and this is consistent with the expression changes of different markers analyzed by in situ hybridization.

In conclusion, the data obtained from the compared analysis of Meis and Raldh2 mutants support the hypothesis of a direct control of Raldh2 expression by Meis during mesodermal differentiation and suggest that at least in part, the axial skeleton defects observed in Meis mutants derive from a defect in RA signaling. 


\section{Discussion}



Meis proteins and their orthologs are involved in regulating Hox protein function through direct protein-protein interaction and thereby modulation of Hox DNA binding properties. In flies, elimination of the Meis ortholog homothorax results in strong homeotic phenotypes which, however, do not involve changes in Hox gene expression but in Hox protein DNA affinity and target selectivity (Rieckhof et al. 1997). In vertebrates, in addition to the ability of Meis proteins to interact with Hox proteins, a dense pattern of Meis protein binding to Hox complexes (Penkov et al. 2013) has suggested they may play a role as well in transcriptional regulation of the Hox complexes.

\section{Meis 1 and Meis 2 expression in early mouse embryo development}

Meis 1 and Meis 2 genes start expression at early stages in the mouse embryo, when gastrulation has just started. The initial expression pattern of both genes is different in time and space, suggesting a possible differential early function for both genes. Meis 1 starts to be expressed slightly later than Meis2, and its first expression is found in the mesodermal layer of the lateral region of the embryo, which we think could correspond with the cardiac precursors. On the other hand, Meis 2 starts to be expressed at E7 and, interestingly, its early activation coincides in time and space with the onset of Hox gene expression (Deschamps et al. 1999). In addition, in situ hybridization and immunostaining showed that Meis 2 is expressed in the three germ layers in the posterior region at E7.5. At this stage neuromesodermal progenitors are localized in the caudal lateral epiblast and in the adjacent NSB, within the Meis2-expressing region. At late headfold stages, Meis1 and Meis2 are expressed in more anterior regions, although some Meis 2 transcripts are still seen in the posterior region (Fig. 8 R). At E8, neither Meis 1 nor Meis 2 are expressed in the most posterior region where the neuromesodermal progenitors continue generating neural and mesodermal cells that contribute to axial extension (Henrique et al. 2015). Although it is not clear when these neuromesodermal progenitors arise, we have a time window in which Meis and these neuromesodermal progenitors coincide in the posterior epiblast until the late headfold stage, when Meis withdraws from the posterior region. Therefore, the cells that ingress through the PS and contribute to the mesoderm during this time window, including the paraxial mesoderm, have been under the action of Meis from the time they were in the epiblast.

\section{$\underline{\text { Role of Meis in mouse axial skeletal development }}$}

As the Hox code is acquired through the temporal sequence of gene activation, first in the epiblast and later in neuromesodermal progenitors, we have used different Cre lines to 
dissect Meis roles in time and space in axial precursors and determine their relationship to Hox regulation and axial pattern formation.

Therefore, the deletion of Meis was carried out with Sox2Cre for eliminating the earliest function of Meis in the epiblast; with Mesp1Cre for eliminating Meis function in the nascent mesoderm and with Dll1Cre for eliminating Meis from the mesoderm at the level of the PSM (Fig. 25). As double heterozygotes for Meis 1 and Meis 2 floxed alleles recombined with either Sox2Cre or Mesp1Cre were not viable, we were unable to generate double-knockouts embryos using these Cre lines. Based on the early expression

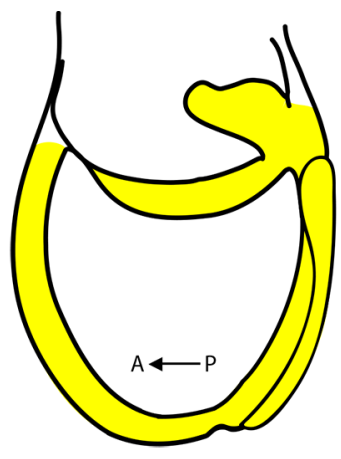

Sox2Cre

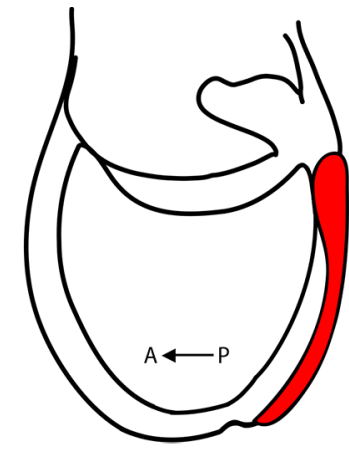

Mesp1Cre

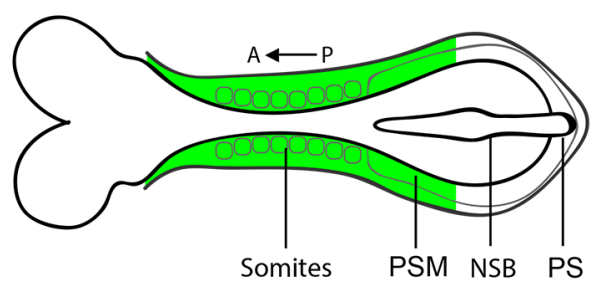

DII1Cre

Figure 25: Recombination pattern of the different Cre lines used.

pattern of both genes, we reasoned that Meis 2 and not Meis 1 would be the most likely gene to play early roles in axial patterning, so in a first approach we deleted Meis 2 with either Sox2Cre or Mesp1Cre. Similar skeletal defects were detected in Sox2Cre;Meis $2^{-/-}$ and Mesp1Cre;Meis2 ${ }^{-/}$E14.5 fetuses, affecting mainly to the cervical vertebrae and to a lesser extent, the thoracic region (Fig. 26). Although the deletion with Sox2Cre and Mesp 1Cre produced the same type of defects, the penetrance and the severity of the abnormalities was milder using the MesplCre line. This could suggest that the timing of Meis 2 elimination is important, which would identify a role for the earliest Meis 2 expression in axial patterning. While this idea is consistent with the lower penetrance and severity observed in Dll1Cre; Meis $2^{-/}$fetuses, we cannot discard that the different genetic backgrounds and/or the mosaicism observed for Dll1Cre underlie these differences. The fact that the quality and axial level of the defects is similar in the three models in fact argues for an essential function for Meis2, not in epiblast or nascent mesoderm but during and/or beyond their transit through the PSM. In addition, it is important to highlight that the variation in the penetrance is mostly observed in the thoracic region and in the posterior cervical vertebrae, whereas the most anterior defects, like the fusion and the repositioning of the atlas $(\mathrm{C} 1)$ to the exoccipital, we obtained similar penetrance with 

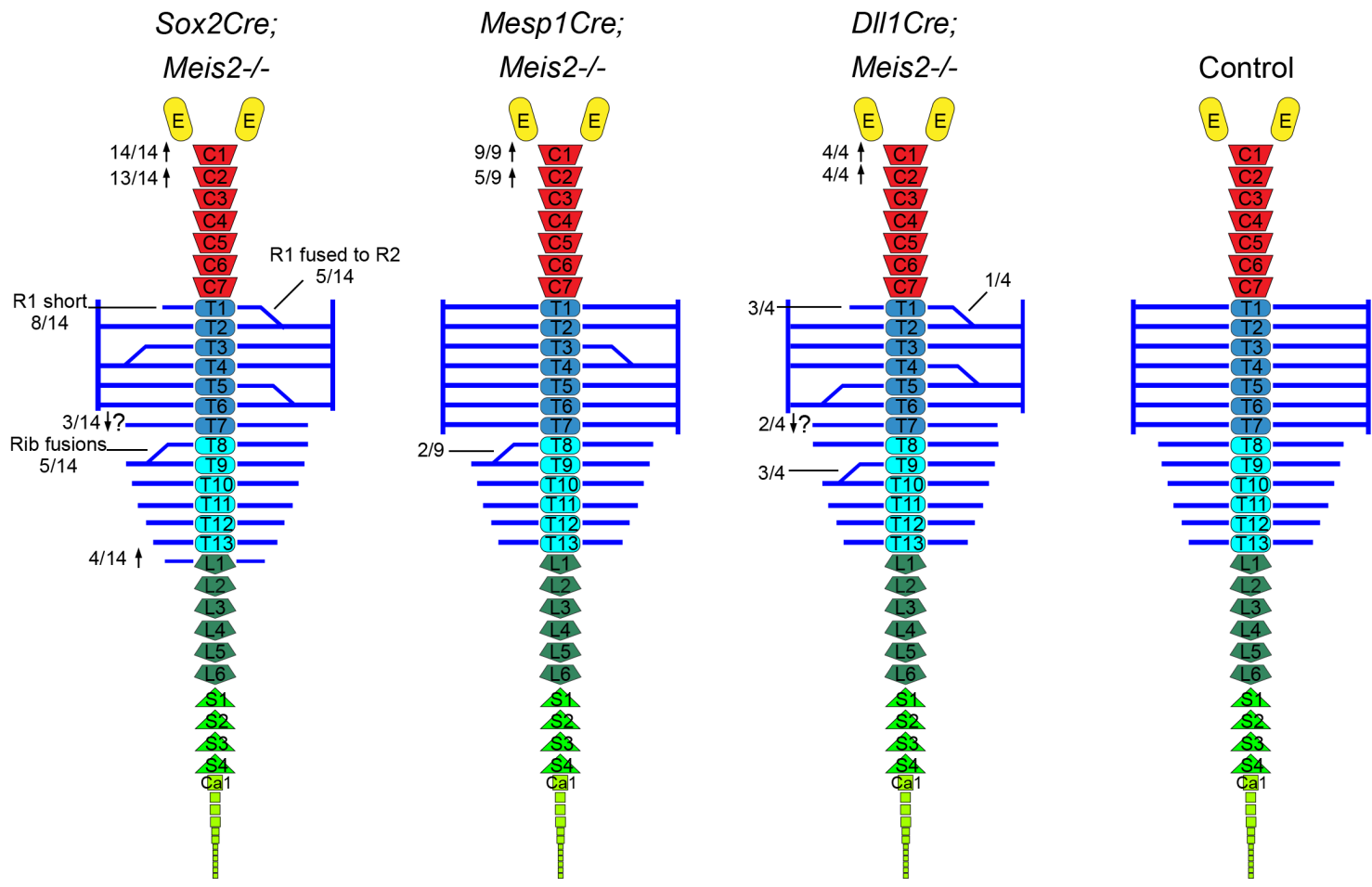

Figure 26: Schematic representation of the skeletal defects observed in Sox2Cre, Mesp1Cre and Dll1Cre;Meis2 $2^{-/}$fetuses and their frequencies. Arrows indicate the direction of the homeotic transformation. NA, neural arch; E, exoccipital; C, cervical; T, thoracic; L, lumbar; S, sacral; Ca, caudal; R, rib.

the three Meis2 $2^{-/}$models (see supplementary Table 2). Our analysis thus identifies no obvious patterning functions for the earliest Meis2 expression in the epiblast and nascent mesoderm. Yet, we show a previous unknown role for Meis in the specification of axial skeletal element identity and proper patterning. Early expression of Meis 2 could be involved in cardiac development since cardiac defects are more severe in Sox2Cre;Meis2-/mice than in Mesp1Cre;Meis2-/- and even milder when Meis2 is deleted specifically in cardiac progenitors with Nkx2.5Cre (Carramolino and Torres, unpublished).

Previous data suggests that the role of Hox genes in the specification of segmental identity occurs in the PSM before the cells form the somites (Carapuço et al. 2005). Our results would be consistent with this model, as Meis is present initially from the earliest stages of axial precursor development and later from the PSM; furthermore, axial skeletal transformations were observed when eliminating Meis function from the PSM. However, we cannot exclude later functions during somite development, provided Meis is also present in the differentiating paraxial mesoderm and we have not eliminated Meis function specifically in the differentiated somites, as it was performed in the overexpression experi- 
ments of Carapuço et al. (2005).

Since Meis 1 and Meis2 show a similar expression pattern from E8 and Meis1 and Meis2 proteins are highly similar, we cannot discard the cooperation of these two transcription factors, as it has been observed for Meis function in heart and limb development (Delgado, López-Delgado, Carramolino and Torres, unpublished). For this reason, we generated Meis 1/2 double KO using Dll1Cre and, as we expected, the severity of the defects increases with the number of alleles deleted (Fig. 27). This is evident in E14.5 fetuses in which the fusions between vertebrae are most frequently observed in Meis 1/2 double $\mathrm{KO}$, and are accompanied by incompletely developed ribs (Fig. 13). Meis1/2 double KO at E18.5 did not show this strong phenotype, probably because the most affected fetuses died before this stage, provided that the survival rate was $37 \%$ at E18.5. The cooperation between Meis 1 and 2 in axial patterning further supports the lack of relevance of Meis 2 early expression in this process, provided Meis 1 is not expressed at the early stages.

Regarding the defects observed in DlllCre-induced mutants, and consistently with the phenotype of Meis2-deficient mice discussed above, we observed an almost complete penetrance of defects affecting the exoccipital and C1. At E18.5 we also observed lack of ossification of the supraoccipital bone and defects in the basioccipital morphology in several genotypes. Quail-chick grafting experiments have shown that the exoccipital and basioccipital receive contribution from the first 5 somites, while the supraoccipital only receives contribution from somites 1 and 2 (Huang et al. 2000). Assuming these contributions are similar in the mouse, defects in the first two somites, which contribute to the three occipital bones, could suffice to explain the phenotypes observed, however, the highly penetrant affection of the first cervical vertebra suggests a more general role for Meis in specifying skeletal elements across the occipital-anterior cervical region.

The basioccipital and supraoccipital bones are not yet formed at E14.5, so we could not observe if Sox2Cre- and Mesp1Cre-induced Meis2-deficient mice show defects in these bones; however, provided Dll1Cre; Meis $1^{-/-}$mice do not present defects in any of the occipital bones, it is likely that Meis2 plays the main role in occipital development. This role of Meis 2 in the earliest and most anterior structures formed under Hox control correlated with the early expression of Meis2 as compared with Meis1. The early onset of Meis2 expression might thus have to do with the need to have the pathway active early enough for occipital patterning. On the other hand, fusion of the exoccipital and the basioccipital bones with posterior structures could involve an alteration in the fifth somite since after re-segmentation its rostral half contributes to the exoccipital and basioccipital bone, 

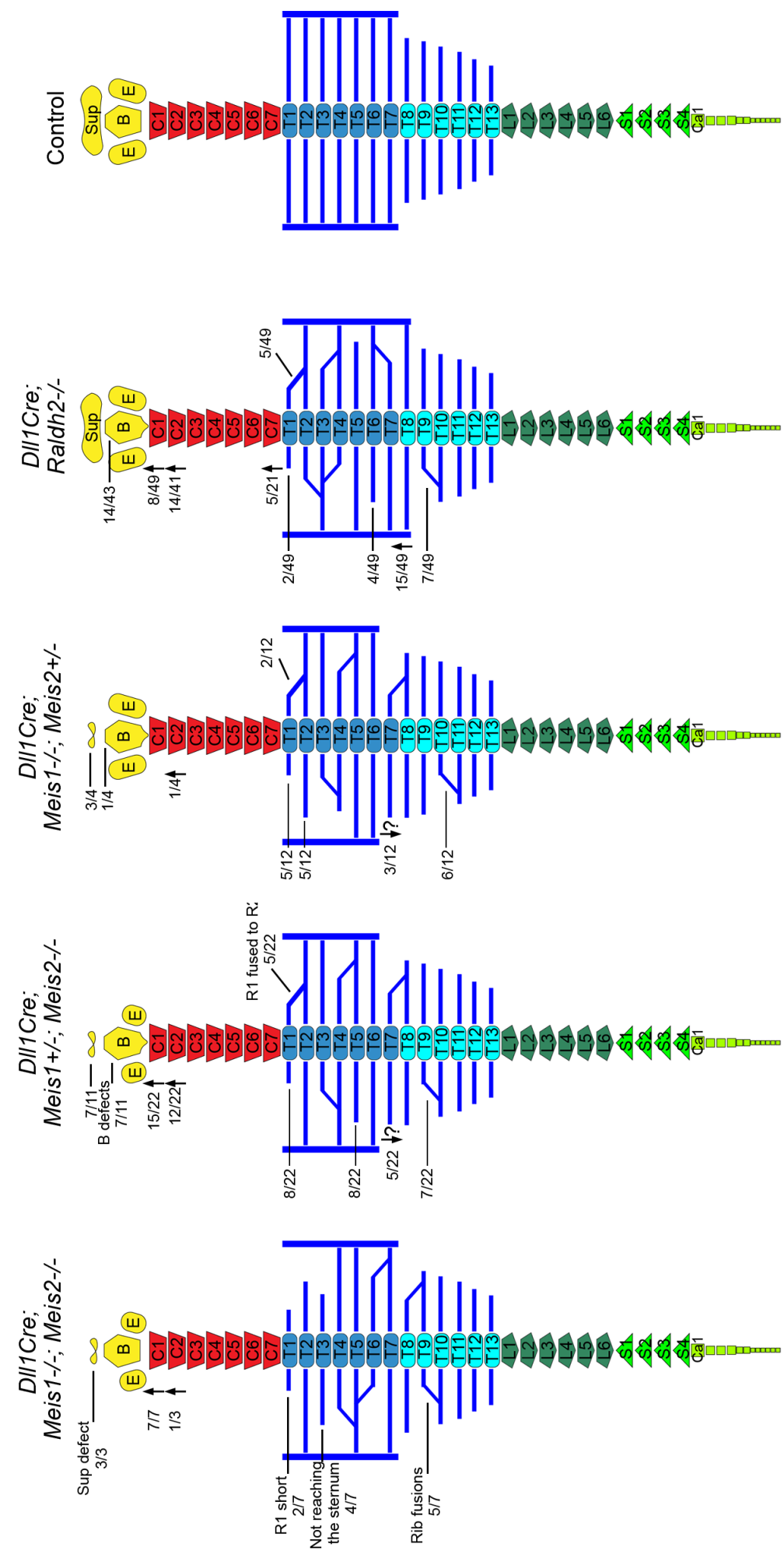

Figure 27: Schematic representation of Dll1Cre;Meis $1^{-1 /} ;$ Meis $2^{-/,}$, DlllCre;Meis $1^{+/-}$ ;Meis $2^{-/}$, Dll1Cre;Meis $1^{-/}$;Meis $2^{+/-}$and Dll1Cre;Raldh2 $2^{-/}$mice and their frequencies. Arrows indicate the direction of the homeotic transformation. aaa, anterior arch of the atlas; NA, neural arch; B, basioccipital; E, exoccipital; Sup, supraoccipital; C, cervical; T, thoracic; L, lumbar; S, sacral; Ca, caudal; R, rib. 
while its caudal part forms the first cervical vertebra. Fusions between these structures in Meis mutants could indicate an alteration in AP identity of the fifth somite and/or a failure in re-segmentation. The fusions observed between other vertebrae could be due to the similar abnormalities.

The change of the identity of the neural arches of $\mathrm{C} 2$ to $\mathrm{C} 1$-like was only observed in embryos in which both Meis 2 alleles were deleted. However, the presence of the aaa in C2 was not exclusive of the Meis 2 deficiency, as it was also detected in Dll1Cre;Meis $1^{-/-}$ ;Meis $2^{+/}$and in Dll1Cre; Meis $1^{-/-}$animals. This ectopic aaa indicates a partial acquisition of a $\mathrm{C} 1$ identity since $\mathrm{C} 2$ maintains the odontoid process characteristic of $\mathrm{C} 2$.

The morphological changes observed in $\mathrm{C} 1$ and its fusion to occipital bones as well as the transformations of $\mathrm{C} 2$ and $\mathrm{C} 3$ represent anterior homeotic transformations, since vertebrae are transformed into their immediate anterior homologs. We consider the shortening of the first rib (even its fusion to the second rib) as a possible anterior transformation, since the first thoracic vertebrae is not developing a proper rib as cervical vertebrae do. Nonetheless, the general affection of rib development might be a confounding factor here, whereby the defects in T1 might derive from a general defect in hypaxial development and not correspond to a change in identity.

Likewise, the different proportion sternum-attached versus floating ribs observed in Meis mutants (6/7 sternal/floating ribs instead of 7/6) could be consider a posterior transformation or, as we have discussed above, it could derive from the defects in the hypaxial somite development. In fact, Sox2Cre;Meis 2 mutants also showed the presence of ribs in L1, which clearly indicates an anterior transformation. These observations argue for a general effect of anterior transformation affecting from the occipital to the anterior lumbar region, with and added specific effect on hypaxial development that is mostly manifested in rib and intercostal muscle misspatterning. Interestingly, similar phenotypes to those produced by Meis 1 and Meis 2 mutations have been described in Hox mutants. Hoxd $3^{-/-}$ (Condie and Capechi, 1993) and Hoxd4^- mutants (Horan et al. 1995a) present a change in the morphology at the base of the basioccipital protruding posteriorly to the aaa and in some cases it is fused to the aaa.

$\mathrm{C} 1$ repositioning towards the exoccipital and a thicker $\mathrm{C} 2$ vertebra are also observed in these mutants. Hoxd3 and Hoxd4 deficient mice therefore show the same kind of homeotic transformation seen in Meis mutants. Compound mutations in genes from the paralog group 4 present as well defects in the cervical region such as the presence of the aaa in $\mathrm{C} 2$ and the fusion of the dorsal region of the neural arches (Horan et al. 1995b). 
Defects observed in the thoracic region of Meis-deficient mice such as the fusion of the first and second ribs and a fourteenth rib were also observed in Hoxa9 and Hoxb9 compound mutants, (Chen and Capecchi, 1997); while the absence of the first rib appeared in paralogous mutants of Hox 5 and Hox6 (McIntyre et al. 2007).

Skeletal defects similar to those described here for Meis mutants were also observed in $C d x$ mutants. $C d x$ are homeobox genes and are regulators of axial patterning. Mutations in these genes lead to anterior transformations predominantly in anterior regions. $C d x 1^{-}$ - mice present a broader basioccipital with neural arches of the $\mathrm{C} 1$ sometimes fused to it. In addition, anterior transformations of $\mathrm{C} 1, \mathrm{C} 2$ and $\mathrm{C} 3$ were also observed (Subramanian et al. 1995). In the compound mutant $C d x 1^{-/} ; C d x 2^{+/}$, the penetrance of these defects was increased, suggesting that both genes cooperate in the regulation of axial patterning (van den Akker et al. 2002). Fusions between spinal ganglia was also observed in these compound $C d x 1^{-/} ; C d x 2^{+-}$mutants, a phenotype that we have also observed in Dll1Cre;Meis $1^{-}$ ${ }^{-}$;Meis $2^{--}$, revealed by Eya2 mRNA distribution (Fig. 17 B and B'). Contrary to our observations in Meis mutants, $C d x$ loss of function affects Hox gene expression boundaries, which are shifted posteriorly, in correlation with the anterior transformations observed (van den Akker et al. 2002; Subramanian et al. 1995). In good agreement, overexpression of $C d x$ genes shifted anteriorly Hox gene expression and produced posterior transformations (Gaunt et al. 2008).

\section{Meis role in Hox regulation}

Hox gene mRNA expression patterns in Sox2Cre;Meis2 $2^{-/-}$and DlllCre;Meis ${ }^{-1 /}$;Meis2 $2^{-/-}$ mice did not show any alteration (Fig. 9 and 15). We analyzed Hoxal early expression in order to see if the earliest activation was affected; however, we did not detect any modification of the expression pattern. Examination of other 3' Hox genes whose anterior boundaries of expression lie in the regions where defects were observed did not show any alteration. In most of the cases, the analysis was performed at early stages, to avoid the changes in the boundary of expression that take place during later development (Gaunt et al. 1999).

In addition to this spatial description of the pattern, no significant differences in the levels of transcripts were found in the RNA-seq analysis performed in Dll1Cre;Meis ${ }^{-}$ ${ }^{\wedge}$;Meis $2^{-/}$embryos at E9, indicating that Meis function does not affect the amount of Hox transcripts. In summary, despite the early activation of Meis in the epiblast and the profuse binding of Meis proteins to the DNA of Hox clusters, we did not find any role for Meis in establishing the pattern, timing or intensity of Hox gene transcription. The fact 
that Meis mutants reproduce the phenotypes of Hox mutants and $C d x$ mutants without altering Hox expression, points to their role as Hox protein cofactors, which agrees with the established role of Meis and its Drosophila homolog hth as Hox protein co-factors. In contrast with the observations in Drosophila, where the transformations described are posterior (Ryoo et al. 1999), our observations indicate the loss of Meis provokes anterior transformations. These contrasting observations indicate that, despite their similar level of regulation of Hox activity, no direct correlation can be established between Meis and hth molecular function. The fact that in vertebrates two subfamilies of hth-like factors exists; Meis and Prep and that specific and even antagonistic functions have been described for these two sub-families (Blasi et al. 2017; Penkov et al 2013) possibly underlies this complex scenario.

\section{Somite development in the absence of Meis}

RNA-seq analysis in Dll1Cre-induced mutants revealed a set of genes expressed in somites that change expression in Meis mutants, which could shed light in the role of Meis in axial development. From this analysis we investigated the expression pattern of different markers that helped us to decipher defects in somite development. The myogenic regulatory factors: $M y f 5, M R F 4$, myogenin and MyoD present alterations in Meis 1/2 double KOs. In situ hybridization of MRF4 and myogenin (Fig. 19) showed fusions and bifurcations of the expression domains. We have not detected these fusions and splits in Myf5 in the inter-limb region but some somites were misshaped in this region. Myf5, MRF4 and myogenin-deficient mice show rib defects including fusion between ribs (Patapoutian et al. 1995; Hasty et al. 1993; Braun et al. 1992). These ribs defects resemble those observed in Meis mutants. Myf5-deficient mice present defective chondrogenesis on the rib primordia (Grass et al. 1996); according with this, the altered pattern of these markers could be responsible of the rib mispatterning in Meis1/2 double KOs. Moreover, FGF4 and FGF6 are highly downregulated in these myotomal mutants (Fraidenraich et al. 2000; Grass et al. 1996) and this was also observed in Meis mutants, suggesting a function of Meis in the cross-regulation between different somite-derived compartments. A link between signaling in different compartments has been related with the activity of Hox genes (Vinagre et al. 2010). Vinagre et al. (2010) correlate the presence of Myf5 and MRF4 in the axial region of the interlimb somites with the presence of ribs. They suggest that Hox proteins could bind to enhancer elements of Myf5 and MRF4 and regulate its expression, affecting consequently FGFs and PDGF $\alpha$ that are downstream effectors that could transmit the myotomal information to the sclerotome. We have not detected a lack of signal in this region, either for $M y f 5$ or for $M R F 4$, but fusions between expression domains from diffe- 
rent segments and abnormal signal distribution was present preceding the rib phenotype observed at later stages. Altered expression or absence of several genes analyzed here, indicated an alteration of hypaxial myotome development. Eya 1, Pax3 and Sim 1 are some examples of genes that showed hypaxial expression reduction. During somite differentiation, hypaxial dermomyotome growths and expands ventrally to give rise to thoracic and abdominal muscle. It has been described that the hypaxial expression of Eyal together with Six homeodomain transcription factors induce Pax3 in the hypaxial region promoting the myotomal migration (Grifone et al. 2007). On the other hand, Pax3 has been proposed to activate the myogenic program through regulation of myogenic regulatory factors, MRF4, myogenin, MyoD and Myf5 (Grifone et al. 2005). Similarly, Vinagre et al. (2010) suggested that Pax3 and Six factors could be involved in the regulation of Myf5 and MRF4 by Hox genes.

On the other hand, Myf5 seems to regulate FGF4 and FGF6 expression in the myotome (Fraidenraich et al. 2000; Grass et al. 1996) and Shisa, that appeared downregulated also in Meis 1/2 double KO, may act to modulate FGF signaling (Furushima et al. 2007). This downregulation of FGF4 and 6 was evident in Meis $1 / 2$ double KO, as it was shown by in situ hybridization, so FGF signaling in the myotome could be disrupted in Meis mutants and this could affect the sclerotome in a non-autonomous manner, affecting rib formation.

In conclusion, Meis 1/2 double KO presented defects in several factors expressed in the inter-limb region that could explain the rib phenotype. Meis factors could be acting early, together with Six and Eya factors in the induction of the myotomal program through Pax3. This hypothesis is supported by ChIP seq data (Delgado and Torres, unpublished) that show several Meis binding sites in the Pax3 locus in E10.5 embryos and limb buds (Fig. 28).

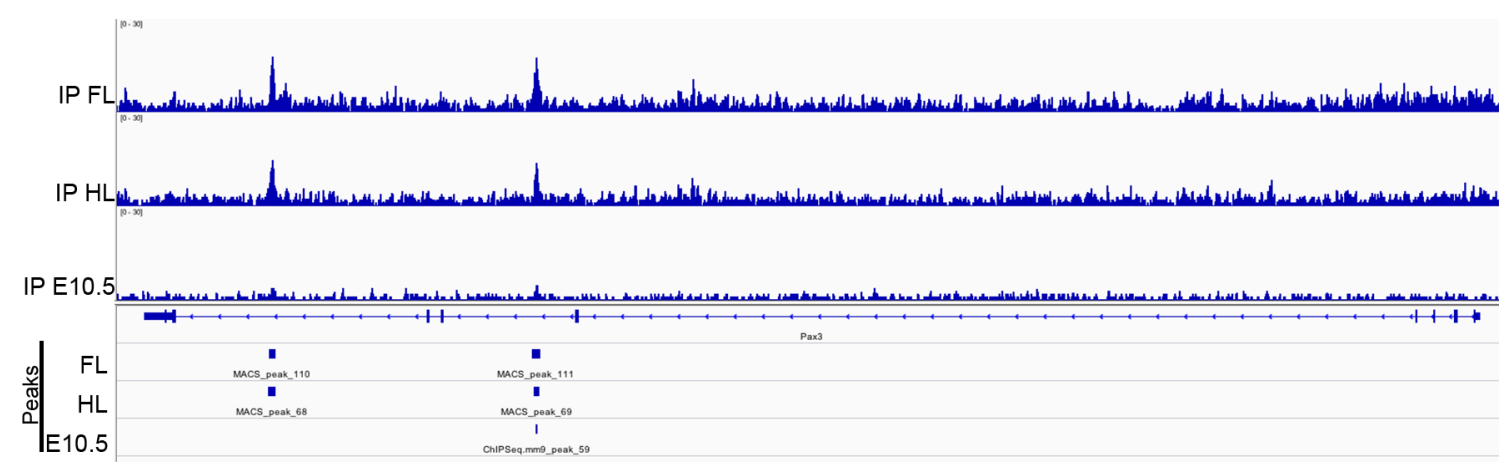

Figure 28: Meis binding sites in Pax3 locus from ChIP-seq experiments of FL, HL and E10.5 embryos (Delgado and Torres, unpublished). 
Apart from the defects observed in the inter-limb region, the anterior region of the embryo, comprising occipital, cervical and forelimb-level somites, presents altered expression of most of the factors studied here, including all the myogenic regulatory factors but also the dermomyotomal marker $\operatorname{Pax} 3$, and the sclerotomal marker $\operatorname{Pax} 9$. This altered expression in the anterior region may be related to the defects in the occipital and cervical vertebrae.

Altered expression of genes involved in cell adhesion was also detected, including $C d h 15$, integrins Itga 8 and Itga 9 and the actin cytoskeleton organizer Palld. We have checked Cdh15, which was upregulated in RNAseq and this upregulation probably comes from the ectopic patches observed by in situ hybridization in the anterior region. However, integrins and Palld appeared downregulated and by in situ hybridization we observed a strong reduction in the expression of Palld in the interlimb and anterior region. In previous works, Palld function has been related with cell adhesion and cell migration (Liu et al. 2007a; Liu et al. 2007b), which might be related to an inability of differentiating somites to maintain their structural organization or to migrate properly, producing the defects observed in the vertebrae and ribs.

\section{Involvement of Meis in retinoic acid metabolism}

Raldh2 mRNA distribution was found severely altered in Meis mutant embryos. This reduced expression of Raldh2 is in accordance with RNA-seq data in which both Raldh2 and Cyp26b1; the main regulators of embryonic RA levels, are downregulated. Although Cyp26b1 and Raldh2 have antagonistic functions on RA abundance, both genes appeared downregulated. It has been shown that Cyp26 is a RA-activated gene in vitro (Ray et al. 1997) and in vivo (Fujii et al. 1997). Thus, RA level-dependent regulation of Cyp26b1 could occur in Meis mutants, so that low levels of RA would be responsible for Cyp26b1 low levels. Raldh2 downregulation could thus be the primary event and the reduction in RA could secondarily lead to a downregulation of Cyp $26 b 1$.

On the other hand, Cyp26 mutants (Sakai et al. 2001) present axial skeletal defects, the most striking of which is the caudal truncation due to the action of excess RA on the posterior region where axial progenitors reside, but interestingly, these mice also present posterior homeotic transformations in the cervical region such, as fusions between the exoccipital and the first cervical vertebrae, and posteriorization of the rest of the cervical vertebrae (Sakai et al. 2001). These alterations considered to be the result of a RA excess are opposite to those observed here for Meis mutants. On the other hand, Raldh2 knockout mice die around E10.5 from an impairment in RA synthesis (Niederreither et al. 
1999), so it has not been described if the absence of RA produces homeotic transformations in constitutive mutants. We have generated a Raldh 2 conditional knockout using the Dll1Cre driver and found homeotic transformations affecting the occipital and cervical region, and additional patterning defects in the skeletal elements of the thoracic region. Transformations in Dll1Cre;Raldh2 $2^{-/}$mutants are observed at a low frequency; one possible explanation is the mosaicism observed in the recombination of DlllCre, together with the diffusible properties of RA, which could lead to cell non-autonomous phenotypic rescue in many specimens. The fusion of the basioccipital to the aaa, the transformation of $\mathrm{C} 2$ to an atlas identity, the presence of the tuberculi anterior in $\mathrm{C} 7$, the fusion of the first rib to the second, and the presence of 8 sternal ribs instead of 7 are defects found in Dll1Cre;Raldh2 $2^{-/}$similar to those found in Meis mutants. In addition, similar defects are observed in $R A R$ mutants, which, in addition, show rib fusions and sternum defects similar to those observed in Meis mutants (Lohnes et al. 1994). $R A R \gamma$ mutants, and in a very low frequency $R A R \alpha$ mutants, show homeotic transformations in isolation (Kastner et al 1995; Luo et al. 1995; Lohnes et al. 1994; Lohnes et al. 1993), while the frequency of the defects is increased in compound mutants of the three isoforms of $R A R: \alpha, \beta$ and $\gamma$ (Kastner et al. 1995; Lohnes et al. 1994). $R A R \gamma$ is expressed in the regressing PS at E8 and in the sclerotome-derived precartilage of the prevertebrae at E12.5 (Ruberte et al. 1990); so, it stands as a candidate to convey RA signaling during vertebral patterning. In addition, a synergistic interaction exists between RAR $\gamma$ and either Cdx (Allan et al. 2001) or Hoxd4 (Folberg et al. 1999) and in both compound mutants, the phenotype was more severe than in the single $R A R \gamma$ mutant, but always affecting the occipito-cervical region. In these works, the expression of Hoxd4 in $R A R \gamma^{-/}$(Folberg et al. 1999) and $R A R \gamma^{-/-} ; C d x 1^{-/}$mutants was unchanged (Allan et al. 2001). These studies suggested the possibility that both $R A R \gamma^{-/}$and $C d x 1^{-/}$genes were involved in the same genetic pathways regulating the same targets genes in parallel to and without affecting Hox gene expression. This conclusion however is in conflict with the observation that several conditions in which $C d x$ genes are mutated show clear alterations of Hox expression domains (van den Akker et al. 2002). Although it has been shown that Hox genes respond to increased RA and this induction could be mediated by RARs (Folberg et al. 1997; Marshall et al. 1996), $R A R \gamma$ and $R A R \beta$ loss of function mutants show anterior transformations but do not show changes in Hox expression patterns (Folberg et al. 1999a, b). Even though the analysis of Hox expression in $R A R$ mutants is not comprehensive in the literature and it has not been determined in compound mutants (Dollé, 2009; Kastner et al. 1995; Lohnes et al. 1994), the data so far available thus indicate similar phenotypic alterations and similar absence of Hox expression changes in RA-pathway mutants and Meis mutants. 
On the other hand, Kessel and Gruss (1991) performed in vivo treatments with RA during mouse gestation and obtained anterior or posterior homeotic transformations depending on the stage of the treatment. They correlate these homeotic transformations with shifts in the boundary of expression of Hox genes and in fact proposed a Hox code whereby specific combinations of Hox factors specify vertebral identity. Anterior transformations with concomitant Hox expression changes were observed following treatments at E7.5, however, RA treatment at E10.5 produced posterior transformations in the cervical region, without altering the Hox expression code (Kessel, 1992). These observations led Kessel (1992) to suggest two phases sensitive to RA in vertebral column development. In the first phase, during gastrulation, RA would alter Hox expression to promote anterior transformations, while in a later stage, RA could alter the AP-specific differentiation programs to promote posterior transformations without altering Hox expression.

Although most of the alterations found in the basioccipital, cervical and thoracic regions of mutants of the RA pathway were similar to those observed in Meis mutants, other alterations appear to be RA-specific phenotypes independent of Meis function, like the posteriorization of the tuberculi anterior and the presence of eight sternal ribs instead of seven in DlllCre;Raldh2 ${ }^{-/}$and $R A R \gamma^{-/}$mutants and after RA treatment.

The similarities in skeletal transformations between Raldh2 and Meis mutants and the downregulation of Raldh2 in Meis mutants suggest a functional regulatory relationship. Our results suggest a positive regulation of Raldh2 by Meis and this result was confirmed by the immunostaining of Raldh2 and Meis in the mosaically deleted Dll1Cre;Meis $1^{-/-}$ ;Meis $2^{-/}$embryos, in which the regions lacking Meis are fail to express Raldh2 protein. On the other hand, Raldh2 is a Meis target in the hindbrain (Vitobello et al. 2018) and human neuroblastoma cells (Groß et al. 2018). Provided RA activates Meis in the limb bud and P19 cells (Yashiro et al 2004; Mercader et al. 2000; Oulad-Abdelghani et al. 1997) one possibility is that a positive feedback loop exists between Raldh2 and Meis. In fact, Meis could affect RA metabolism at various levels, as it represses Cyp26b1 during limb development in a cell-autonomous manner (Roselló-Díez et al. 2014).

To understand how and when Meis regulates Raldh2, we performed in situ hybridization of Raldh2 at early stages and we observed that Raldh2 activation occurs slightly later than Meis expression and strikingly we observed a very early expression in the lateral region of the embryo, very similar to the expression observed for Meis 1 mRNA. At a later stage, a posterior mesodermal Raldh2 expression appears (Niederreither et al., 1997) that is similar to Meis2 expression pattern. Raldh2 could therefore be activated initially 
by Meis 1 in the lateral mesoderm (putative cardiogenic region) and then by Meis 2 in the posterior mesoderm. While the earliest Raldh2 expression in the lateral mesoderm of E7.5 embryo was not found in the Meis double-zygotic knockouts (zMeisDKO), the main expression domain in the posterior mesoderm was unaffected in E8-8.5 embryos. These results suggest that the early lateral expression of Raldh2 could be Meis1-dependent but the posterior expression relies on Meis-independent mechanism. Our results thus suggest that Meis is not generally required for Raldh2 expression but this relationship is context dependent. The requirement of Meis activity for Raldh2 transcription in the paraxial mesoderm therefore seems to be restricted to the differentiation stages but does not apply to the nascent or segmenting mesoderm. The affection of RA synthesis only at differentiation stages and the observed Hox-expression independent anterior transformations in the occipital-cervical area match well with the reported Hox-independent cervical posterior transformations following RA administration at E10.5 (Kessel 1992).

Meis regulation of Raldh2 transcription could be direct; in fact, Hox, Pbx and Meis2 bind an enhancer in the Raldh2 locus thereby regulating Raldh2 transcription directly in the hindbrain (Vitobello et al. 2011). This result agrees with ChIP-seq studies performed in E10.5 whole embryos and E10.5 limb buds, which showed Meis binding sites in the Raldh2 locus (Fig. 29) (Delgado and Torres, unpublished). In similarity to our findings, Vitobello et al. (2011) also reported that Pbx1/2 null embryos did not present altered expression of Raldh2 at early stages; however, from E8.75 Raldh2 levels start to decrease and at E9.0-E10.0 the expression is strongly downregulated in the somitic mesoderm. Raldh2 expression could be dependent on Meis and $\mathrm{Pbx}$ at later stages but not in the early development of the somitic mesoderm. In fact, axial skeletal defects similar to those observed in Meis and Raldh2 mutants have been described for Pbxl and compound Pbx1-2

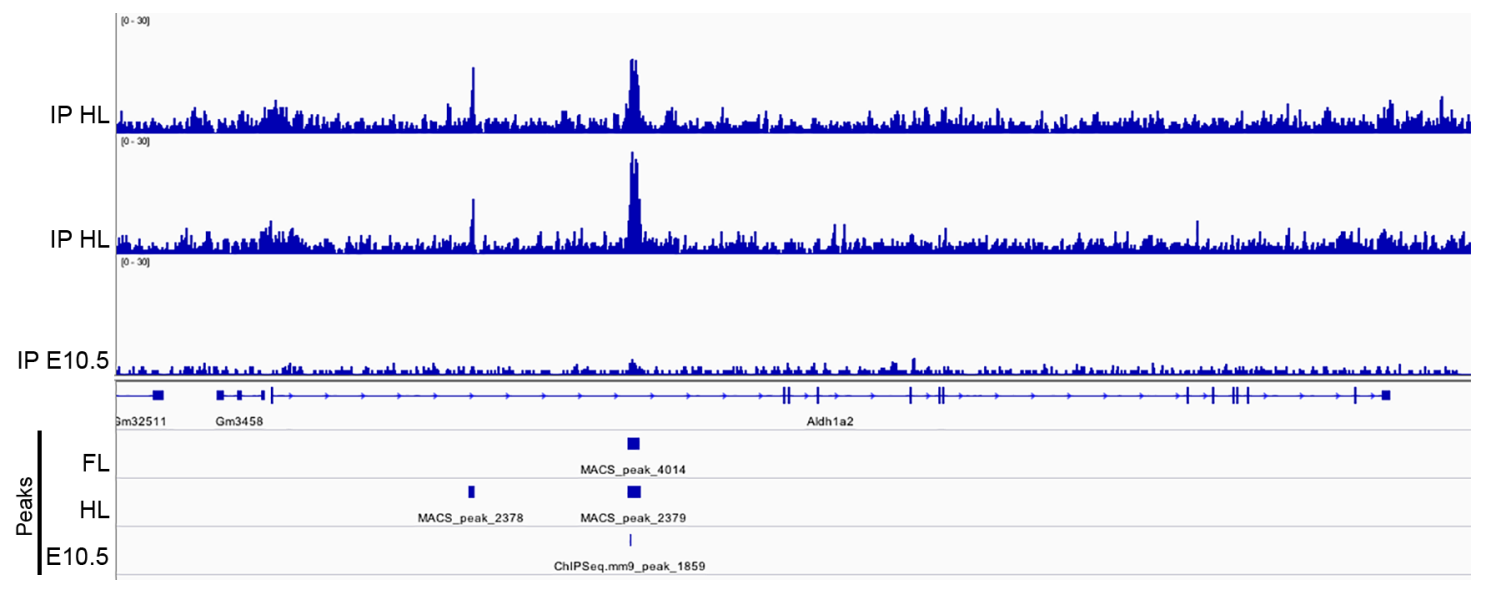

Figure 29: Meis binding sites in Raldh2 locus from ChIP-seq experiments of FL, HL and E10.5 embryos (Delgado and Torres, unpublished). 
deficient mice, such as abnormalities in the occipital region, loss of identity in cervical vertebrae, distal shortening of the ribs and rib fusions (Capellini et al. 2008; Selleri et al. 2001).

Our results thus support a role of Meis as a cofactor of Pbx and Hox transcription factors, which would alter axial skeletal identity by modifying Hox protein activity, without altering Hox expression. In addition, Meis alone or in combination with $\mathrm{Pbx}$ and/or Hox transcription factors may regulate RA synthesis through directly controlling Raldh2 transcription during the differentiation phase. How RA levels change AP skeletal identities without altering Hox expression at this stage remains unknown, however, the similarities observed between Meis and RA-pathway mutants suggest they act in close cooperation. One interesting possibility is that a positive feedback loop exists between Meis and RA, so that alterations in RA levels impact on Hox functions exclusively by modifying the availability of Meis proteins for interaction with Hox proteins.

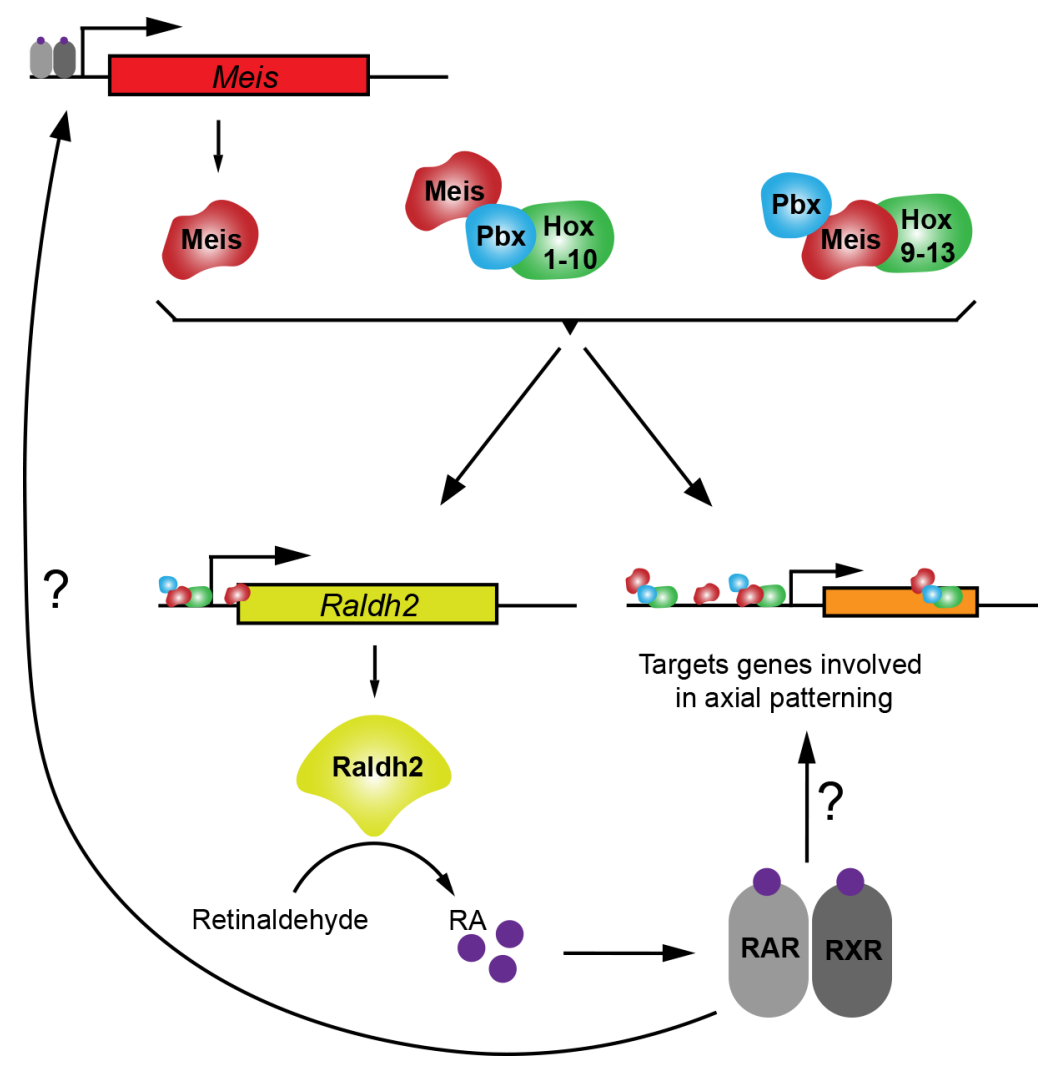

Figure 30: Proposed model of the role of Meis in axial specification as cofactor of Hox and Pbx. These factors regulate targets genes involve in axial patterning, and this regulation could be mediated by RA produced by Raldh2. Likewise, Meis is involved in direct regulation of Raldh2 expression. RA, retinoic acid; RAR, retinoic acid receptor; $\mathrm{RXR}$, retinoid $\mathrm{X}$ receptor. 


\section{Conclusions}



1- Meis1 and Meis2 present divergent expression patterns during their earliest activation in the mouse embryo with Meis 2 transcription appearing in the posterior epiblast and nascent mesoderm and Meis 1 in lateral mesoderm. Around the onset of somitogenesis both patterns converge.

2- Meis2 loss of function leads to anterior transformations of axial skeletal elements in the occipital to anterior lumbar regions.

3- Compound Meis 1 and Meis2 loss of function mutants exhibit stronger axial defects, showing a cooperation between Meis1 and Meis2 functions in axial patterning.

4- The early expression of Meis 2 in the epiblast and nascent mesoderm does not play a detectable role in anteroposterior axis identity specification.

5- Meis roles in axial patterning do not involve transcriptional regulation of Hox genes.

6- Raldh2 loss of function produces skeletal defects at occipital and cervical levels that partially match those observed in Meis mutants.

7- Raldh2 is a target of Meis during axial development, possibly through a direct transcriptional regulation.

8- Meis function is required for a molecular program involved in hypaxial myotomal development, which could underlie the defects observed in rib distal patterning. 

1- Meis1 y Meis2 presentan diferentes patrones de expresión durante su activación temprana en el embrión de ratón empezando la transcripción de Meis 2 en la zona posterior del epiblasto y el mesodermo temprano mientras que Meis 1 comienza en el mesodermo lateral. Al comienzo de la somitogénesis ambos patrones convergen.

2- La pérdida de función de Meis2 lleva a la aparición de transformaciones homeóticas anteriores en el esqueleto axial desde la región occipital a la lumbar.

3- Mutantes con pérdida de función de Meis1 y Meis2 muestran defectos axiales más severos que los mutantes simples de sendos genes mostrando una cooperación entre las funciones de Meis1 y Meis2 en el patrón axial.

4- La expresión temprana de Meis 2 en el epiblasto y en el mesodermo temprano no tienen un papel en la especificación de la identidad anteroposterior del eje axial.

5- El papel de Meis en el patrón axial no está implicado en la regulación transcripcional de los genes Hox.

6- La pérdidad de función de Raldh2 produce defectos esqueléticos en la región occipital y cervical que parcialmente coinciden con los observados en los mutantes de Meis.

7- Raldh2 es una diana de Meis durante el desarrollo axial, posiblemente mediante una regulación transcripcional directa.

8- La función de Meis es necesaria para el desarrollo del miotomo hypaxial, que podría ser responsable de los defectos observados en el patrón distal de las costillas. 

Supplementary Material 



\begin{tabular}{|c|c|c|c|}
\hline Phenotypes & Sox2Cre;M2ckO & Mesp1Cre;M2cKO & DIl1Cre;M2cKO \\
\hline \multicolumn{4}{|l|}{ Abnormalities cervical vertebra } \\
\hline C1 fused to E unilateral & 1 & 3 & 1 \\
\hline C1 fused to E bilateral & 13 & 3 & 0 \\
\hline C1 NA approaching E unilateral & 0 & 2 & 1 \\
\hline C1 NA approaching E bilateral & 0 & 1 & 3 \\
\hline C2 with C1-like morphology unilateral & 2 & 2 & 0 \\
\hline C2 with C1-like morphology bilateral & 11 & 3 & 4 \\
\hline C3 with C2-like morphology unilateral & 1 & 0 & 0 \\
\hline C3 with C2-like morphology bilateral & 1 & 0 & 0 \\
\hline 6 cervical vertebra or less & 0 & 2 & 0 \\
\hline Other abnormalities * & 10 & 4 & 3 \\
\hline \multicolumn{4}{|l|}{ Rib defects } \\
\hline R1 short unilateral & 3 & 0 & 0 \\
\hline R1 short bilateral & 5 & 0 & 3 \\
\hline R1 short and fused R2 unilateral & 4 & 0 & 1 \\
\hline R1 fused R2 unilateral & 0 & 0 & 0 \\
\hline R1 fused R2 bilateral & 1 & 0 & 0 \\
\hline R13 short & 6 & 1 & 2 \\
\hline Other rib fusions/splits & 5 & 2 & 3 \\
\hline T14 little rib & 4 & 1 & 0 \\
\hline R7/7 unilateral & 0 & 1 & 0 \\
\hline R6/7 unilateral & 1 & 0 & 2 \\
\hline R6/7 bilateral & 2 & 0 & 2 \\
\hline Sternum defects & 5 & 1 & 0 \\
\hline № of embryos & 14 & 9 & 4 \\
\hline
\end{tabular}

Supplementary Table 1: Skeletal defects of Meis $2^{-/}$with Sox2Cre, Mesp1Cre and DlllCre. E, exoccipital; $\mathrm{C}$, cervical vertebra; $\mathrm{R}$, rib; $\mathrm{T}$, thoracic vertebra.

* Includes cervical vertebra misshapen, split neural arches, extra-elements in the cervical region and mismatch in the posterior arch. 


\begin{tabular}{|c|c|c|c|c|c|c|c|c|c|c|}
\hline \multirow[b]{2}{*}{ Phenotypes } & \multicolumn{7}{|c|}{ DIl1; Meis1; Meis2 } & \multicolumn{3}{|c|}{ DII1; Raldh2 } \\
\hline & \multicolumn{2}{|c|}{ М1ком2Ко М1НтМ2ко } & \multicolumn{2}{|c|}{ М1ком2НТ М1нтМ2НT } & \multirow[t]{2}{*}{ М1ко } & \multirow[t]{2}{*}{ М2Ко } & \multirow[t]{2}{*}{ CONTROL } & \multirow[t]{2}{*}{ ко } & \multirow[t]{2}{*}{ HT } & \multirow[t]{2}{*}{ CONTROL } \\
\hline Abnormalities occipital bones & & & & & & & & & & \\
\hline Basioccipital & $0(3)$ & $7(11)$ & $1(4)$ & $0(2)$ & $0(3)$ & $4(4)$ & $0(23)$ & $14(43)$ & $0(8)$ & $5(39)$ \\
\hline $\mathrm{B}$ fused to aaa & & $6(7)$ & $1(1)$ & & & $1(4)$ & & 7 (14) & & $4(5)$ \\
\hline Supraoccipital & $3(3)$ & $7(11)$ & $3(4)$ & $0(2)$ & $1(3)$ & $4(4)$ & $0(23)$ & $2(25)$ & $0(8)$ & $4(33)$ \\
\hline Exoccipital & 7 & 5 & 0 & 0 & 0 & 0 & 0 & 3 & 0 & 0 \\
\hline \multicolumn{11}{|l|}{ Abnormalities vertebra1 } \\
\hline C1 NA short unilateral & 0 & 0 & 1 & 0 & 0 & 0 & 0 & 5 & 0 & 0 \\
\hline C1 NA short bilateral & 1 & 1 & 0 & 0 & 0 & 3 & 0 & 2 & 0 & 0 \\
\hline $\mathrm{C} 1$ short and fused to $\mathrm{E}$ unilateral & 10 & 4 & 0 & 0 & 0 & 1 & 0 & 1 & 0 & 0 \\
\hline$C 1$ fused to $E$ unilateral & 0 & 0 & 0 & 0 & 0 & 0 & 0 & 2 & 0 & 0 \\
\hline C1 fused to $E$ biilateral & 6 & 7 & 0 & 0 & 0 & 0 & 0 & 3 & 0 & 0 \\
\hline C1 NA approaching E unilateral & 0 & 4 & 0 & 0 & 0 & 1 & 0 & 2 & & \\
\hline C1 NA approaching E bilateral & 1 & 0 & 0 & 0 & 0 & 3 & 0 & 0 & & \\
\hline \multicolumn{11}{|l|}{ Abnormalities vertebra2 } \\
\hline $\mathrm{C} 2$ fused to $\mathrm{C} 1$ unilateral & 1 & 0 & 0 & 0 & 0 & 0 & 0 & 8 & 0 & 2 \\
\hline $\mathrm{C} 2$ fused to $\mathrm{C} 1$ bilateral & 1 & 0 & 0 & 0 & 0 & 0 & 0 & 1 & 0 & 0 \\
\hline $\mathrm{C} 2$ fused to $\mathrm{C} 3$ unilateral & 1 & 3 & 1 & 0 & 0 & 0 & 0 & 10 & 0 & 1 \\
\hline C2 fused to C3 bilateral & 0 & 0 & 0 & 0 & 0 & 0 & 0 & 1 & 0 & 0 \\
\hline Forming aaa & $1(3)$ & $4(11)$ & $1(4)$ & $0(2)$ & $1(3)$ & $3(4)$ & $0(23)$ & $14(41)$ & $0(8)$ & $0(38)$ \\
\hline C1-like morphology unilateral & 1 & 3 & 0 & 0 & 0 & 0 & 0 & 2 & 0 & 0 \\
\hline C1-like morphology bilateral & 1 & 9 & 0 & 0 & 0 & 4 & 0 & 6 & 0 & 0 \\
\hline \multicolumn{11}{|l|}{ Abnormalities cervical vertebra } \\
\hline Fusions & 6 & 4 & 1 & 1 & 2 & 0 & 0 & 10 & 0 & 0 \\
\hline Other* & 3 & 16 & 6 & 1 & 1 & 3 & 2 & 12 & 1 & 2 \\
\hline \multicolumn{11}{|l|}{ Tuberculi anterior } \\
\hline Absence of Tuberculi anterior & $0(3)$ & $1(11)$ & $0(4)$ & $0(2)$ & $0(3)$ & $0(4)$ & $0(23)$ & $1(21)$ & $0(8)$ & $0(25)$ \\
\hline Vb 6 y 7 unilateral & $0(3)$ & $0(11)$ & $0(4)$ & $0(2)$ & $0(3)$ & $0(4)$ & $0(23)$ & $4(21)$ & $0(8)$ & $2(25)$ \\
\hline Vb 7 bilateral & $0(3)$ & $0(11)$ & $0(4)$ & $0(2)$ & $0(3)$ & $0(4)$ & $0(23)$ & $1(21)$ & $0(8)$ & $0(25)$ \\
\hline \multicolumn{11}{|l|}{ Rib defects } \\
\hline R1 short unilateral & 0 & 0 & 0 & 0 & 0 & 0 & 0 & 2 & 0 & 0 \\
\hline R1 short bilateral & 2 & 8 & 5 & 0 & 0 & 3 & 0 & 0 & 0 & 0 \\
\hline R1 short and fused R2 unilateral & 1 & 5 & 2 & 0 & 0 & 1 & 0 & 2 & 0 & 0 \\
\hline R1 fused R2 unilateral & 0 & 0 & 0 & 0 & 0 & 0 & 0 & 0 & 0 & 0 \\
\hline R1 fused R2 bilateral & 0 & 0 & 0 & 0 & 0 & 0 & 0 & 5 & 0 & 1 \\
\hline Other rib fusions/splits & 5 & 7 & 6 & 0 & 2 & 3 & 0 & 7 & 0 & 0 \\
\hline Not reaching sternum & 4 & 8 & 5 & 0 & 1 & 2 & 0 & 4 & 0 & 0 \\
\hline R8/5 unilateral & & & & & & & & 7 & 0 & 5 \\
\hline $\mathrm{R} 8 / 5$ bilateral & & & & & & & & 8 & 1 & 9 \\
\hline R6/7 unilateral & 0 & 3 & 1 & 0 & 1 & 2 & 4 & 1 & 0 & 0 \\
\hline R6/7 bilateral & 0 & 2 & 2 & 1 & 0 & 2 & 0 & 0 & 0 & 0 \\
\hline T14 little rib & 0 & 2 & 0 & 0 & 0 & 0 & 1 & 5 & 0 & 2 \\
\hline Sternum defects & 5 & 2 & 0 & 1 & 0 & 0 & 0 & 1 & 0 & 0 \\
\hline \multicolumn{11}{|l|}{ Limb defects } \\
\hline $\mathrm{FL}$ & 4 & 1 & 5 & 0 & 0 & 0 & 0 & & & \\
\hline $\mathrm{HL}$ & 6 & 11 & 10 & 0 & 0 & 0 & 0 & & & \\
\hline & & & & & & & & & & \\
\hline № of embryos & 7 & 22 & 12 & 8 & 4 & 4 & 46 & 49 & 15 & 42 \\
\hline
\end{tabular}

Supplementary Table 2: Skeletal defects of Meis and Raldh2 mutants with Dll1Cre. $\mathrm{B}$, basioccipital; aaa, anterior arch of the atlas; E, exoccipital; C, cervical vertebra; R, rib.

* Includes cervical vertebra misshapen, split, extra-elements in the cervical region and mismatch in the posterior arch.

( ) Number of embryos is indicated in parenthesis when it is different from the total. 


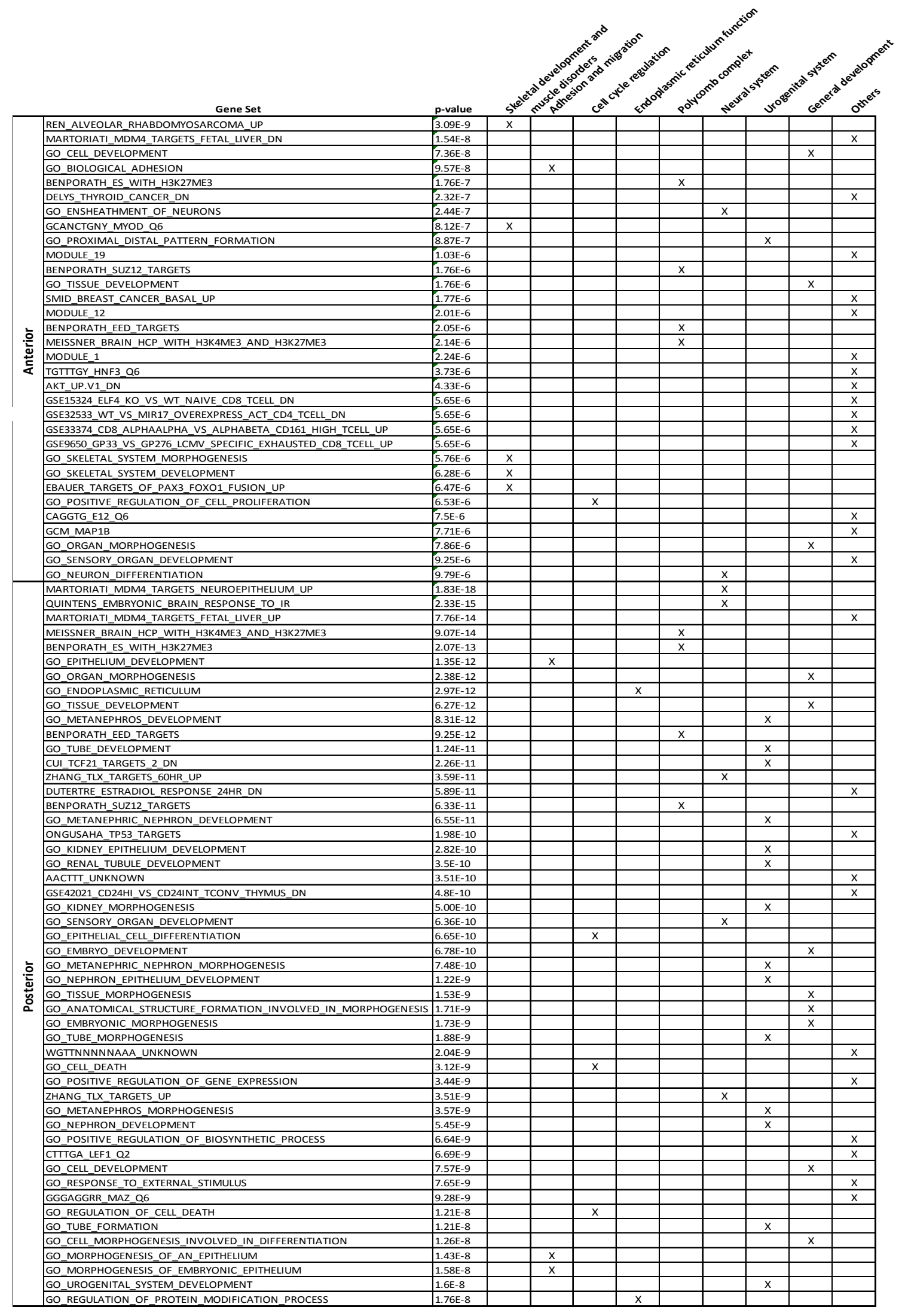

Supplementary Table 3: Skeletal Gene Set Enrichment Analysis of the genes differentially expressed ( $p$-value $\leq 0.05$ ). 


\begin{tabular}{|c|c|c|c|c|c|c|c|c|c|c|c|}
\hline \multicolumn{4}{|c|}{ Anterior } & \multicolumn{4}{|c|}{ Posterior } & \multicolumn{4}{|c|}{ Posterior } \\
\hline mgi_symbol & adj.P.Val & foldChange & $\log \mathrm{FC}$ & mgi_symbol & adj.P.Val & foldChange & $\log \mathrm{FC}$ & mgi_symbol & adj.P.Val & foldChange & $\log \mathrm{FC}$ \\
\hline 4930481B07Rik & 0.0001 & 6.7453 & 2.7539 & 4930481B07Rik & 0.0002 & 5.0125 & 2.3255 & Tmed9 & 0.0253 & -1.1699 & -0.2264 \\
\hline Eya2 & 0.0069 & -1.8355 & -0.8762 & A930024N18Rik & 0.0002 & -8.5291 & -3.0924 & Ephb1 & 0.0253 & 1.5618 & 0.6432 \\
\hline Bnc1 & 0.0069 & 3.2875 & 1.7170 & Slitrk6 & 0.0010 & 3.2674 & 1.7081 & Tspan7 & 0.0275 & -1.2069 & -0.2713 \\
\hline S1pr3 & 0.0069 & 1.5321 & 0.6155 & Sesn2 & 0.0012 & -1.5746 & -0.6550 & Hen4 & 0.0281 & 1.8459 & 0.8843 \\
\hline Pgm5 & 0.0069 & 3.6710 & 1.8762 & Cdkn1a & 0.0020 & -2.0538 & -1.0383 & Gper1 & 0.0286 & -2.4910 & -1.3167 \\
\hline Pdgfra & 0.0077 & 1.8002 & 0.8482 & Pax2 & 0.0053 & 2.2434 & 1.1657 & Yjefn3 & 0.0297 & -1.9689 & -0.9774 \\
\hline Hes5 & 0.0077 & -1.5830 & -0.6627 & $\mathrm{H} 2-\mathrm{K} 1$ & 0.0063 & -1.6437 & -0.7169 & Ppib & 0.0297 & -1.2476 & -0.3191 \\
\hline LgalsI & 0.0100 & 1.3074 & 0.3867 & Alx1 & 0.0074 & 4.1973 & 2.0695 & Sap25 & 0.0297 & -1.9857 & -0.9897 \\
\hline Rian & 0.0100 & 1.3051 & 0.3842 & Meis2 & 0.0093 & 1.4244 & 0.5103 & Ank3 & 0.0303 & 1.2353 & 0.3049 \\
\hline Ncam1 & 0.0101 & -1.2851 & -0.3619 & Tap1 & 0.0093 & -2.6088 & -1.3834 & Erp29 & 0.0303 & -1.3263 & -0.4074 \\
\hline Chrnb1 & 0.0109 & -2.2738 & -1.1851 & Fam212b & 0.0114 & -3.6617 & -1.8725 & Ppp1r1a & 0.0303 & -1.4328 & -0.5189 \\
\hline Peg3 & 0.0192 & 1.6741 & 0.7434 & Lyst & 0.0114 & 1.6360 & 0.7102 & Dse & 0.0303 & 1.2592 & 0.3325 \\
\hline Tmem252 & 0.0192 & 3.3147 & 1.7289 & SIc27a4 & 0.0114 & -1.3314 & -0.4130 & Meox1 & 0.0303 & 1.5609 & 0.6424 \\
\hline Alpk2 & 0.0192 & -1.7307 & -0.7913 & Azin2 & 0.0114 & -1.5831 & -0.6627 & Eya1 & 0.0309 & 1.2448 & 0.3159 \\
\hline Gm36958 & 0.0194 & 1.8586 & 0.8942 & Sim1 & 0.0147 & 2.4444 & 1.2895 & Lpp & 0.0309 & 1.2308 & 0.2996 \\
\hline Epb41/3 & 0.0239 & 1.5279 & 0.6115 & Slfng & 0.0159 & 1.4661 & 0.5520 & Rab3gap1 & 0.0309 & -1.1838 & -0.2435 \\
\hline Nab1 & 0.0239 & 1.5069 & 0.5916 & Bsg & 0.0178 & -1.2321 & -0.3011 & Rspo1 & 0.0309 & 1.6853 & 0.7530 \\
\hline Mecom & 0.0239 & 1.7547 & 0.8112 & Wt1 & 0.0192 & 4.6931 & 2.2305 & Gdnf & 0.0309 & -1.6105 & -0.6875 \\
\hline Сур26b1 & 0.0239 & 2.0444 & 1.0316 & Lgalsl & 0.0211 & 1.2612 & 0.3348 & Shisa3 & 0.0309 & 2.0362 & 1.0259 \\
\hline Shisa3 & 0.0239 & 3.2871 & 1.7168 & Sh3kbp1 & 0.0211 & 1.3502 & 0.4332 & Shroom3 & 0.0309 & 1.3332 & 0.4149 \\
\hline Aldh1a2 & 0.0250 & 1.9680 & 0.9768 & Pltp & 0.0211 & -1.3852 & -0.4701 & Tmem97 & 0.0309 & -1.2073 & -0.2718 \\
\hline Cdh15 & 0.0250 & -1.6563 & -0.7279 & Gm14226 & 0.0211 & 2.6778 & 1.4210 & Zfp937 & 0.0313 & 1.5519 & 0.6341 \\
\hline Nr1h5 & 0.0269 & -32.5832 & -5.0261 & Nr1h5 & 0.0211 & -29.6678 & -4.8908 & Sdf4 & 0.0323 & -1.1443 & -0.1945 \\
\hline Gpc1 & 0.0269 & -1.2052 & -0.2693 & Hes5 & 0.0211 & -1.6201 & -0.6961 & Foxd2os & 0.0328 & 1.7263 & 0.7877 \\
\hline Ptprk & 0.0316 & 1.2856 & 0.3625 & Ddit4I & 0.0211 & -1.8141 & -0.8592 & Rpn2 & 0.0339 & -1.1410 & -0.1904 \\
\hline Meis2 & 0.0332 & 1.3301 & 0.4116 & Dexr & 0.0211 & -1.6248 & -0.7003 & Trp53inp1 & 0.0339 & -1.7201 & -0.7825 \\
\hline Lyve1 & 0.0332 & 6.2079 & 2.6341 & Foxd2 & 0.0211 & 1.9513 & 0.9644 & Rxfp3 & 0.0339 & 8.4743 & 3.0831 \\
\hline Enox1 & 0.0332 & 1.5411 & 0.6240 & Runx1t1 & 0.0211 & 1.9822 & 0.9871 & Prkce & 0.0339 & 1.3600 & 0.4436 \\
\hline 2610016A17Rik & 0.0332 & 2.9555 & 1.5634 & Qrfpr & 0.0211 & -2.9556 & -1.5635 & Mecom & 0.0356 & 1.6591 & 0.7304 \\
\hline Sim1 & 0.0338 & 2.2725 & 1.1843 & Cpt1c & 0.0211 & -1.3554 & -0.4387 & Gm21992 & 0.0356 & -1.3281 & -0.4093 \\
\hline Usp29 & 0.0340 & 1.6373 & 0.7113 & Mvk & 0.0211 & -1.3077 & -0.3870 & Cst3 & 0.0356 & -1.2561 & -0.3289 \\
\hline Pappa2 & 0.0384 & 2.5186 & 1.3326 & Ptn & 0.0211 & -1.2671 & -0.3415 & Med14 & 0.0356 & 1.2274 & 0.2957 \\
\hline Ppp1r16b & 0.0434 & -1.4897 & -0.5751 & Cd63 & 0.0211 & -1.2370 & -0.3069 & Mkrn1 & 0.0385 & -1.2083 & -0.2730 \\
\hline \multirow[t]{25}{*}{ Pde9a } & 0.0483 & 1.8997 & 0.9258 & Igfbp3 & 0.0211 & -1.2962 & -0.3743 & Atg 4d & 0.0402 & -1.2613 & -0.3349 \\
\hline & & & & Peg3 & 0.0211 & 1.5845 & 0.6640 & Spon2 & 0.0402 & -1.7217 & -0.7839 \\
\hline & & & & Thoc6 & 0.0211 & -1.2079 & -0.2725 & Mgat5 & 0.0402 & 1.3599 & 0.4435 \\
\hline & & & & Zfp442 & 0.0211 & 1.7247 & 0.7864 & B930095G15Rik & 0.0422 & 1.5589 & 0.6405 \\
\hline & & & & Irx1 & 0.0217 & -1.3614 & -0.4451 & Ergic3 & 0.0422 & -1.1989 & -0.2617 \\
\hline & & & & Klhl14 & 0.0217 & 2.1444 & 1.1006 & Ptprv & 0.0422 & -3.1391 & -1.6503 \\
\hline & & & & Cong1 & 0.0217 & -1.5644 & -0.6456 & KIhdc10 & 0.0433 & 1.2037 & 0.2675 \\
\hline & & & & Shisa2 & 0.0217 & 1.5505 & 0.6327 & Fzd1 & 0.0433 & 1.4349 & 0.5209 \\
\hline & & & & Edem3 & 0.0217 & 1.3674 & 0.4514 & Npdc1 & 0.0433 & -1.3471 & -0.4299 \\
\hline & & & & Ctsl & 0.0217 & -1.1780 & -0.2363 & Anapc16 & 0.0441 & -1.2453 & -0.3164 \\
\hline & & & & Ntsr1 & 0.0217 & 5.3250 & 2.4128 & Ly6e & 0.0457 & -1.2359 & -0.3055 \\
\hline & & & & $\mathrm{H} 2-\mathrm{Q} 4$ & 0.0217 & -1.2883 & -0.3655 & $\operatorname{ltg} a 9$ & 0.0457 & 1.4807 & 0.5663 \\
\hline & & & & Gadd45a & 0.0217 & -1.2700 & -0.3448 & Ttc28 & 0.0467 & 1.5072 & 0.5918 \\
\hline & & & & Ebf3 & 0.0223 & 2.0784 & 1.0554 & Asxl3 & 0.0480 & 1.2763 & 0.3520 \\
\hline & & & & Palld & 0.0223 & 1.2101 & 0.2751 & Gm44215 & 0.0481 & -1.2905 & -0.3679 \\
\hline & & & & Arhgef3 & 0.0226 & 1.4920 & 0.5773 & Prex2 & 0.0485 & 1.3374 & 0.4194 \\
\hline & & & & Zfp365 & 0.0226 & -2.3158 & -1.2115 & Ssr4 & 0.0485 & -1.2328 & -0.3019 \\
\hline & & & & Dpf3 & 0.0226 & 1.7468 & 0.8047 & B4galt6 & 0.0485 & 1.2822 & 0.3586 \\
\hline & & & & Fndc3c1 & 0.0230 & 1.2784 & 0.3543 & Nell1 & 0.0485 & 5.1463 & 2.3635 \\
\hline & & & & Sdf2 & 0.0231 & -1.2450 & -0.3162 & Lrig3 & 0.0485 & 1.1854 & 0.2454 \\
\hline & & & & Pappa2 & 0.0244 & 3.8265 & 1.9360 & Phlda3 & 0.0485 & -1.4449 & -0.5309 \\
\hline & & & & Hmcn1 & 0.0252 & 1.5642 & 0.6455 & Ctgf & 0.0488 & -1.6226 & -0.6983 \\
\hline & & & & Lhx1 & 0.0253 & 2.8812 & 1.5267 & Top1 & 0.0488 & 1.1481 & 0.1992 \\
\hline & & & & Pth1r & 0.0253 & -1.3408 & -0.4231 & Itga 8 & 0.0488 & 1.7608 & 0.8162 \\
\hline & & & & KIhdc8a & 0.0253 & 2.5177 & 1.3321 & Tmod4 & 0.0488 & -4.7433 & -2.2459 \\
\hline
\end{tabular}

Supplementary Table 4: RNA-seq data of genes differentially expressed ( $p$-value $\leq 0.05)$ in the anterior and posterior region of E9 Dll1Cre;Meis $1^{-/} ; M_{e i s} 2^{-/}$embryos. 


\section{References}



Ahmed MU, Cheng L, Dietrich S. 2006. Establishment of the epaxial-hypaxial boundary in the avian myotome. Dev Dyn 235: 1884-94.

Akam M. 1989. Hox and HOM: homologous gene clusters in insects and vertebrates. Cell 57: 347-349.

Allan D, Houle M, Bouchard N, Meyer BI, Gruss P, Lohnes D. 2001. RARgamma and Cdx1 interactions in vertebral patterning. Dev Biol 240: 46-60.

Amin S, Donaldson IJ, Zannino DA, Hensman J, Rattray M, Losa M, Spitz F, Ladam F, Sagerström C, Bobola N. 2015. Hoxa2 selectively enhances Meis binding to change a branchial arch ground state. Dev Cell 32: 265-277.

Aulehla A, Pourquié O. 2010. Signaling gradients during paraxial mesoderm development. Cold Spring Harb Perspect Biol 2: a000869.

Azcoitia V, Aracil M, Martínez-A C, Torres M. 2005. The homeodomain protein Meis1 is essential for definitive hematopoiesis and vascular patterning in the mouse embryo. Dev Biol 280: 307-320.

Bagnall KM, Higgins SJ, Sanders EJ. 1988. The contribution made by a single somite to the vertebral column: experimental evidence in support of resegmentation using the chick-quail chimaera model. Development 103: 69-85.

Bertolino E, Reimund B, Wildt-Perinic D, Clerc RG. 1995. A novel homeobox protein which recognizes a TGT core and functionally interferes with a retinoid-responsive motif. J Biol Chem 270: 31178-31188.

Blasi F, Bruckmann C, Penkov D, Dardaei L. 2017. A tale of TALE, PREP1, PBX1, and MEIS1: Interconnections and competition in cancer. Bioessays 39.

Bobola N, Merabet, S. 2017. Homeodomain proteins in action: similar DNA binding preferences, highly variable connectivity. Curr Opin Genet Dev 43: 1-8.

Braun T, Arnold HH. 1995. Inactivation of Myf-6 and Myf-5 genes in mice leads to alterations in skeletal muscle development. EMBO J 14: 1176-86. 
Braun T, Rudnicki MA, Arnold HH, Jaenisch R. 1992. Targeted inactivation of the muscle regulatory gene Myf-5 results in abnormal rib development and perinatal death. Cell 71: 369-382.

Bürglin TR, Affolter M. 2016. Homeodomain proteins: an update. Chromosoma 125: 497-521.

Bürglin TR, Ruvkun G. 1992. New motif in PBX genes. Nat Genet 1: 319-320.

Burke AC, Nelson CE, Morgan BA, Tabin C.1995. Hox genes and the evolution of vertebrate axial morphology. Development 121: 333-346.

Cambray N, Wilson V. 2002. Axial progenitors with extensive potency are localised to the mouse chordoneural hinge. Development 129: 4855-4866.

Capellini TD, Zewdu R, Di Giacomo G, Asciutti S, Kugler JE, Di Gregorio A, Selleri L. 2008. Pbx1/Pbx2 govern axial skeletal development by controlling Polycomb and Hox in mesoderm and Pax1/Pax9 in sclerotome. Dev Biol 321: 500-514.

Carapuço M, Nóvoa A, Bobola N, Mallo M. 2005. Hox genes specify vertebral types in the presomitic mesoderm. Genes Dev 19: 2116-2121.

Cecconi F, Proetzel G, Alvarez-Bolado G, Jay D, Gruss P. 1997. Expression of Meis2, a Knotted-related murine homeobox gene, indicates a role in the differentiation of the forebrain and the somitic mesoderm. Dev Dyn 210: 184-190.

Chambeyron S, Bickmore WA. 2004. Chromatin decondensation and nuclear reorganization of the HoxB locus upon induction of transcription. Genes Dev 18: 1119-1130.

Chan SK, Jaffe L, Capovilla M, Botas J, Mann RS. 1994. The DNA binding specificity of Ultrabithorax is modulated by cooperative interactions with extradenticle, another homeoprotein. Cell 78: 603-615.

Chang CP, Brocchieri L, Shen WF, Largman C, Cleary ML. 1996. Pbx modulation of Hox homeodomain amino-terminal arms establishes different DNA-binding specificities across the Hox locus. Mol Cell Biol 16: 1734-1745. 
Chen F, Capecchi MR. 1997. Targeted mutations in hoxa-9 and hoxb-9 reveal synergistic interactions. Dev Biol 181: 186-196.

Chen H, Rossier C, Nakamura Y, Lynn A, Chakravarti A, Antonarakis SE. 1997. Cloning of a novel homeobox-containing gene, PKNOX1, and mapping to human chromosome 21q22.3. Genomics 41: 193-200.

Chisaka O, Capecchi MR. 1991. Regionally restricted developmental defects resulting from targeted disruption of the mouse homeobox gene hox-1.5. Nature 350: 473-479.

Choe SK, Ladam F, Sagerström CG. 2014. TALE factors poise promoters for activation by Hox proteins. Dev Cell 28: 203-211.

Cinnamon Y, Kahane N, Kalcheim C. 1999. Characterization of the early development of specific hypaxial muscles from the ventrolateral myotome. Development 126: 43054315.

Condie BG, Capecchi MR. 1993. Mice homozygous for a targeted disruption of Hoxd-3 (Hox-4.1) exhibit anterior transformations of the first and second cervical vertebrae, the atlas and the axis. Development 119: 579-595.

Cordes R, Schuster-Gossler K, Serth K, Gossler A. 2004. Specification of vertebral identity is coupled to Notch signalling and the segmentation clock. Development 131: 1221-1233.

de Vries WN, Binns LT, Fancher KS, Dean J, Moore R, Kemler R, Knowles BB. 2000. Expression of Cre recombinase in mouse oocytes: a means to study maternal effect genes. Genesis 26: 110-112.

Deschamps J, Duboule D. 2017. Embryonic timing, axial stem cells, chromatin dynamics, and the Hox clock. Genes Dev 31: 1406-1416.

Deschamps J, van den Akker E, Forlani S, De Graaff W, Oosterveen T, Roelen B, Roelfsema J. 1999. Initiation, establishment and maintenance of Hox gene expression patterns in the mouse. Int J Dev Biol 43: 635-650.

Deschamps J, van Nes J. 2005. Developmental regulation of the Hox genes during axial 
morphogenesis in the mouse. Development 132: 2931-2942.

Deschamps J, Wijgerde M. 1993. Two phases in the establishment of HOX expression domains. Dev biology 156: 473-480.

Dollé P. 2009. Developmental expression of retinoic acid receptors (RARs). Nucl Recpt Signal 7: e006.

Dollé P, Izpisúa-Belmonte JC, Falkenstein H, Renucci A, Duboule D. 1989. Coordinate expression of the murine Hox-5 complex homoeobox-containing genes during limb pattern formation. Nature 342: 767-772.

Duboule D. 2007. The rise and fall of Hox gene clusters. Development 134: 2549-2560.

Dubrulle J, McGrew MJ, Pourquié O. 2001. FGF signaling controls somite boundary position and regulates segmentation clock control of spatiotemporal Hox gene activation. Cell 106: 219-232.

Fognani C, Kilstrup-Nielsen C, Berthelsen J, Ferretti E, Zappavigna V, Blasi F. 2002. Characterization of PREP2, a paralog of PREP1, which defines a novel sub-family of the MEINOX TALE homeodomain transcription factors. Nucleic Acids Res 30: 2043-2051.

Folberg A, Kovács EN, Featherstone MS. 1997. Characterization and retinoic acid responsiveness of the murine Hoxd4 transcription unit. J Biol Chem 272: 29151-29157.

Folberg A, Kovács EN, Huang H, Houle M, Lohnes D, Featherstone MS. 1999a. Hoxd4 and Rarg interact synergistically in the specification of the cervical vertebrae. Mech Dev 89: 65-74.

Folberg A, Nagy Kovács E, Luo J, Giguère V, Featherstone MS. 1999b. RARbeta mediates the response of Hoxd4 and Hoxb4 to exogenous retinoic acid. Dev Dyn 215: 96-107.

Forlani S, Lawson KA, Deschamps J. 2003. Acquisition of Hox codes during gastrulation and axial elongation in the mouse embryo. Development 130: 3807-3819.

Fraidenraich D, Iwahori A, Rudnicki M, Basilico C. 2000. Activation of fgf4 gene ex- 
pression in the myotomes is regulated by myogenic bHLH factors and by sonic hedgehog. Dev Biol 225: 392-406.

Fujii H, Sato T, Kaneko S, Gotoh O, Fujii-Kuriyama Y, Osawa K, Kato S, Hamada H. 1997. Metabolic inactivation of retinoic acid by a novel P450 differentially expressed in developing mouse embryos. EMBO J 16: 4163-4173.

Furushima K, Yamamoto A, Nagano T, Shibata M, Miyachi H, Abe T, Ohshima N, Kiyonari H, Aizawa S. 2007. Mouse homologues of Shisa antagonistic to Wnt and Fgf signalings. Dev Biol 306: 480-492.

Gaunt SJ, Dean W, Sang H, Burton RD. 1999. Evidence that Hoxa expression domains are evolutionarily transposed in spinal ganglia, and are established by forward spreading in paraxial mesoderm. Mech Dev 82: 109-118.

Gaunt SJ, Drage D, Trubshaw RC. 2008. Increased Cdx protein dose effects upon axial patterning in transgenic lines of mice. Development 135: 2511-2520.

Gaunt SJ, Sharpe PT, Duboule D. 1988. Spatially restricted domains of homeo-gene transcripts in mouse embryos: relation to a segmented body plan. Development 104: 169179.

Gehring WJ, Affolter M, Bürglin T. 1994. Homeodomain proteins. Annu Rev Biochem 63: 487-526.

González-Lázaro M, Roselló-Díez A, Delgado I, Carramolino L, Sanguino MA, Giovinazzo G, Torres M. 2014. Two new targeted alleles for the comprehensive analysis of Meis1 functions in the mouse. Genesis 52: 967-975.

Grass S, Arnold HH, Braun T. 1996. Alterations in somite patterning of Myf-5-deficient mice: a possible role for FGF-4 and FGF-6. Development 122: 141-150.

Grifone R, Demignon J, Giordani J, Niro C, Souil E, Bertin F, Laclef C, Xu PX, Maire P. 2007. Eya1 and Eya2 proteins are required for hypaxial somitic myogenesis in the mouse embryo. Dev Biol 302: 602-616.

Grifone R, Demignon J, Houbron C, Souil E, Niro C, Seller MJ, Hamard G, Maire 
P. 2005. Six 1 and Six 4 homeoproteins are required for Pax3 and Mrf expression during myogenesis in the mouse embryo. Development 132: 2235-2249.

Groß A, Schulz C, Kolb J, Koster J, Wehner S, Czaplinski S, Khilan A, Rohrer H, Harter PN, Klingebiel T, Langer JD, Geerts D, Schulte D. 2018. Tumorigenic and Antiproliferative Properties of the TALE-Transcription Factors MEIS2D and MEIS2A in Neuroblastoma. Cancer Res 78: 1935-1947.

Hasty P, Bradley A, Morris JH, Edmondson DG, Venuti JM, Olson EN, Klein WH. 1993. Muscle deficiency and neonatal death in mice with a targeted mutation in the myogenin gene. Nature 364: 501-506.

Hayashi S, Lewis P, Pevny L, McMahon AP. 2002. Efficient gene modulation in mouse epiblast using a Sox2Cre transgenic mouse strain. Mech Dev 119 Suppl 1: S97-S101.

Henderson DJ, Conway SJ, Copp AJ. 1999. Rib truncations and fusions in the Sp2H mouse reveal a role for Pax3 in specification of the ventro-lateral and posterior parts of the somite. Dev Biol 209: 143-158.

Henrique D, Abranches E, Verrier L, Storey KG. 2015. Neuromesodermal progenitors and the making of the spinal cord. Development 142: 2864-2875.

Hisa T, Spence SE, Rachel RA, Fujita M, Nakamura T, Ward JM, Devor-Henneman DE, Saiki Y, Kutsuna H, Tessarollo L, Jenkins NA, Copeland NG. 2004. Hematopoietic, angiogenic and eye defects in Meis1 mutant animals. EMBO J 23: 450-459.

Horan GS, Kovàcs EN, Behringer RR, Featherstone MS. 1995a. Mutations in paralogous Hox genes result in overlapping homeotic transformations of the axial skeleton: evidence for unique and redundant function. Dev Biol 169: 359-372.

Horan GS, Ramírez-Solis R, Featherstone MS, Wolgemuth DJ, Bradley A, Behringer RR. 1995b. Compound mutants for the paralogous hoxa-4, hoxb-4, and hoxd-4 genes show more complete homeotic transformations and a dose-dependent increase in the number of vertebrae transformed. Genes Dev 9: 1667-1677.

Huang R, Zhi Q, Patel K, Wilting J, Christ B. 2000. Contribution of single somites to the skeleton and muscles of the occipital and cervical regions in avian embryos. Anat 
Embryol (Berl) 202: 375-383.

Iimura T, Pourquié O. 2006. Collinear activation of Hoxb genes during gastrulation is linked to mesoderm cell ingression. Nature 442: 568-571.

Ikeya M, Takada, S. 1998. Wnt signaling from the dorsal neural tube is required for the formation of the medial dermomyotome. Development 125: 4969-4976.

Izpisúa-Belmonte JC, Falkenstein H, Dollé P, Renucci A, Duboule D. 1991. Murine genes related to the Drosophila AbdB homeotic genes are sequentially expressed during development of the posterior part of the body. EMBO J 10: 2279-2289.

Jurberg AD, Aires R, Nóvoa A, Rowland JE, Mallo M. 2014. Compartment-dependent activities of Wnt3a/ $\beta$-catenin signaling during vertebrate axial extension. Dev Biol 394: 253-263.

Kashyap V, Gudas LJ, Brenet F, Funk P, Viale A, Scandura JM. 2011. Epigenomic reorganization of the clustered Hox genes in embryonic stem cells induced by retinoic acid. J Biol Chem 286: 3250-3260.

Kastner P, Mark M, Chambon P. 1995. Nonsteroid nuclear receptors: what are genetic studies telling us about their role in real life? Cell 83: 859-869.

Kaufman TC, Seeger MA, Olsen G. 1990. Molecular and genetic organization of the antennapedia gene complex of Drosophila melanogaster. Adv Genet 27:309-362.

Kessel M. 1992. Respecification of vertebral identities by retinoic acid. Development 115: 487-501.

Kessel M, Balling R, Gruss P. 1990. Variations of cervical vertebrae after expression of a Hox-1.1 transgene in mice. Cell 61: 301-308.

Kessel M, Gruss P. 1991. Homeotic transformations of murine vertebrae and concomitant alteration of Hox codes induced by retinoic acid. Cell 67: 89-104.

Kostic D, Capecchi MR. 1994. Targeted disruptions of the murine Hoxa-4 and Hoxa-6 genes result in homeotic transformations of components of the vertebral column. Mech 
Dev 46: 231-247.

Krumlauf R. 1994. Hox gene in vertebrate development. Cell 78: 191-201.

Lewis EB. 1963. Genes and developmental pathways. Amer Soc Zoologist 3: 33-56.

Lewis EB. 1978. A gene complex controlling segmentation in Drosophila. Nature 276: 565-570.

Lewis EB. 1992. The 1991 Albert Lasker Medical Awards. Clusters of master control genes regulate the development of higher organisms. JAMA 267: 1524-1531.

Li B, Dewey CN. 2011. RSEM: accurate transcript quantification from RNA-Seq data with or without a reference genome. BMC Bioinformatics 12: 323.

Liu XS, Li XH, Wang Y, Shu RZ, Wang L, Lu SY, Kong H, Jin YE, Zhang LJ, Fei J, Chen SJ, Chen Z, Gu MM, Lu ZY, Wang ZG. 2007. Disruption of palladin leads to defects in definitive erythropoiesis by interfering with erythroblastic island formation in mouse fetal liver. Blood 110: 870-876.

Liu XS, Luo HJ, Yang H, Wang L, Kong H, Jin YE, Wang F, Gu MM, Chen Z, Lu ZY, Wang ZG. 2007. Palladin regulates cell and extracellular matrix interaction through maintaining normal actin cytoskeleton architecture and stabilizing beta1-integrin. $J$ Cell Biochem 100: 1288-1300.

Lohnes D, Kastner P, Dierich A, Mark M, LeMeur M, Chambon P. 1993. Function of retinoic acid receptor gamma in the mouse. Cell 73: 643-658.

Lohnes D, Mark M, Mendelsohn C, Dollé P, Dierich A, Gorry P, Gansmuller A, Chambon P. 1994. Function of the retinoic acid receptors (RARs) during development (I). Craniofacial and skeletal abnormalities in RAR double mutants. Development 120: 2723-2748.

Longobardi E, Penkov D, Mateos D, De Florian G, Torres M, Blasi F. 2014. Biochemistry of the tale transcription factors PREP, MEIS, and PBX in vertebrates. Dev Dyn 243: 59-75.

Lufkin T, Mark M, Hart CP, Dollé P, LeMeur M, Chambon P. 1992. Homeotic trans- 
formation of the occipital bones of the skull by ectopic expression of a homeobox gene. Nature 359: 835-841.

Luo J, Pasceri P, Conlon RA, Rossant J, Giguère V. 1995. Mice lacking all isoforms of retinoic acid receptor beta develop normally and are susceptible to the teratogenic effects of retinoic acid. Mech Dev 53: 61-71.

Machon O, Masek J, Machonova O, Krauss S, Kozmik Z. 2015. Meis2 is essential for cranial and cardiac neural crest development. BMC Dev Biol 15: 40.

Madisen L, Zwingman TA, Sunkin SM, Oh SW, Zariwala HA, Gu H, Ng LL, Palmiter RD, Hawrylycz MJ, Jones AR, Lein ES, Zeng H. 2010. A robust and high-throughput Cre reporting and characterization system for the whole mouse brain. Nat Neurosci 13: $133-140$.

Mann RS, Affolter M. 1998. Hox proteins meet more partners. Curr Opin Genet Dev 8: 423-429.

Mallo M, Vinagre T, Carapuço M. 2009. The road to the vertebral formula. Int J Dev Biol 53: 1469-1481.

Mariani FV, Ahn CP, Martin GR. 2008. Genetic evidence that FGFs have an instructive role in limb proximal-distal patterning. Nature 453: 401-405.

Marshall H, Morrison A, Studer M, Pöpperl H, Krumlauf R. 1996. Retinoids and Hox genes. FASEB J 10: 969-978.

Marshall H, Nonchev S, Sham MH, Muchamore I, Lumsden A, Krumlauf R. 1992. Retinoic acid alters hindbrain Hox code and induces transformation of rhombomeres 2/3 into a 4/5 identity. Nature 360:737-41.

Martin BL. 2016. Factors that coordinate mesoderm specification from neuromesodermal progenitors with segmentation during vertebrate axial extension. Semin Cell Dev Biol 49: 59-67.

Martin M. 2011. Cutadapt removes adapter sequences from high-throughput sequencing reads. EMBnet.journal 17: 10-12. 
Mercader N, Leonardo E, Piedra ME, Martínez-A C, Ros MA, Torres M. 2000. Opposing RA and FGF signals control proximodistal vertebrate limb development through regulation of Meis genes. Development 127: 3961-3970.

Mercader N, Tanaka EM, Torres M. 2005. Proximodistal identity during vertebrate limb regeneration is regulated by Meis homeodomain proteins. Development 132: 41314142 .

McIntyre DC, Rakshit S, Yallowitz AR, Loken L, Jeannotte L, Capechi MR, Wellik DM. 2007. Hox patterning of the vertebrate rib cage. Development 134: 2981-2989.

Montavon T, Soshnikova N. 2014. Hox gene regulation and timing in embryogenesis. Semin Cell Dev Biol 34: 76-84.

Moskow JJ, Bullrich F, Huebner K, Daar IO, Buchberg AM. 1995. Meis1, a PBX1 -related homeobox gene involved in myeloid leukemia in BXH-2 mice. Mol Cell Biol 15: 5434-5443.

Murphy P, Hill RE. 1991. Expression of the mouse labial-like homeobox-containing genes, Hox 2.9 and Hox 1.6, during segmentation of the hindbrain. Development 111: $61-74$.

Musumeci G, Castrogiovanni P, Coleman R, Szychlinska MA, Salvatorelli L, Parenti R, Magro G, Imbesi R. 2015. Somitogenesis: From somite to skeletal muscle. Acta Histochem 117: 313-328.

Nagano T, Takehara S, Takahashi M, Aizawa S, Yamamoto A. 2006. Shisa2 promotes the maturation of somitic precursors and transition to the segmental fate in Xenopus embryos. Development 133:4643-4654.

Nakamura T, Jenkins NA, Copeland NG. 1996. Identification of a new family of Pbxrelated homeobox genes. Oncogene 13: 2235-2242.

Neijts R, Deschamps J. 2017. At the base of colinear Hox gene expression: cis-features and trans-factors orchestrating the initial phase of Hox cluster activation. Dev Biol 428: 293-299. 
Niederreither K, McCaffery P, Dräger UC, Chambon P, Dollé P. 1997. Restricted expression and retinoic acid-induced downregulation of the retinaldehyde dehydrogenase type 2 (RALDH-2) gene during mouse development. Mech Dev 62: 67-78.

Niederreither K, Subbarayan V, Dollé P, Chambon P. 1999. Embryonic retinoic acid synthesis is essential for early mouse post-implantation development. Nat Genet 21: 444-448.

Niederreither K, Vermot J, Schuhbaur B, Chambon P, Dollé P. 2000. Retinoic acid synthesis and hindbrain patterning in the mouse embryo. Development 127: 75-85.

Noordermeer D, Leleu M, Splinter E, Rougemont J, De Laat W, Duboule D. 2011. The dynamic architecture of Hox gene clusters. Science 334: 222-225.

Noordermeer D, Leleu M, Schorderet P, Joye E, Chabaud F, Duboule D. 2014. Temporal dynamics and developmental memory of 3D chromatin architecture at Hox gene loci. Elife 3: e02557.

Nourse J, Mellentin JD, Galili N, Wilkinson J, Stanbridge E, Smith SD, Cleary ML. 1990. Chromosomal translocation $\mathrm{t}(1 ; 19)$ results in synthesis of a homeobox fusion mRNA that codes for a potential chimeric transcription factor. Cell 60: 535-545.

Patapoutian A, Yoon JK, Miner JH, Wang S, Stark K, Wold B. 1995. Disruption of the mouse MRF4 gene identifies multiple waves of myogenesis in the myotome. Development 121: 3347-3358.

Oulad-Abdelghani M, Chazaud C, Bouillet P, Sapin V, Chambon P, Dollé P. 1997. Meis2, a novel mouse Pbx-related homeobox gene induced by retinoic acid during differentiation of P19 embryonal carcinoma cells. Dev Dyn 210: 173-183.

Penkov D, Mateos San Martín D, Fernández-Díaz LC, Rosselló CA, Torroja C, Sánchez-Cabo F, Warnatz HJ, Sultan M, Yaspo ML, Gabrieli A, Tkachuk V, Brendolan A, Blasi F, Torres M. 2013. Analysis of the DNA-binding profile and function of TALE homeoproteins reveals their specialization and specific interactions with Hox genes/proteins. Cell Rep 3: 1321-1333.

Ramírez-Solis R, Zheng H, Whiting J, Krumlauf R, Bradley A. 1993. Hoxb-4 (Hox2.6) mutant mice show homeotic transformation of a cervical vertebra and defects in the 
closure of the sternal rudiments. Cell 73: 279-294.

Rauskolb C, Peifer M, Wieschaus E. 1993. extradenticle, a regulator of homeotic gene activity, is a homolog of the homeobox-containing human proto-oncogene pbx1. Cell 74: 1101-1112.

Ray WJ, Bain G, Yao M, Gottlieb DI. 1997. CYP26, a novel mammalian cytochrome $\mathrm{P} 450$, is induced by retinoic acid and defines a new family. J Biol Chem 272: 1870218708.

Rhinn M, Dollé P. 2012. Retinoic acid signalling during development. Development 139: 843-858.

Rieckhof GE, Casares F, Ryoo HD, Abu-Shaar M, Mann RS. 1997. Nuclear translocation of extradenticle requires homothorax, which encodes an extradenticle-related homeodomain protein. Cell 91: 171-183.

Ritchie ME, Phipson B, Wu D, Hu Y, Law CW, Shi W, Smyth GK. 2015. limma powers differential expression analyses for RNA-sequencing and microarray studies. $\mathrm{Nu}$ cleic Acids Res 43: e47.

Rivera-Pérez JA, Hadjantonakis AK. 2015. The dynamics of morphogenesis in the early mouse embryo. Cold Spring Harb Perspect Biol 7: pii: a015867.

Roelen BA, de Graaf W, Forlani S, Deschamps J. 2002. Hox cluster polarity in early transcriptional availability: a high order regulatory level of clustered Hox genes in the mouse. Mech Dev 119: 81-90.

Roselló-Díez A, Arques CG, Delgado I, Giovinazzo G, Torres M. 2014. Diffusible signals and epigenetic timing cooperate in late proximo-distal limb patterning. Development 141: 1534-1543.

Ruberte E, Dolle P, Krust A, Zelent A, Morriss-Kay G, Chambon P. 1990. Specific spatial and temporal distribution of retinoic acid receptor gamma transcripts during mouse embryogenesis. Development 108: 213-222.

Ryoo HD, Marty T, Casares F, Affolter M, Mann RS. 1999. Regulation of Hox target genes by a DNA bound Homothorax/Hox/Extradenticle complex. Development 126 : 
$5137-5148$.

Sadate-Ngatchou PI, Payne CJ, Dearth AT, Braun RE. 2008. Cre recombinase activity specific to postnatal, premeiotic male germ cells in transgenic mice. Genesis 46: 738-742.

Saga Y, Kitajima S, Miyagawa-Tomita S. 2000. Mesp1 expression is the earliest sign of cardiovascular development. Trends Cardiovasc Med 10: 345-352.

Saga Y, Miyagawa-Tomita S, Takagi A, Kitajima S, Miyazaki Ji, Inoue T. 1999. MesP1 is expressed in the heart precursor cells and required for the formation of a single heart tube. Development 126: 3437-3447.

Sakai Y, Meno C, Fujii H, Nishino J, Shiratori H, Saijoh Y, Rossant J, Hamada H. 2001. The retinoic acid-inactivating enzyme CYP26 is essential for establishing an uneven distribution of retinoic acid along the anterio-posterior axis within the mouse embryo. Genes Dev 15: 213-225.

Salzberg A, Elias S, Nachaliel N, Bonstein L, Henig C, Frank D. 1999. A Meis family protein caudalizes neural cell fates in Xenopus. Mech Dev 80: 3-13.

Sánchez-Herrero E, Vernós I, Marco R, Morata G. 1985. Genetic organization of Drosophila bithorax complex. Nature 313: 108-113.

Sánchez-Herrero E, Casanova J, Kerridge S, Morata G. 1985b. Anatomy and function of the bithorax complex of Drosophila. Cold Spring Harb Symp Quant Biol 50: 165-72.

Selleri L, Depew MJ, Jacobs Y, Chanda SK, Tsang KY, Cheah KS, Rubenstein JL, O'Gorman S, Cleary ML. 2001. Requirement for Pbx1 in skeletal patterning and programming chondrocyte proliferation and differentiation. Development 128: 3543-3557.

Shen WF, Montgomery JC, Rozenfeld S, Moskow JJ, Lawrence HJ, Buchberg AM, Largman C. 1997. AbdB-like Hox proteins stabilize DNA binding by the Meis1 homeodomain proteins. Mol Cell Biol 17: 6448-6458.

Soriano P. 1997. The PDGF alpha receptor is required for neural crest cell development and for normal patterning of the somites. Development 124: 2691-2700. 
Soshnikova N, Duboule D. 2009a. Epigenetic temporal control of mouse Hox genes in vivo. Science 324: 1320-1323.

Soshnikova N, Duboule D. 2009b. Epigenetic regulation of vertebrate Hox genes: a dynamic equilibrium. Epigenetics 4: 537-540.

Stern HM, Lin-Jones J, Hauschka SD. 1997. Synergistic interactions between bFGF and a TGF-beta family member may mediate myogenic signals from the neural tube. Development 124: 3511-3523.

Subramanian V, Meyer BI, Gruss P. 1995. Disruption of the murine homeobox gene Cdx1 affects axial skeletal identities by altering the mesodermal expression domains of Hox genes. Cell 83: 641-653.

Sundin OH, Busse HG, Rogers MB, Gudas LJ, Eichele G. 1990. Region-specific expression in early chick and mouse embryos of Ghox-lab and Hox 1.6, vertebrate homeobox-containing genes related to Drosophila labial. Development 108: 47-58.

Sweetman D, Wagstaff L, Cooper O, Weijer C, Münsterberg A. 2008. The migration of paraxial and lateral plate mesoderm cells emerging from the late primitive streak is controlled by different Wnt signals. BMC Dev Biol 8: 63.

Tallquist MD, Weismann KE, Hellström M, Soriano P. 2000. Early myotome specification regulates PDGFA expression and axial skeleton development. Development 127: 5059-5070.

Tzouanacou E, Wegener A, Wymeersch FJ, Wilson V, Nicolas JF. 2009. Redefining the progression of lineage segregations during mammalian embryogenesis by clonal analysis. Dev Cell 17: 365-376.

Unnisa Z, Clark JP, Roychoudhury J, Thomas E, Tessarollo L, Copeland NG, Jenkins NA, Grimes HL, Kumar AR. 2012. Meis1 preserves hematopoietic stem cells in mice by limiting oxidative stress. Blood 120: 4973-4981.

van den Akker E, Forlani S, Chawengsaksophak K, de Graaff W, Beck F, Meyer BI, Deschamps J. 2002. Cdx1 and Cdx2 have overlapping functions in anteroposterior patterning and posterior axis elongation. Development 129: 2181-2193. 
Vermot J, Garnier JM, Dierich A, Niederreither K, Harvey RP, Chambon P, Dollé P. 2006. Conditional (loxP-flanked) allele for the gene encoding the retinoic acid-synthesizing enzyme retinaldehyde dehydrogenase 2 (RALDH2). Genesis 44: 155-158.

Vinagre T, Moncaut N, Carapuço M, Nóvoa A, Bom J, Mallo M. 2010. Evidence for a myotomal Hox/Myf cascade governing nonautonomous control of rib specification within global vertebral domains. Dev Cell 18: 655-61.

Vitobello A, Ferretti E, Lampe X, Vilain N, Ducret S, Ori M, Spetz JF, Selleri L, Rijli FM. 2011. Hox and Pbx factors control retinoic acid synthesis during hindbrain segmentation. Dev Cell 20:469-82.

Vivian JL, Gan L, Olson EN, Klein WH. 1999. A hypomorphic myogenin allele reveals distinct myogenin expression levels required for viability, skeletal muscle development, and sternum formation. Dev Biol 208: 44-55.

Vivian JL, Olson EN, Klein WH. 2000. Thoracic skeletal defects in myogenin- and MRF4-deficient mice correlate with early defects in myotome and intercostal musculature. Dev Biol 224: 29-41.

Vlachakis N, Choe SK, Sagerström CG. 2001. Meis3 synergizes with Pbx4 and Hoxb1b in promoting hindbrain fates in the zebrafish. Development 128: 1299-1312.

Wallin J, Wilting J, Koseki H, Fritsch R, Christ B, Balling R. 1994. The role of Pax-1 in axial skeleton development. Development 120: 1109-1121.

Ward L, Evans SE, Stern CD. 2017. A resegmentation-shift model for vertebral patterning. J Anat 230: 290-296.

Wehn AK, Gallo PH, Chapman DL. 2009. Generation of transgenic mice expressing Cre recombinase under the control of the Dll1 mesoderm enhancer element. Genesis 47: 309-313.

Wellik DM, Capecchi MR. 2003. Hox10 and Hox11 genes are required to globally pattern the mammalian skeleton. Science 301: 363-367.

Wilson V, Olivera-Martínez I, Storey KG. 2009. Stem cells, signals and vertebrate 
body axis extension. Development 136: 1591-1604.

Yashiro K, Zhao X, Uehara M, Yamashita K, Nishijima M, Nishino J, Saijoh Y, Sakai Y, Hamada H. 2004. Regulation of retinoic acid distribution is required for proximodistal patterning and outgrowth of the developing mouse limb. Dev Cell 6: 411-422.

Yokoyama S, Ito Y, Ueno-Kudoh H, Shimizu H, Uchibe K, Albini S, Mitsuoka K, Miyaki S, Kiso M, Nagai A, Hikata T, Osada T, Fukuda N, Yamashita S, Harada D, Mezzano V, Kasai M, Puri PL, Hayashizaki Y, Okado H, Hashimoto M, Asahara H. 2009. A systems approach reveals that the myogenesis genome network is regulated by the transcriptional repressor RP58. Dev Cell 17: 836-848.

Young T, Rowland JE, van de Ven C, Bialecka M, Novoa A, Carapuço M, van Nes J, de Graaff W, Duluc I, Freund JN, Beck F, Mallo M, Deschamps J. 2009. Cdx and Hox genes differentially regulate posterior axial growth in mammalian embryos. Dev Cell 17: $516-526$.

Zákány J, Kmita M, Alarcon P, de la Pompa JL, Duboule D. 2001. Localized and transient transcription of Hox genes suggests a link between patterning and the segmentation clock. Cell 106: 207-217.

Zhang W, Behringer RR, Olson EN. 1995. Inactivation of the myogenic bHLH gene MRF4 results in up-regulation of myogenin and rib anomalies. Genes Dev 9: 1388-1389. 


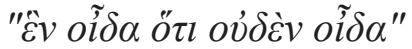

"Yo solo sé que no sé nada"

Sócrates en la Apología de

Sócrates de Platón 


\section{Cover page:}

Alcian blue and Alizarin red skeletal staining of E18.5 fetus.

\section{Back page:}

In situ hybridization of Meis1 (left) and Meis2 (right) in E7.5 embryos. 